\title{
Our future in the Anthropocene biosphere
}

\author{
Carl Folke @ , Stephen Polasky, Johan Rockström, Victor Galaz, \\ Frances Westley, Michèle Lamont, Marten Scheffer, Henrik Österblom, \\ Stephen R. Carpenter, F. Stuart Chapin III, Karen C. Seto, \\ Elke U. Weber, Beatrice I. Crona, Gretchen C. Daily, Partha Dasgupta, \\ Owen Gaffney, Line J. Gordon, Holger Hoff, Simon A. Levin, \\ Jane Lubchenco, Will Steffen, Brian H. Walker
}

Received: 25 November 2020/Revised: 31 January 2021/ Accepted: 10 February 2021/Published online: 14 March 2021

\begin{abstract}
The COVID-19 pandemic has exposed an interconnected and tightly coupled globalized world in rapid change. This article sets the scientific stage for understanding and responding to such change for global sustainability and resilient societies. We provide a systemic overview of the current situation where people and nature are dynamically intertwined and embedded in the biosphere, placing shocks and extreme events as part of this dynamic; humanity has become the major force in shaping the future of the Earth system as a whole; and the scale and pace of the human dimension have caused climate change, rapid loss of biodiversity, growing inequalities, and loss of resilience to deal with uncertainty and surprise. Taken together, human actions are challenging the biosphere foundation for a prosperous development of civilizations. The Anthropocene realityof rising system-wide turbulence-calls for transformative change towards sustainable futures. Emerging technologies, social innovations, broader shifts in cultural repertoires, as well as a diverse portfolio of active stewardship of human actions in support of a resilient biosphere are highlighted as essential parts of such transformations.
\end{abstract}

Keywords Anthropocene - Biosphere stewardship · Biodiversity $\cdot$ Climate $\cdot$ Resilience $\cdot$ Social-ecological

This work has not been officially peer-reviewed and represents the authors' personal but well supported read and understanding of the field.

\section{INTRODUCTION}

Humans are the dominant force of change on the planet, giving rise to a new epoch referred to as the Anthropocene. This new epoch has profound meaning for humanity and one that we are only beginning to fully comprehend. We now know that society needs to be viewed as part of the biosphere, not separate from it. Depending on the collective actions of humanity, future conditions could be either beneficial or hostile for human life and wellbeing in the Anthropocene biosphere. Whether humanity has the collective wisdom to navigate the Anthropocene to sustain a livable biosphere for people and civilizations, as well as for the rest of life with which we share the planet, is the most formidable challenge facing humanity.

This article provides a systemic overview of the Anthropocene biosphere, a biosphere shaped by human actions. It is structured around the core themes of the first Nobel Prize Summit-Our Planet, Our Future, namely climate change and biodiversity loss, inequality and global sustainability, and science, technology, and innovation to enable societal transformations while anticipating and reducing potential harms (Box 1). These interconnected themes are framed in the context of the biosphere and the Earth system foundation for global sustainability, emphasizing that people and nature are deeply intertwined. Scientific evidence makes clear that both climate change and biodiversity loss are symptoms of the great acceleration of human actions into the Anthropocene, rather than independent phenomena, and that they interact, and interact with social, economic, and cultural development. It emphasizes that efficiency through simplification of our global production ecosystem challenges biosphere resilience in times when resilience is needed more than ever, as a critical asset of flexibility and insurance, for navigating 
BOX 1 The first Nobel Prize Summit - Our Planet, Our Future

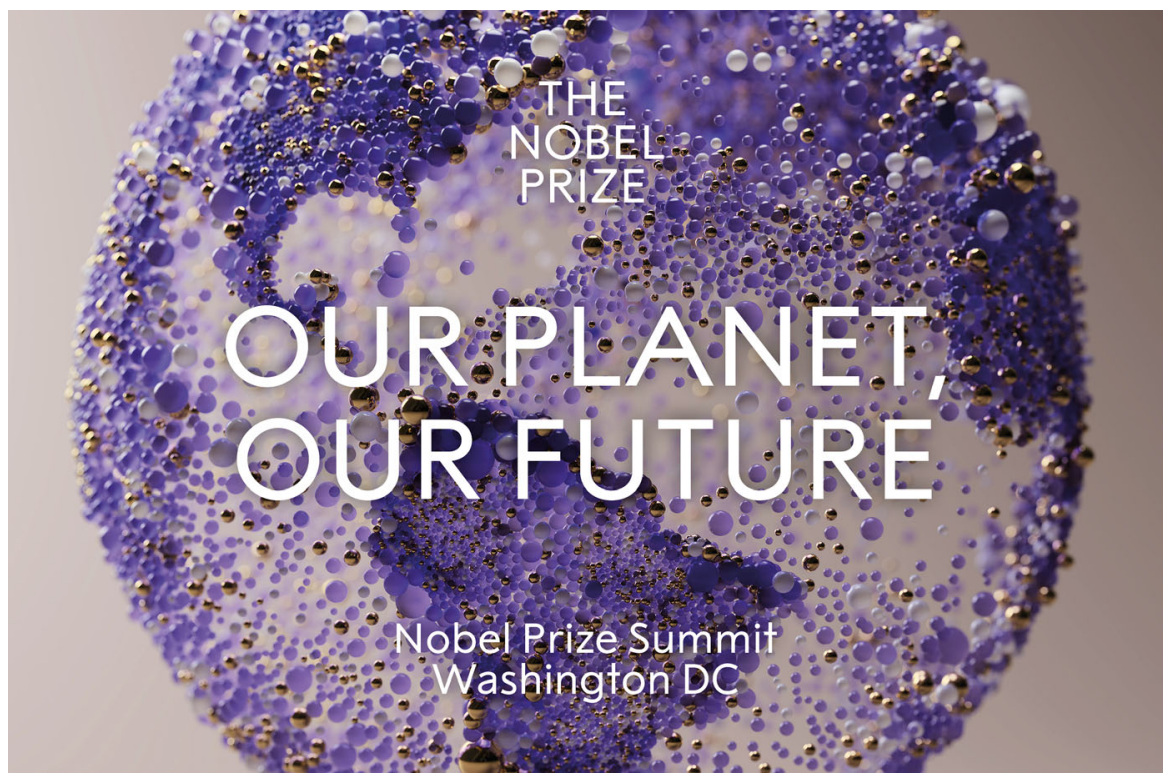

The first Nobel Prize Summit, Our Planet, Our Future, is an online convening to discuss the state of the planet at a critical juncture for humanity. The Summit brings together Nobel Laureates and other leading scientists with thought leaders, policy makers, business leaders, and young people to explore solutions to immediate challenges facing our global civilization: mitigate and adapt to the threat posed by climate change and biodiversity loss, reduce inequalities and lift people out of poverty, and made even more urgent due to the economic hardships posed by the pandemic, and harness science, technology, and innovation to enable societal transformations while anticipating and reducing potential harms. The Nobel Prize Summit includes both workshops, publications, and online programmes in forms of webinars, pre-events, and the Nobel Prize Summit days on April 26-28, 2021. The Summit is convened by the Nobel Foundation, in partnership with the U.S. National Academy of Sciences, the Potsdam Institute for Climate Impact Research, and the Stockholm Resilience Centre, Stockholm University/Beijer Institute, Royal Swedish Academy of Sciences. This article is a condensed and updated version of the White Paper "Our future in the Anthropocene biosphere: global sustainability and resilient societies" (Folke et al. 2020) written for the Nobel Prize Summit.

rising turbulence, extreme events, and the profound uncertainty of the Anthropocene. This implies that not only will it be critical to curb human-induced climate change but also to enhance the regenerative capacity of the biosphere, and its diversity, to support and sustain societal development, to collaborate with the planet that is our home, and collaborate in a socially just and sustainable manner. This is the focus of the last part of this article on biosphere stewardship for prosperity. We stress that prosperity and wellbeing for present and future generations will require mobilization, innovation, and narratives of societal transformations that connect development to stewardship of human actions as part of our life-supporting biosphere.

\section{THE BIOSPHERE AND THE EARTH SYSTEM FOUNDATION}

\section{Embedded in the biosphere}

The Universe is immense, estimates suggest at least two trillion galaxies (Conselice et al. 2016). Our galaxy, the Milky Way, holds 100 to 400 billion stars. One of those stars, our sun, has eight planets orbiting it. One of those, planet Earth, has a biosphere, a complex web of life, at its surface. The thickness of this layer is about twenty kilometres (twelve miles). This layer, our biosphere, is the only place where we know life exists. We humans emerged and 


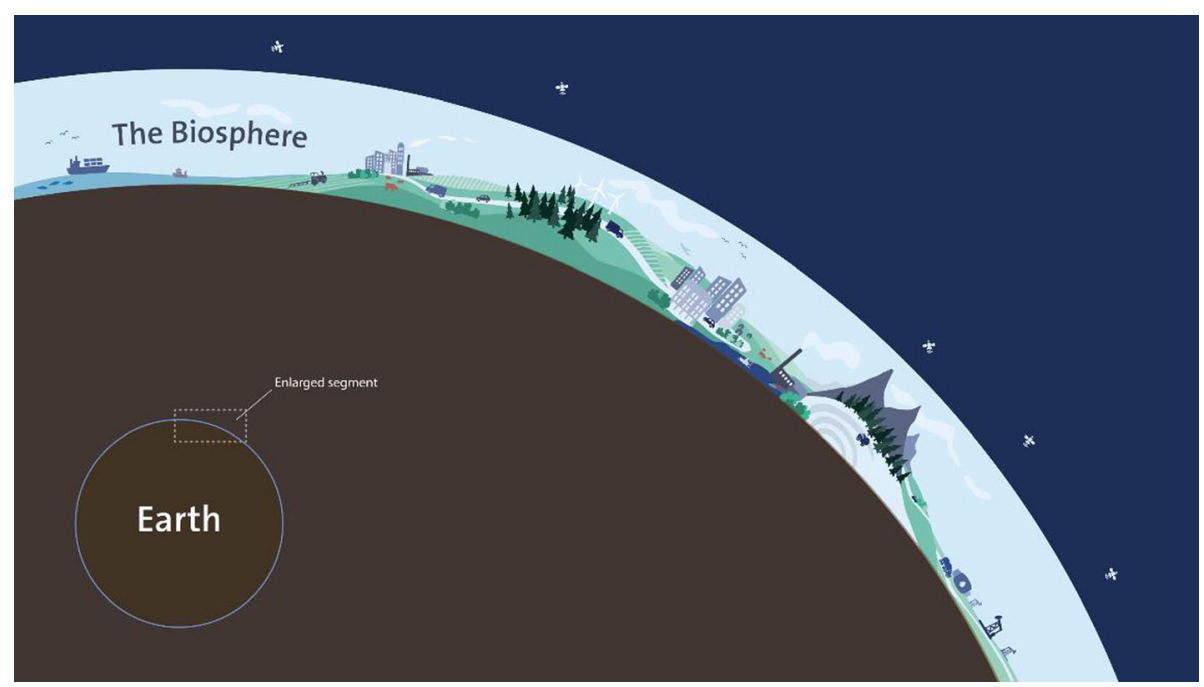

Fig. 1 The home of humankind. Our economies, societies, and civilizations are embedded in the Biosphere, the thin layer of life on planet Earth. There is a dynamic interplay between the living biosphere and the broader Earth system, with the atmosphere, the hydrosphere, the lithosphere, the cryosphere, and the climate system. Humans have become a major force in shaping this interplay. Artwork by J. Lokrantz, Azote

evolved within the biosphere. Our economies, societies, and cultures are part of it. It is our home.

Across the ocean and the continents, the biosphere integrates all living beings, their diversity, and their relationships. There is a dynamic connection between the living biosphere and the broader Earth system, with the atmosphere, the hydrosphere, the lithosphere, the cryosphere, and the climate system. Life in the biosphere is shaped by the global atmospheric circulation, jet streams, atmospheric rivers, water vapour and precipitation patterns, the spread of ice sheets and glaciers, soil formation, upwelling currents of coastlines, the ocean's global conveyer belt, the distribution of the ozone layer, movements of the tectonic plates, earthquakes, and volcanic eruptions. Water serves as the bloodstream of the biosphere, and the carbon, nitrogen, and other biogeochemical cycles are essential for all life on Earth (Falkenmark et al. 2019; Steffen et al. 2020). It is the complex adaptive interplay between living organisms, the climate, and broader Earth system processes that has evolved into a resilient biosphere.

The biosphere has existed for about 3.5 billion years. Modern humans (Homo sapiens) have effectively been around in the biosphere for some 250000 years (Mounier and Lahr 2019). Powered by the sun, the biosphere and the Earth system coevolve with human actions as an integral part of this coevolution (Lenton 2016; Jörgensen et al. 2019). Social conditions, health, culture, democracy, power, justice, inequity, matters of security, and even survival are interwoven with the Earth system and its biosphere in a complex interplay of local, regional, and worldwide interactions and dependencies (Folke et al. 2016).

Belief systems that view humans and nature as separate entities have emerged with economic development, technological change, and cultural evolution. But the fact that humans are living within and dependent upon a resilient biosphere has and will not change. Existing as embedded within the biosphere means that the environment is not something outside the economy or society, or a driver to be accounted for when preferred, but rather the very foundation that civilizations exist within and rely upon (Fig. 1).

\section{A dominant force on earth}

The human population reached one billion around 1800. It doubled to two billion around 1930, and doubled again to four billion around 1974. The global population is now approaching 8 billion and is expected to stabilize around 9-11 billion towards the end of this century (UN 2019). During the past century, and especially since the 1950s, there has been an amazing acceleration and expansion of human activities into a converging globalized society, supported by the discovery and use of fossil energy and innovations in social organization, technology, and cultural evolution (Ellis 2015; van der Leeuw 2019). Globalization has helped focus attention on human rights, international relations, and agreements leading to collaboration (Keohane et al. 2009; Rogelj et al. 2016; Bain 2019) and, rather remarkably, it appears, at least so far, to have inhibited large-scale conflict between states that have plagued civilizations from time immemorial. Health and material 
standards of living for many have improved and more people live longer than at any time in history. Boundaries between developed and developing regions have become blurred, and global economic activity is increasingly dispersed across production networks that connect metropolitan areas around the world (Coe et al. 2004; Liu et al. 2015).

Now, there is ample evidence that the cumulative human culture has expanded to such an extent that it has become a significant global force affecting the operation of the Earth system and its biosphere at the planetary level (Steffen et al. 2018). As a reflection of this unprecedented expansion, a new geological epoch-the Anthropocene, the age of mankind-has been proposed in the Geological Time Scale (AWG 2019).

Work on anthropogenic biomes finds that more than $75 \%$ of Earth's ice-free land is directly altered as a result of human activity, with nearly $90 \%$ of terrestrial net primary production and $80 \%$ of global tree cover under direct human influence (Ellis and Ramankutty 2008). Similarly, in the ocean, no area is unaffected by human influence and a large fraction (41\%) is strongly affected by multiple human impacts (Halpern et al. 2008). For example, oxygen-minimum zones for life and oxygen concentrations in both the open ocean and coastal waters have been declining since at least the middle of the twentieth century, as a consequence of rising nutrient loads from human actions coupled with warmer temperatures (Limburg et al. 2020). Just as on land, there has been a blue acceleration in the ocean, with more than $50 \%$ of the vast ocean seabed claimed by nations (Jouffray et al. 2020).

The human dominance is further reflected in the weight of the current human population-10 times the weight of all wild mammals. If we add the weight of livestock for human use and consumption to the human weight, only $4 \%$ of the weight of mammals on Earth remain wild mammals. The weight of domesticated birds exceeds that of wild birds by about threefold (Bar-On et al. 2018). The human dimension has become a dominant force in shaping evolution of all species on Earth. Through artificial selection and controlled reproduction of crops, livestock, trees, and microorganisms, through varying levels of harvest pressure and selection, through chemicals and pollution altering life-histories of species, and by sculpting the new habitats that blanket the planet, humans, directly and indirectly, determine the constitution of species that succeed and fail (Jörgensen et al. 2019).

Humans are now primarily an urban species, with about $55 \%$ of the population living in urban areas. By mid-century, about 7 out of 10 people are expected to live in cities and towns (UN DESA 2018). In terms of urban land area, this is equivalent to building a city the size of New York City every 8 days (Huang et al. 2019). Urbanization leads to more consumption, and the power relations, inequalities, behaviours, and choices of urban dwellers shape landscapes and seascapes and their diversity around the world (Seto et al. 2012a, b). There is growing evidence that urban areas accelerate evolutionary changes for species that play important functional roles in communities and ecosystems (Alberti et al. 2017).

In addition, essential features of the globalized world like physical infrastructure, technological artefacts, novel substances, and associated social and technological networks have been developing extraordinarily fast. The total weight of everything made by humans-from houses and bridges to computers and clothes-is about to exceed the mass of all living things on Earth (Elhacham et al. 2020). The extensive "technosphere" dimension underscores the novelty of the ongoing planetary changes, plays a significant role in shaping global biosphere dynamics, and has already left a deep imprint on the Earth system (Zalasiewicz et al. 2017).

The notion that humanity is external to the biosphere has allowed for models in which technological progress is expected to enable humanity to enjoy ever-growing GDP and thus consumption. This view was comparatively harmless, as long as the biosphere was sufficiently resilient to supply the demands humanity made of it. This is no longer the case, and it has far-reaching implications for contemporary models of economic possibilities that many still work with and draw policy conclusions from (Dasgupta and Ramanathan 2014; Dasgupta 2021).

\section{The intertwined planet of people and nature}

The Anthropocene is characterized by a tightly interconnected world operating at high speeds with hyper-efficiency in several dimensions. These dimensions include the globalized food production and distribution system, extensive trade and transport systems, strong connectivity of financial and capital markets, internationalized supply and value chains, widespread movements of people, social innovations, development and exchange of technology, and widespread communication capacities (Helbing 2013) (Fig. 2).

In the Anthropocene biosphere, systems of people and nature are not just linked but intertwined, and intertwined across temporal and spatial scales (Reyers et al. 2018). Local events can escalate into global challenges, and local places are shaped by global dynamics (Adger et al. 2009; Crona et al. 2015, 2016; Liu et al. 2016; Kummu et al. 2020). The tightly coupled human interactions of globalization that allow for the continued flow of information, capital, goods, services, and people, also create global systemic risk (Centeno et al. 2015; Galaz et al. 2017). However, this interplay is not only global between people 


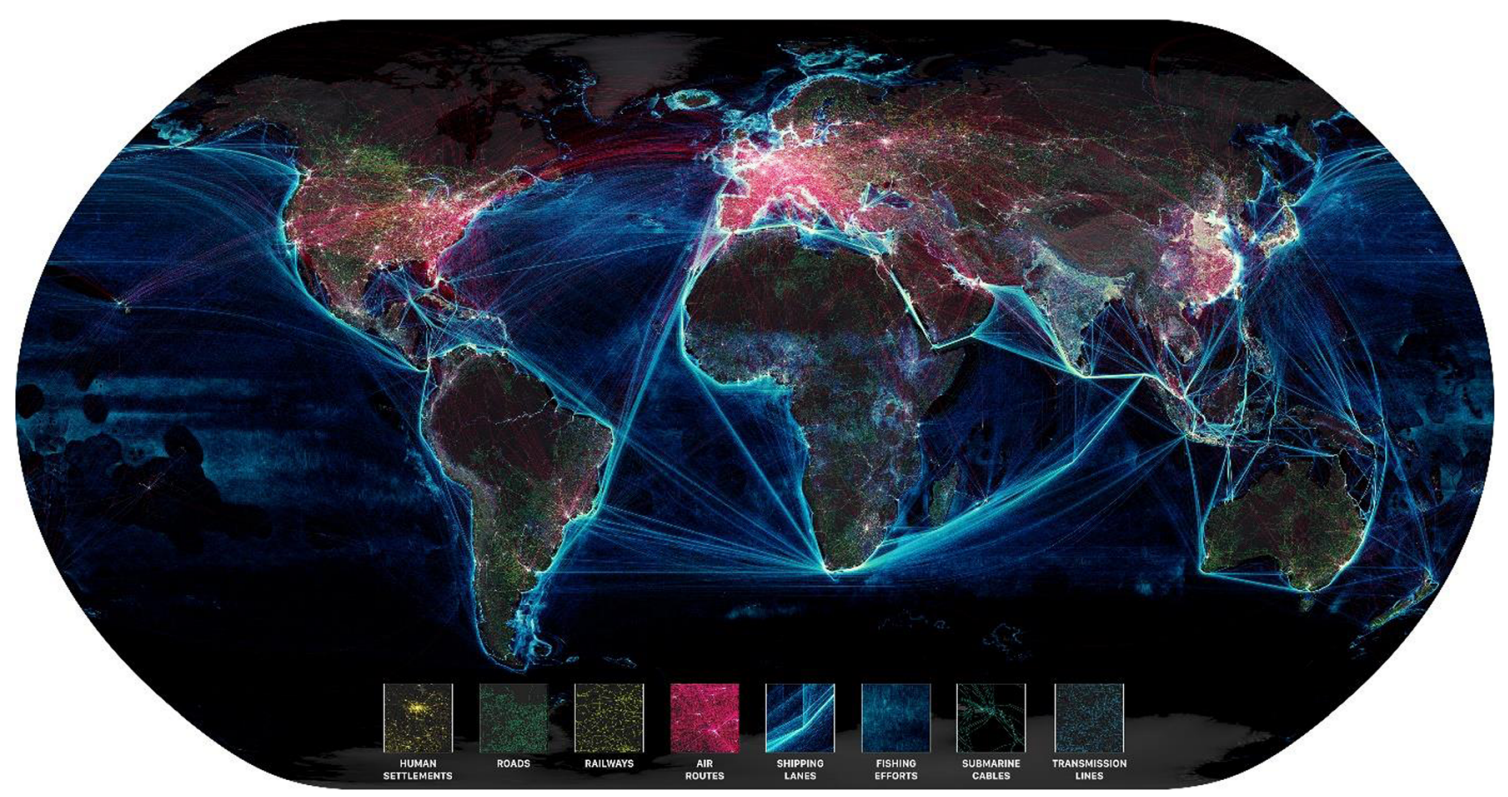

Fig. 2 A snapshot of the interconnected globalized world, showing the human influence in terms of settlements, roads, railways, air routes, shipping lanes, fishing efforts, submarine cables, and transmission lines (Credit: Globaïa). Reprinted with permission

and societies but co-evolving also with biosphere dynamics shaping the preconditions for human wellbeing and civilizations (Jörgensen et al. 2018; Keys et al. 2019). For example, extreme-weather and geopolitical events, interacting with the dynamics of the food system (Cottrell et al. 2019), can spill over multiple sectors and create synchronous challenges among geographically disconnected areas and rapidly move across countries and regions (Rocha et al. 2018). The rise of antibiotic resistance, the rapid spread of the corona-pandemic, or altered moisture recycling across regions expose the intertwined world. Probabilities and consequences of the changes are not only scale dependent, but also changing over time as a result of human actions, where those actions can either exacerbate or mitigate the likelihood or consequences of a given event.

In the twenty-first century, people and planet are truly interwoven and coevolve, shaping the preconditions for civilizations. Our own future on Earth, as part of the biosphere, is at stake. This new reality has major implications for human wellbeing in the face of climate change, loss of biodiversity, and their interplay, as elaborated in the next section.

\section{CLIMATE CHANGE AND LOSS OF BIODIVERSITY}

Contemporary climate change and biodiversity loss are not isolated phenomena but symptoms of the massive expansion of the human dimension into the Anthropocene. The climate system plays a central role for life on Earth. It sets the boundary for our living conditions. The climate system is integral to all other components of the Earth system, through heat exchange in the ocean, albedo dynamics of the ice sheets, carbon sinks in terrestrial ecosystems, cycles of nutrients and pollutants, and climate forcing through evapotranspiration flows in the hydrological cycle and greenhouse pollutants. Together these interactions in the Earth system interplay with the heat exchange from the sun and the return flow back to space, but also in significant ways with biosphere-climate feedbacks that either mitigate or amplify global warming. These global dynamics interact with regional environmental systems (like ENSO or the monsoon system) that have innate patterns of climate variability and also interact with one another via teleconnections (Steffen et al. 2020). The living organisms of the planet's ecosystems play a significant role in these complex dynamics (Mace et al. 2014).

Now, human-induced global warming alters the capacity of the ocean, forests, and other ecosystems in sequestering about half of the $\mathrm{CO}_{2}$ emissions, as well as storing large amounts of greenhouse gases (GHG) in soils and peatlands (Steffen et al. 2018). Increased emissions of GHG by humans are creating severe climate shocks and extremes already at $1.2^{\circ}$ warming compared to pre-industrial levels (WMO 2020). In addition, human homogenization and simplification of landscapes and seascapes cause loss of biosphere resilience, with subsequent erosion of the role of the fabric of nature in generating ecosystem services (Diaz et al. 2018) and serving as insurance to shocks and surprise and to tipping points and regime shifts (Nyström et al. 2019). 


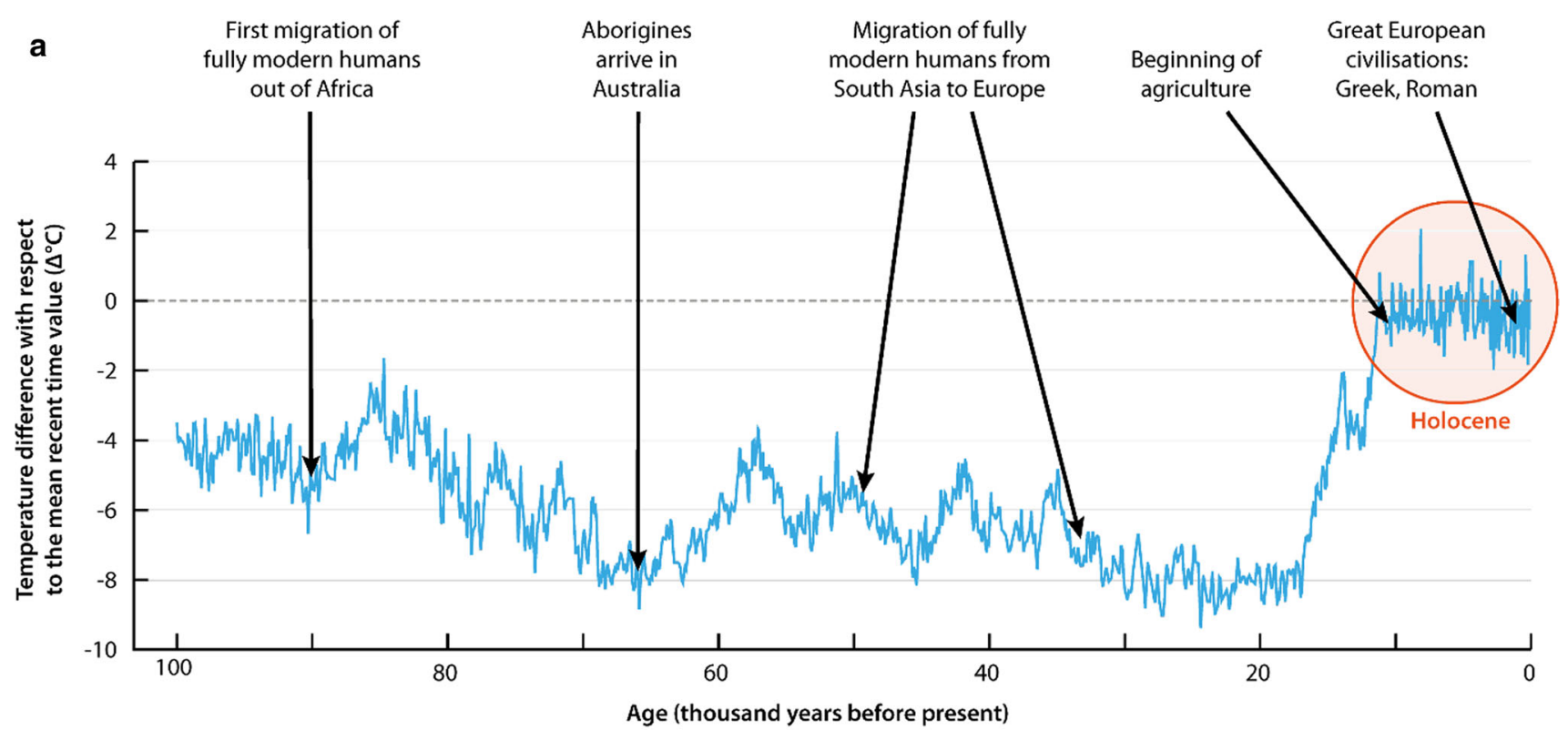

b

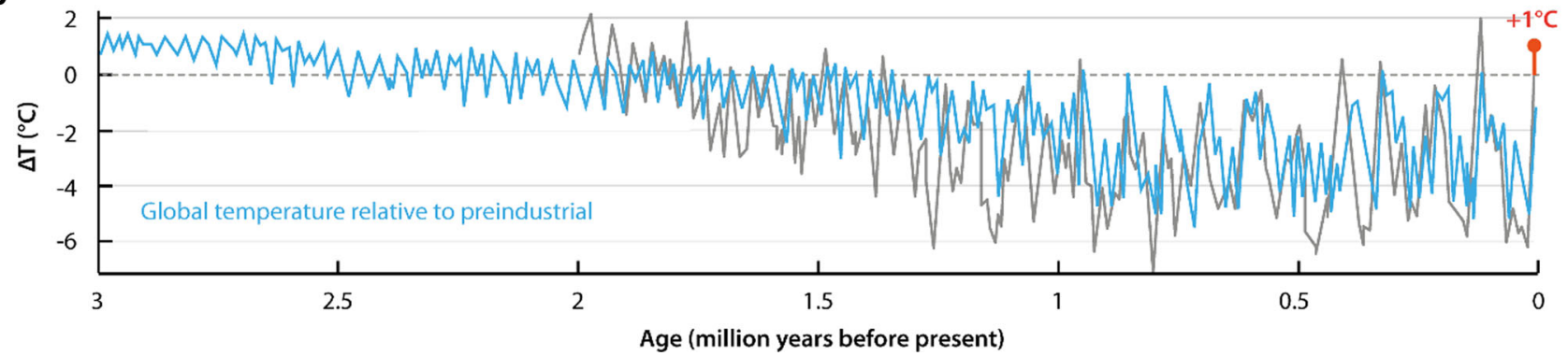

Fig. 3 The Holocene epoch and Earth's resilience. A) Vostok ice-core data, Antarctica, from the last 100000 years in relation to human migration and civilization. The red circle marks the last 11000 years of the accommodating Holocene epoch. B) Global temperature the last 3 million years oscillating within $+2{ }^{\circ} \mathrm{C}$ and $-6{ }^{\circ} \mathrm{C}$ relative to pre-industrial temperature (the 0 line). Observations from ice-core and tree ring proxy data in black and modelling results in blue reflecting interactions between the biosphere and the broader Earth system. Evidence suggests that current levels of anthropogenic warming have forced the Earth system out of the Holocene climate conditions into the Anthropocene. There is increasing consensus that pushing the Earth system to more than $2{ }^{\circ} \mathrm{C}$ warming compared to pre-industrial levels constitutes unknown terrain for contemporary societies and a threat to civilization (Steffen et al. 2018). Figure 3A by W. Steffen, source and data from Petit et al. (1999) and Oppenheimer (2004). Figure 3B adapted from Willeit et al., Sci. Adv. 2019; 5 : eaav7337. ( ) The Authors, some rights reserved; exclusive licensee AAAS. Distributed under a CC BY 4.0 license

\section{Climate change-stronger and faster than predicted}

Earth has been oscillating between colder and warmer periods over a million years (the entire Pleistocene), but the average mean temperature has never exceeded $2{ }^{\circ} \mathrm{C}$ (interglacial) above or $6{ }^{\circ} \mathrm{C}$ below (deep ice age) the preindustrial temperature on Earth $\left(14{ }^{\circ} \mathrm{C}\right)$, reflecting the importance of feedbacks from the living biosphere as part of regulating the temperature dynamics of the Earth (Willeit et al. 2019) (Fig. 3b).

Human-induced global warming is unparalleled. For $98 \%$ of the planet's surface, the warmest period of the past 2000 years occurred in the late twentieth century (Neukom et al. 2019) and has steadily increased into the twenty-first century with the average global temperature for 2015-2020 being the warmest of any equivalent period on record (WMO 2020). Already now at $1.2^{\circ} \mathrm{C}$ warming compared to pre-industrial levels, we appear to be moving out of the accommodating Holocene environment that allowed agriculture and complex human societies to develop (Steffen et al. 2018) (Fig. 3a). Already within the coming 50 years, 1 to 3 billion people are projected to experience living conditions that are outside of the climate conditions that have served humanity well over the past 6000 years (Xu et al. 2020).

Currently, some $55 \%$ of global anthropogenic emissions causing global warming derive from the production of energy and its use in buildings and transport. The remaining 45\% comes from human emissions that arise from the management of land and the production of 
buildings, vehicles, electronics, clothes, food, packaging, and other goods and materials (Ellen MacArthur Foundation 2019). The food system itself accounts for about $25 \%$ of the emissions (Mbow et al. 2019). Human-driven landuse change through agriculture, forestry, and other activities (Lambin and Meyfroidt 2011) causes about 14\% of the emissions (Friedlingstein et al. 2020). Cities account for about $70 \%$ of $\mathrm{CO}_{2}$ emissions from final energy use and the highest emitting 100 urban areas for $18 \%$ of the global carbon footprint (Seto et al. 2014; Moran et al. 2018). About $70 \%$ of industrial greenhouse gas emissions are linked to 100 fossil-fuel producing companies (Griffin and Hede 2017). Collectively, the top 10 emitting countries account for three quarters of global GHG emissions, while the bottom 100 countries account for only 3.5\% (WRI 2020). As a consequence of the pandemic, global fossil $\mathrm{CO}_{2}$ emission in 2020 decreased by about $7 \%$ compared to 2019 (Friedlingstein et al. 2020).

Climate change impacts are hitting people harder and sooner than envisioned a decade ago (Diffenbaugh 2020). This is especially true for extreme events, like heatwaves, droughts, wildfires, extreme precipitation, floods, storms, and variations in their frequency, magnitude, and duration. The distribution and impacts of extreme events are often region specific (Turco et al. 2018; Yin et al. 2018). For example, Europe has experienced several extreme heat waves since 2000 and the number of heat waves, heavy downpours, and major hurricanes, and the strength of these events, has increased in the United States. The risk for wildfires in Australia has increased by at least $30 \%$ since 1900 as a result of anthropogenic climate change (van Oldenborgh et al. 2020). The recent years of repeated wildfires in the western U.S. and Canada have had devastating effects (McWethy et al. 2019). Extreme events have the potential to widen existing inequalities within and between countries and regions (UNDP 2019). In particular, synchronous extremes are risky in a globally connected world and may cause disruptions in global food production (Cottrell et al. 2019; Gaupp et al. 2020). Pandemics, like the COVID-19 outbreak and associated health responses, intersect with climate hazards and are exacerbated by the economic crisis and long-standing socioeconomic and racial disparities, both within countries and across regions (Phillips et al. 2020).

Some of these changes will happen continuously and gradually over time, while others take the form of more sudden and surprising change (Cumming and Peterson 2017). In addition, some are to some extent predictable, others more uncertain and unexpected. An analysis of a large database of social-ecological regime shifts (large shifts in the structure and function of social-ecological systems, transitions that may have substantial impacts on human economies and societies), suggests that in the intertwined world one change may lead to another, or that events can co-occur because they simply share the same driver (Rocha et al. 2018). Large-scale transitions can unfold when a series of linked elements are all close to a tipping point, making it easier for one transition to set off the others like a chain reaction or domino effect (Scheffer et al. 2012; Lenton et al. 2019).

With increased warming, humanity risks departing the glacier-interglacial dynamics of the past 2.6 million years (Burke et al. 2018). If efforts to constrain emissions fail, the global average temperature by 2100 is expected to increase $3-5{ }^{\circ} \mathrm{C}$ (IPCC 2014) above pre-industrial levels. Although higher global temperatures have occurred in deep geological time, living in a biosphere with a mean annual global temperature exceeding $2{ }^{\circ} \mathrm{C}$ of the pre-industrial average (Fig. 3) is largely unknown terrain for humanity and certainly novel terrain for contemporary society.

\section{The climate and the biosphere interplay}

The relation between climate and the biosphere is being profoundly altered and reshaped by human action. The total amount of carbon stored in terrestrial ecosystems is huge, almost 60 times larger than the current annual emissions of global GHG $\left(\mathrm{CO}_{2}\right.$ equivalents, 2017) by humans, and with the major part, about $70 \%(1500-2400 \mathrm{Gt} C)$ found in soil (Ciais et al. 2013). The ocean holds a much larger carbon pool, at about $38000 \mathrm{Gt}$ of carbon (Houghton 2007). Thus far, terrestrial and marine ecosystems have served as important sinks for carbon dioxide and thereby contribute significantly to stabilizing the climate. At current global average temperature, the ocean absorbs about $25 \%$ of annual carbon emissions (Gruber et al. 2019) and absorbs over $90 \%$ of the additional heat generated from those emissions. Land-based ecosystems like forests, wetlands, and grasslands bind carbon dioxide through growth, and all in all sequester close to $30 \%$ of anthropogenic $\mathrm{CO}_{2}$ emissions (Global Carbon Project 2019).

The biosphere's climate stabilization is a critical ecosystem service, or Earth system service, which cannot be taken for granted. Recent research has shown that not only human land-use change but also climate impacts, like extreme events and temperature change, increasingly threaten carbon sinks. For example, the vast fires in Borneo in 1997 released an equivalent of $13-40 \%$ of the mean annual global carbon emissions from fossil fuels at that time (Page et al. 2002; Folke et al. 2011). The devastating forest fires of 2019 in Australia, Indonesia, and the Amazon triggered emissions equivalent to almost $40 \%$ of the annual global carbon sink on land and in the ocean (www. globalfiredata.org).

The Earth system contains several biophysical sub-systems that can exist in multiple states and which contribute 


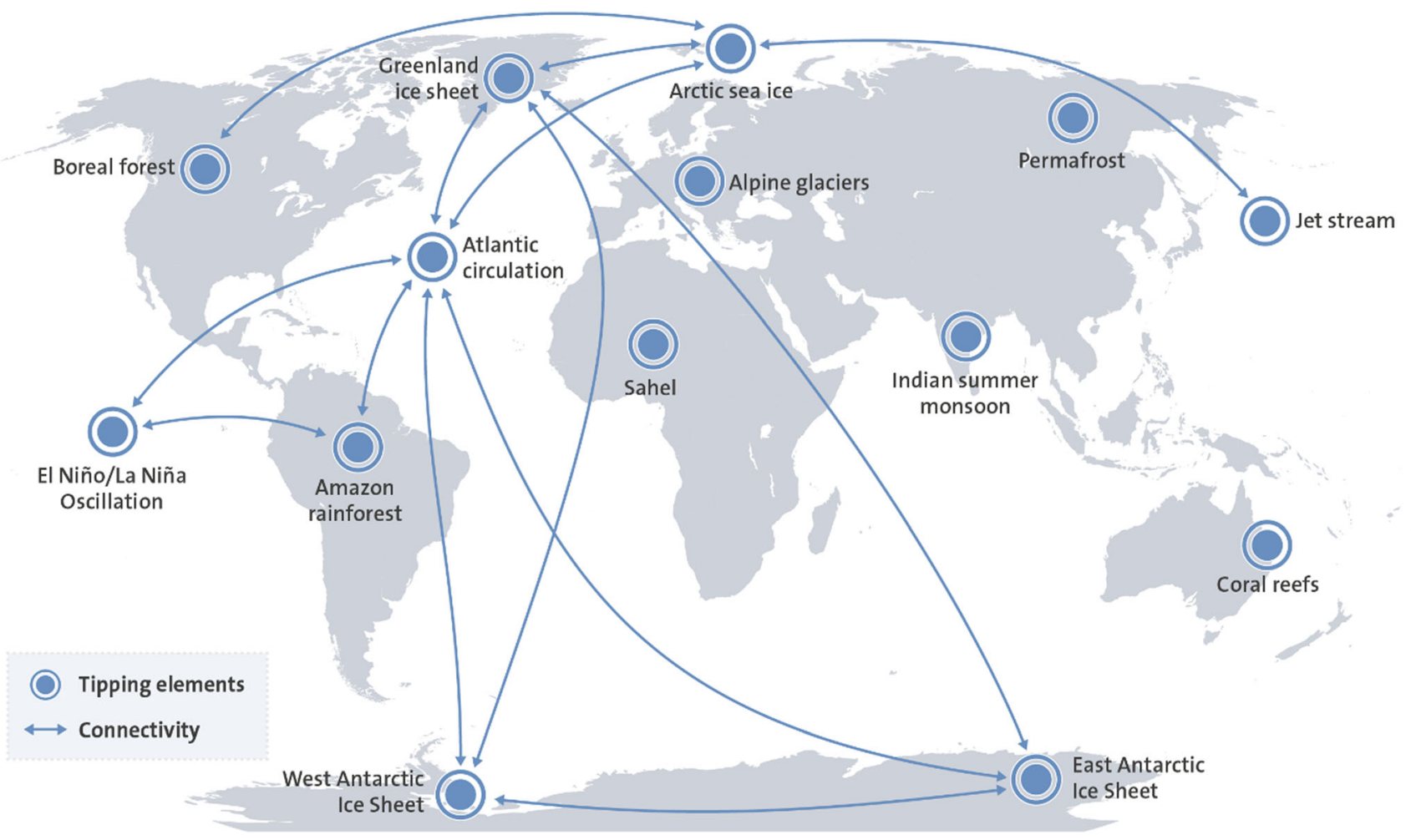

Fig. 4 Tipping elements central in regulating the state of the planet, and identified interactions among them that, for humanity, could cause serious cascading effects and even challenge planetary stability (based on Steffen et al. 2018; Lenton et al. 2019). In addition, ocean acidification, deoxygenation, tropical cyclones, ocean heat waves, and sea level rise are challenging human wellbeing (Pörtner et al. 2019)

to the regulation of the state of the planet as a whole (Steffen et al. 2018). These so-called tipping elements, or sleeping giants (Fig. 4), have been identified as critical in maintaining the planet in favourable Holocene-like conditions. These are now challenged by global warming and human actions, threatening to trigger self-reinforcing feedbacks and cascading effects, which could push the Earth system towards a planetary threshold that, if crossed, could prevent stabilization of the climate at intermediate global warming and cause escalating climate change along a "Hothouse Earth" pathway even as human emissions are reduced (Steffen et al. 2018). Observations find that nine of these known sleeping giants, thought to be reasonably stable, are now undergoing large-scale changes already at current levels of warming, with possible domino effects to come (Lenton et al. 2019).

The significance of the challenge of holding global warming in line with the Paris climate target is obvious. As a matter of fact, the challenge is broader than climate alone. It is about navigating towards a safe-operating space that depends on maintaining a high level of Earth resilience. Incremental tweaking and marginal adjustments will not suffice. Major transformations towards just and sustainable futures are the bright way forward.

\section{The living biosphere and Earth system dynamics}

The interactions and diversity of organisms within and across the planet's ecosystems play critical roles in the coevolution of the biosphere and the broader Earth system. For example, major biomes like tropical and temperate forests and their biological diversity transpire water vapour that connects distant regions through precipitation (Gleeson et al. 2020a, b). Nearly a fifth of annual average precipitation falling on land is from vegetation-regulated moisture recycling, with several places receiving nearly half their precipitation through this ecosystem service. Such water connections are critical for semi-arid regions reliant on rain-fed agricultural production and for water supply to major cities like Sao Paulo or Rio de Janeiro (Keys et al. 2016). As many as 19 megacities depend for more than a third of their water supply on water vapour from land, a dependence especially relevant during dry years (Keys et al. 2018). In some of the world's largest river basins, precipitation is influenced more strongly by land-use change taking place outside than inside the river basin (Wang-Erlandsson et al. 2018).

The biosphere contains life-supporting ecosystems supplying essential ecosystem services that underpin human 


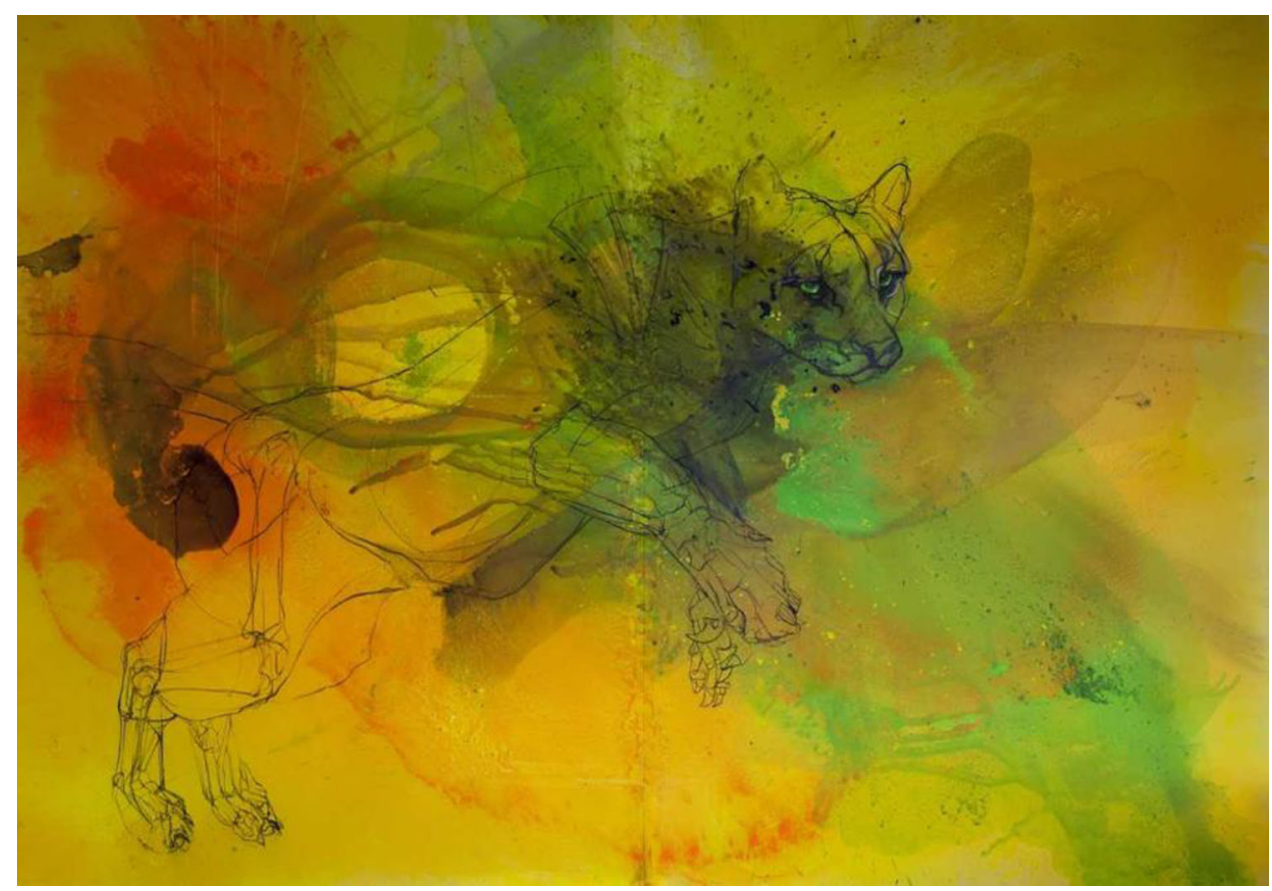

Fig. 5 Biodiversity plays significant roles in biosphere resilience. Puma, Kay Pacha 2017, painting, and courtesy of Angela Leible

wellbeing and socioeconomic development. For example, the biosphere strongly influences the chemical and physical compositions of the atmosphere, and biodiversity contributes through its influence in generating and maintaining soils, controlling pests, pollinating food crops, and participating in biogeochemical cycles (Daily 1997). The ocean's food webs, continental shelves, and estuaries support the production of seafood, serve as a sink for greenhouse gases, maintain water quality, and hedge against unanticipated ecosystem changes from natural or anthropogenic causes (Worm et al. 2006). These services represent critical lifesupporting functions for humanity (Odum 1989; Reyers and Selig 2020) and biological diversity plays fundamental roles in these nature's contributions to people (Diaz et al. 2018).

\section{Biodiversity performing vital roles in biosphere resilience}

Organisms do not just exist and compete, they perform critical functions in ecosystem dynamics and in creating and providing social-ecological resilience (Folke et al. 2004; Hooper et al. 2005; Tilman et al. 2014) (Fig. 5). Resilience refers to the capacity of a system to persist with change, to continue to develop with ever changing environments (Reyers et al. 2018).

Biodiversity plays significant roles in buffering shocks and extreme events, and in regime shift dynamics (Folke et al. 2004). The diversity of functional groups and traits of species and populations are essential for ecosystem integrity and the generation of ecosystem services (Peterson et al. 1998; Hughes et al. 2007; Isbell et al. 2017). Variation in responses of species performing the same function is crucial in resilience to shocks or extreme events (Chapin et al. 1997). Such "response diversity", serves as insurance for the capacity of ecosystems to regenerate, continue to develop after disturbance and support human wellbeing (Elmqvist et al. 2003).

The Amazon rainforest is a prime example. Conserving a diversity of plants species may enable the Amazon forests to adjust to new climate conditions and protect the critical carbon sink function (Sakschewski et al. 2016). Frequent extreme drought events have the potential to destabilize large parts of the Amazon forest especially when subsoil moisture is low (Singh et al. 2020), but the risk of selfamplified forest loss is reduced with increasing heterogeneity in the response of forest patches to reduced rainfall (Zemp et al. 2017). However, continuous deforestation and simultaneous warming are likely to push the forest towards tipping points with wide-ranging implications (Hirota et al. 2011; Staver et al. 2011; Lovejoy and Nobre 2018). Also, with greater climate variability, tree longevity is shortened, thus, influencing carbon accumulation and the role of the Amazon forest as a carbon sink (Brienen et al. 2015). A large-scale shift of the Amazon would cause major impacts on wellbeing far outside the Amazon basin through changes in precipitation and climate regulation, and by linking with other tipping elements in the Earth system (Fig. 4). 
Hence, the resilience of multifunctional ecosystems across space and time, and in both aquatic and terrestrial environments, depends on the contributions of many species, and their distribution, redundancy, and richness at multitrophic levels performing critical functions in ecosystems and biosphere dynamics (Mori et al. 2013; Nash et al. 2016; Soliveres et al. 2016; Frei et al. 2020). Biodiversity and a resilient biosphere are a reflection of life continuously being confronted with uncertainty and the unknown. Diversity builds and sustains insurance and keeps systems resilient to changing circumstances (Hendershot et al. 2020).

\section{Homogenization, hyper-connectivity, and critical transitions}

Conversion and degradation of habitats have caused global biodiversity declines and defaunation (human-caused animal loss), with extensive cascading effects in marine, terrestrial, and freshwater ecosystems as a result, and altered ecosystem functions and services (Laliberte et al. 2010; Estes et al. 2011). Over the past 50 years of human acceleration, the capacity of nature to support quality of life has declined in $78 \%$ of the 18 categories of nature's contributions to people considered by the Intergovernmental Science-Policy Platform on Biodiversity and Ecosystem Services (Diaz et al. 2018).

Much of the Earth's biosphere has been converted into production ecosystems, i.e. ecosystems simplified and homogenized for the production of one or a few harvestable species (Nyström et al. 2019). Urbanization is a force in homogenizing and altering biodiversity in landscapes and seascapes (Seto et al. 2012b), and over the past decade land-use change (Meyfroidt et al. 2018) accounted for nearly a quarter of all anthropogenic greenhouse gas emissions (Arneth et al. 2019).

The increase in homogeneity worldwide denotes the establishment of a global standard food supply, which is relatively species rich at the national level, but species poor globally (Khoury et al. 2014). Globally, local varieties and breeds of domesticated plants and animals are disappearing (Diaz et al. 2018). Land-use intensification homogenizes biodiversity in local assemblages of species worldwide (Newbold et al. 2018) and counteracts a positive association between species richness and dietary quality. It also affects ecosystem services and wellbeing in low- and middle-income countries (Lachat et al. 2018; Vang Rasmussen et al. 2018). In much of the world more than half, up to $90 \%$, of locally adapted varieties of major crop species (e.g. wheat and rice) have been lost due to replacement by single high-yielding varieties (Heal et al. 2004).

The simplification and intensification of production ecosystems and their tight connectivity with international markets have yielded a global production ecosystem that is very efficient in delivering goods to markets, but globally homogeneous, highly interconnected, and characterized by weakened internal feedbacks that mask or dilute the signals of loss of ecosystem resilience to consumers (Nyström et al. 2019; Ortiz et al. 2021). In addition, the global food trade network has over the past 20 years become progressively delocalized as a result of globalization (that is, modularity has been reduced) and as connectivity and homogeneity increase, shocks that were previously contained within a geographical area or a sector are becoming globally contagious and more prevalent (Tamea et al. 2016; Tu et al. 2019; Kummu et al. 2020).

Homogenization reduces resilience, the capacity to live and develop with change and uncertainty, and therby the diversity of ways in which species, people, sectors, and institutions can respond to change as well as their potential to functionally complement each other (Biggs et al. 2012; Grêt-Regamey et al. 2019; Nyström et al. 2019). In addition, homogeneous landscapes lack the diversity of ecosystem types for resilient responses when a single homogeneous landscape patch, such as a production forest or crop, is devastated by pathogens or declines in economic value. In addition, such ecosystem simplification and degradation increase the likelihood of disease emergence, including novel viruses (Myers and Patz 2009). In parallel, people, places, cultures, and economies are increasingly linked across geographical locations and socioeconomic contexts, making people and planet intertwined at all scales.

Evidence suggests that homogenization, simplification, intensification, strong connections, as well as suppression of variance, increase the likelihood of regime shifts, or critical transitions with thresholds and tipping points (Scheffer et al. 2012; Carpenter et al. 2015). These shifts may interact and cascade, thereby causing change at very large scales with severe implications for the wellbeing of human societies (Hughes et al. 2013; Rocha et al. 2018). Comparison of the present extent of biosphere conversion with past global-scale regime shifts suggests that globalscale biosphere regime shift is more than plausible (Barnosky et al. 2012). The biotic hallmark for each earlier biosphere regime shifts was pronounced change in global, regional, and local assemblages of species (Barnosky et al. 2012). 


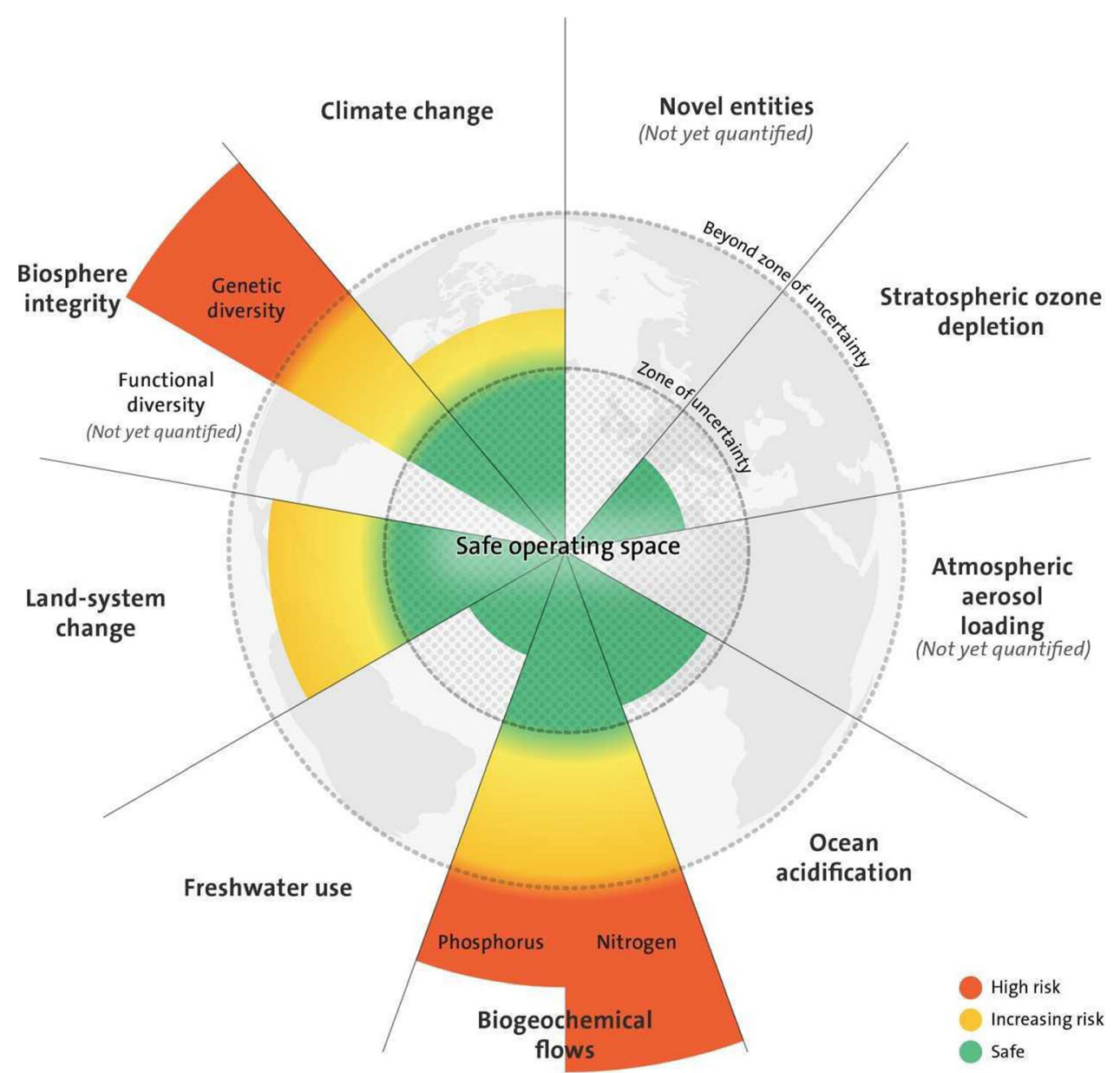

Fig. 6 The nine identified planetary boundaries. The green zone is the safe-operating space (below the boundary), yellow represents the zone of uncertainty (increasing risk), and red is the high-risk zone. In these potentially dangerous zones of increasing risk, there are likely continental and global tipping points for some of the boundaries, although not for all them. The planetary boundary itself lies at the inner heavy circle. A proposed boundary does not represent a tipping point or a threshold but is placed upstream of it, that is, well before the risk of crossing a critical threshold. The intent of this buffer between the boundary and a potential threshold in the dangerous zone is to allow society time to react to early warning signs of approaching abrupt or risky change. Processes for which global-level boundaries are not quantified are represented by grey wedges (adapted from Steffen et al. 2015). Reprinted with permission

\section{Planetary boundaries and a safe-operating space for humanity}

It is in the self-interest of humanity to avoid pushing ecosystems or the entire Earth system across tipping points. Therefore, a major challenge is to enhance biosphere resilience and work towards stabilizing the Earth system and its biosphere in a state that, hopefully, is safe for humanity to operate within, albeit a warmer state than the Holocene and one with a human-dominated biosphere. Clearly, the climatic system and the biological diversity and functional integrity of the biosphere, as well as their interplay, are foundational for cultivating a resilient Earth system.

Climate and biosphere integrity constitute the two fundamental dimensions of the Planetary Boundaries framework, which delineates a Holocene-like state of the Earth system, the state that has enabled civilizations to emerge and flourish (Fig. 6). Four of the nine boundaries, including climate and biodiversity, are estimated to already have been transgressed. The framework provides a naturalscience-based observation that human forcing has already, at the planetary scale, rapidly pushed the Earth system away from the Holocene-like conditions and onto an accelerating Anthropocene trajectory (Steffen et al. 2018).

In recent years, there have been several efforts to further investigate and deepen the understanding of planetary boundaries and the safe-operating space for humanity. These include updates on the biodiversity boundary, the freshwater boundary, the biogeochemical flows (Carpenter and Bennett 2011; de Vries et al. 2013; Mace et al. 2014; Newbold et al. 2016; Gleeson et al. 2020b), multiple 


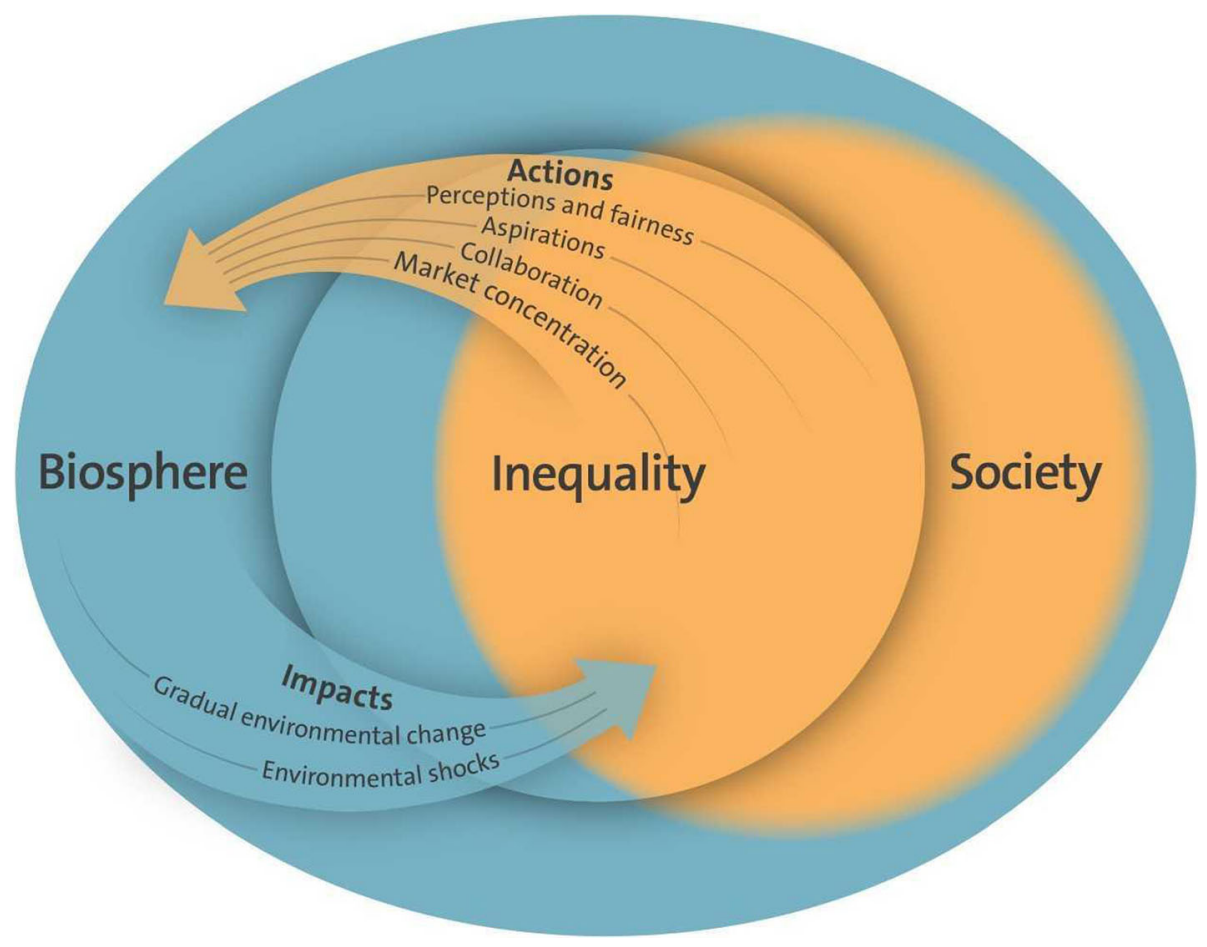

Fig. 7 Examples of pathways of interactions between inequality and the biosphere in intertwined systems of people and nature (adapted from Hamann et al. 2018). Reprinted with permission

regime shifts and possible links between regional and planetary tipping points (Anderies et al. 2013; Hughes et al. 2013), regional perspectives on the framework (Häyhä et al. 2016; O’Neill et al. 2018), and creating safe-operating spaces (Scheffer et al. 2015). Attempts to quantify interactions between planetary boundaries suggest that cascades and feedbacks predominantly amplify human impacts on the Earth system and thereby shrink the safeoperating space for human actions in the Anthropocene (Lade et al. 2020).

There are also propositions for integrating the planetary boundaries framework with economic, social, and human dimensions (Raworth 2012; Dearing et al. 2014; Downing et al. 2019) as well as tackling the policy and governance challenges associated with the approach (Biermann et al. 2012; Galaz et al. 2012; Sterner et al. 2019; Pickering and Persson 2020; Engström et al. 2020). The global food system is also placed within the framework of the planetary boundaries (Gordon et al. 2017), like in the EAT-Lancet Commission's report on healthy diets from sustainable food systems for nearly 10 billion people by 2050 (Willett et al. 2019).

In light of the profound challenges of navigating the future of human societies towards a stabilized Earth state, it becomes clear that modest adjustments on current pathways of societal development are not very likely to guide humanity into sustainable futures (Kates et al. 2012).
Stabilizing the Earth system in a safe-operating space will require transformative changes in many dimensions of human actions and relations (Westley et al. 2011; Sachs et al. 2019).

\section{INEQUALITY AND GLOBAL SUSTAINABILITY}

Inequality describes an unequal distribution of a scarce resource, benefit, or cost and does not necessarily represent a normative statement. Inequity is a more normative term that evokes an unfair or unjust distribution of privileges across society. There are complex interconnections between inequality, the biosphere, and global sustainability (Hamann et al. 2018) (Fig. 7) that go beyond unequal distribution of income or wealth, like distributional, recognitional, and procedural inequities (Leach et al. 2018). Distributional equity refers to how different groups may have access to resources, and how costs, harms, and benefits are shared. Recognitional equity highlights the ongoing struggle for recognition of a diversity of perspectives and groups, e.g. referring to nationality, ethnicity, or gender, whereas procedural equity focuses on how different groups and perspectives are able to engage in and influence decision-making processes and outcomes (Leach et al. 2018). Approaches to sustainability generally include some form of equality, universal prosperity, and poverty 
alleviation. Global environmental change and unsustainable practices may exacerbate inequalities (Hamann et al. 2018). Greater inequality may lead to weaker economic performance and cause economic instability (Stiglitz 2012). Increasing income inequality may also lead to more societal tension and increase the odds of conflict (Durante et al. 2017).

\section{Rising inequality}

The majority of countries for which adequate data exist have seen rising inequality in income and wealth over the past several decades (Piketty 2014). In the U.S., Europe, and China, the top $10 \%$ of the population own $70 \%$ of the wealth, while the bottom $50 \%$ own only $2 \%$. In the U.S., the share of income going to the top $1 \%$ rose from around $11 \%$ in 1980 to above $20 \%$ in 2016 (World Inequality Report 2018), and the share of wealth of the top $0.1 \%$ more than tripled between 1978 and 2012, and is roughly equal to the share of wealth of the bottom 90\% (Saez and Zucman 2016). Also, the wealthiest $1 \%$ of the world's population have been responsible for more than twice as much carbon pollution as the poorest half of humanity (Kartha et al. 2020). Seventy-five per cent of the world's cities have higher levels of income inequalities than two decades ago, and the spatial concentration of low-income unskilled workers in segregated residential areas acts as a poverty trap (UN-Habitat 2016). About $10 \%$ of the world population in 2015, or some 740 million people, were living in extreme poverty (World Bank 2019).

Inequality can impact the sense of community, common purpose, and trust (Jachimowicz et al. 2017) and influences successful management of common pool resources in different ways (Baland et al. 2007). Inequality may give rise to perceptions, behaviour, and social norms about status and wealth, and disparities in worth and cultural membership between groups in a society-so-called "recognition gaps" (Lamont 2018).

\section{Inequalities and the environment}

Greater inequality can lead to more rapid environmental degradation, because low incomes lead to low investment in physical capital and education. Such situations often cause excessive pressure and degradation of natural capital leading to declining incomes and further degradation in a downward spiral, a poverty trap (Bowles et al. 2006). Furthermore, interventions that ignore nature and culture can reinforce poverty traps (Lade et al. 2017), and economic and environmental shocks, food insecurity, and climate change may force people back into poverty (lack of resources and capacities to fulfil basic needs) (Kates and Dasgupta 2007; Wood et al. 2018).
Gender, class, caste, and ethnic identities and relationships, and the specific social, economic and political power, roles and responsibilities they entail, shape the choices and decisions open to individuals and households in dealing with the climate and environmental risks they face (Rao et al. 2020). Gender inequality has important reinforcing feedbacks with environmental change (Fortnam et al. 2019) and has, for example, been shown to change with shifts in tropical land use in Indonesia (Maharani et al. 2019) or with changes in levels of direct use of local ecosystem services by households in South Africa (Hamann et al. 2015). Climate change is projected to disproportionally influence disadvantaged groups, especially women, girls, and indigenous communities (Islam and Winkel 2017).

People with less agency and fewer resources at their disposal are more vulnerable to climate change (Althor et al. 2016; Morton 2007) and to environmental shocks and extreme events such as floods and droughts (Hallegatte et al. 2016; Jachimowicz et al. 2017). The COVID-19 pandemic has further exposed the inequality in vulnerability to shocks among communities that lack the financial resources and essentials for a minimum standard of living, feeding off existing inequalities and making them worse (Drefahl et al. 2020; Stiglitz 2020). There is significant concern that climate-driven events exacerbate conflict because they affect economic insecurity which, in itself, has been shown to be a major cause of violent conflict and unrest (Mach et al. 2019; Ide et al. 2020).

Vulnerability to climate change is also due to many lowincome countries' location in low latitudes where further warming pushes these countries ever further away from optimal temperatures for climate-sensitive economic sectors (King and Harrington 2018). Examples include countries with high numbers of vulnerable, poor or marginalized people in climate-sensitive systems like deltas, semi-arid lands, and river basins dependent on glaciers and snowmelt (Conway et al. 2019). Changes to glaciers, snow and ice in mountains will likely influence water availability for over a billion people downstream by mid-century (Pihl et al. 2019). Under future scenarios of land-use and climate change, up to 5 billion people face higher water pollution and insufficient pollination for nutrition, particularly in Africa and South Asia. Hundreds of millions of people face heightened coastal risk across Africa, Eurasia, and the Americas (Chaplin-Kramer et al. 2019).

\section{Ocean inequity}

In the ocean, inequity manifests, for example, in skewed distribution of commercial fish catches, limited political power of small-scale fishers, particularly women and other minority groups, limited engagement of developing nations 
in high-seas activities and associated decision making, and consolidated interests of global supply chains in a few transnational corporations, with evidence of poor transparency and human rights abuses (Österblom et al. 2019). The results of inequity include a loss of livelihoods and limited financial opportunities, increased vulnerabilities of already marginalized groups, who are facing nutritional and food security challenges, and negative impacts on marine ecosystems (Harper et al. 2013; Hicks et al. 2019).

Coastal communities are sensitive to climate-induced shifts in the distribution and abundance of fish stocks crucial to their livelihoods and nutrition (Blasiak et al. 2017). This accentuated sensitivity is coupled with comparatively low levels of adaptive capacity, as remote coastal communities often have limited access to education, health services and alternative livelihoods, all of which could buffer the projected negative impacts from climate change (Cinner et al. 2018).

As a means to improve fish abundance for coastal communities of low-income nations, there have been suggestions of closing the high seas to fishing through groups of states that commit to a set of international rules. This would not only slow the pace of overfishing, but would also rebuild stocks that migrate into countries' Exclusive Economic Zones (EEZs), which could reduce inequality by
$50 \%$ in the distribution of fisheries benefits among the world's maritime countries (Sumaila et al. 2015; Green and Rudyk 2020).

\section{Inequities and sustainability}

Alleviating inequality and poverty is a central objective of the U.N. Sustainable Development Goals agreed to by national governments. Achieving global sustainability is another important set of objectives in the Sustainable Development Goals. The relation between inequality and sustainability is the outcome of this dynamics and not simply of cause and effect, but rather unfolding in different places, as experienced and understood by the people living there. Supporting and enhancing the emergence of capacities for dealing with shocks and surprises as part of strategies for learning and developing with change in the turbulent times of the Anthropocene will be central to confront inequality and advance wellbeing (Biggs et al. 2012; Clark and Harley 2020). Multiple inequities and sustainabilities will require diverse forms of responses, attuned to diverse contexts (Leach et al 2018; Clark and Harley 2020) (Fig. 8) and framed by transformations towards global sustainability as embedded in the biosphere (Westley et al. 2011).

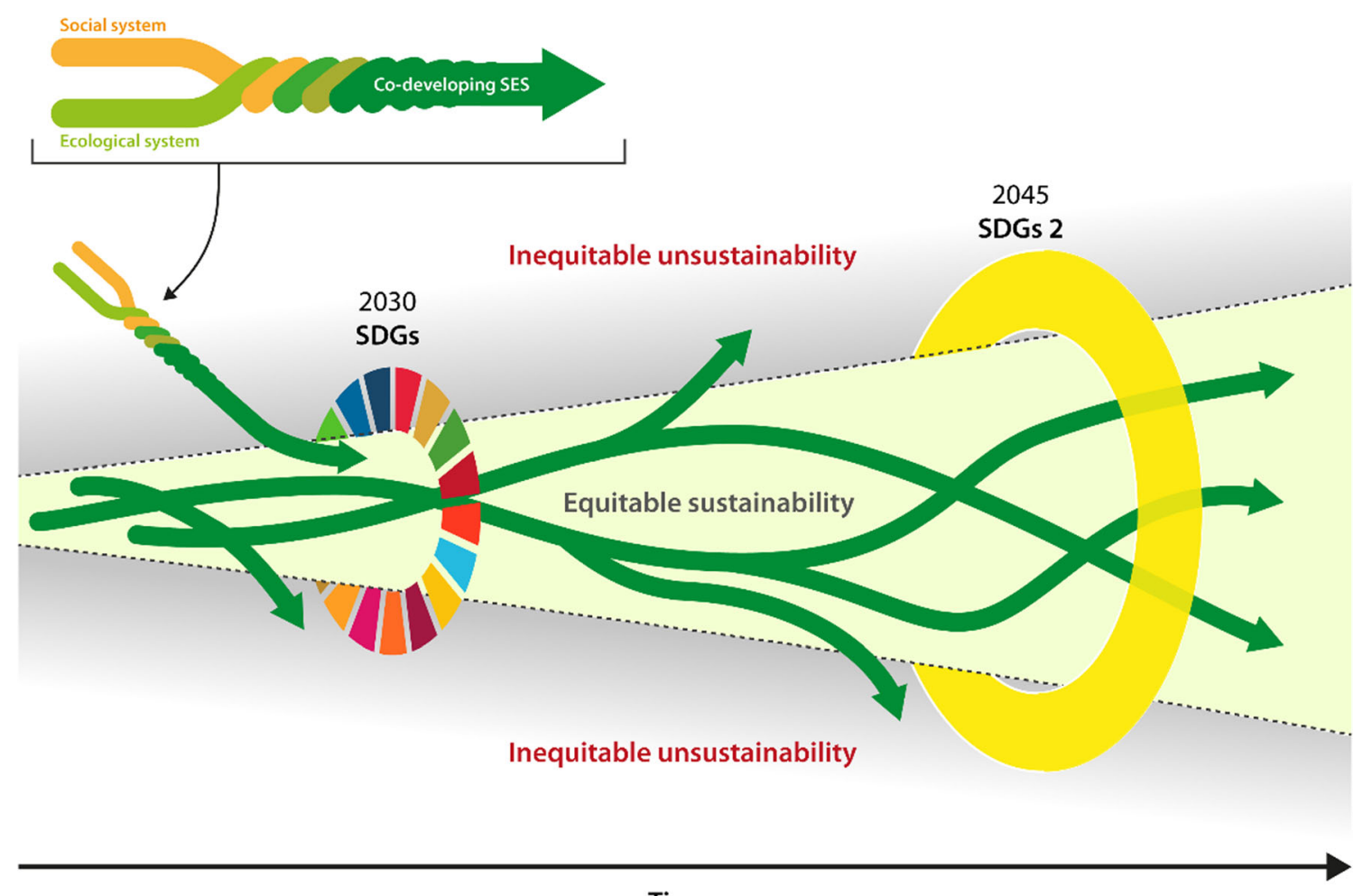

Time

Fig. 8 Alternative social-ecological development pathways over time, navigated by efforts like the SDGs and emergent outcomes for equity and sustainability, with an "equitable sustainability space" highlighted (adapted from Leach et al. 2018). Reprinted with permission 


\section{SOCIETAL TRANSFORMATION AND TECHNOLOGICAL CHANGE}

By transformation, we refer to the capacity to create fundamentally new systems of human-environmental interactions and feedbacks when ecological, economic, or social structures make the continuation of the existing system untenable (Folke et al. 2010). It involves multiple elements, including agency, practices, behaviours, incentives, institutions, beliefs, values, and world views and their leverage points at multiple levels (Abson et al. 2017; Moore and Milkoreit 2020). Understanding transformation goes beyond a focus on the triggers, to unravelling the capacities for reducing resilience of an undesired, status quo, system, and nurturing and navigating the emergence of new, desired systems (Elmqvist et al. 2019); to confront path-dependencies, build capacities for new shocks and risks, and shift towards sustainable pathways (Olsson et al. 2017).

Here, we stress that technological change and social innovation in relation to sustainability will need a deeper focus on intertwined social-ecological interactions and feedbacks of the Anthropocene, since that will be necessary to understand and achieve large-scale changes towards global sustainability. We start this section with the role of emerging technologies and social media in this context, followed by findings from social innovation and transformation research and with an emphasis on the significance of narratives of hope for shifting towards sustainable futures.

\section{Emerging technologies and sustainability}

Most likely, technological change such as information technology, artificial intelligence, and synthetic biology will drastically change economies, human relations, social organization, culture and civilization, creating new unknown futures. However, technological change alone will not lead to transformations towards sustainability. It could lead humanity in diverse directions, pleasant and unpleasant ones, and with different social and environmental impacts. For example, rapid advances in sequencing technologies and bioinformatics have enabled exploration of the ocean genome, but the capacity to access and use sequence data is inequitably distributed among countries and companies (Blasiak et al. 2018, 2020). The technological dimension of development has to be deliberately and strategically guided, to contribute to just and sustainable futures and guided how and by whom as a central challenge (Galaz 2014; van der Leeuw 2018).

On the other hand, it is most unlikely that transformations to sustainability will happen without the deployment of technologies that, e.g. help build resilience and development on the ground (Brown 2016), support transformations of current food production and innovation systems (Gordon et al. 2017; Costello et al. 2020), and contribute to a shift towards carbon neutral (or even negative) energy systems (Rockström et al. 2017).

The following categories of new technologies are already having bearing on global sustainability: the diversity of existing and emerging renewable energy technologies, like solar cells, hydrogen energy, wind generators, or geothermal heating; technologies that remove greenhouse gases from the atmosphere; the digital transformation, with Artificial Intelligence (AI), satellite remote sensing, quantum computing, and precision agriculture; synthetic biology, including biotechnology and genetic and molecular engineering, by redesigning and using organisms to solve problems in medicine, manufacturing and agriculture; mechanical engineering, like robotics and also nanotechnology. Their development, as embedded in the larger social-ecological systems, should be connected to and become part of ways forward when designing transformative pathways towards sustainability within planetary boundaries.

As human pressures on the biosphere increase, so does the hope that rapid advances in AI (including automated decision making, data mining, and predictive analytics) in combination with rapid progresses in sensor technology and robotics, will be able to increase society's capacities to detect, adapt, and respond to climate and environmental change without creating new vulnerabilities (Joppa 2017). Such technologies are applied in a number of research fields related to the environment and climate change, including environmental monitoring, conservation, and "green" urban planning (Hino et al. 2018; Ilieva and McPhearson 2018; Wearn et al. 2019; Reichstein et al. 2019). While nascent in terms of both scale and impact, such technological "niche-innovations" have the potential to rapidly upscale and shape ecosystems and institutions in multiple geographies (Geels et al. 2017). Such innovations have been claimed to be central for a "digital revolution for sustainable development" (Sachs et al. 2019).

Applications of these technologies have effects that span beyond climate and environmental research and monitoring, and more efficient natural resource use. AIsupported recommender systems as an example, influence consumer choices already today (André et al. 2018). Targeted attacks in social media by social bots, applications of computer algorithms that automatically produce content and interact with humans on social media, "trying to emulate and possibly alter their behavior" (Ferrara et al. 2016; Grinberg et al. 2019), also influence conversations in social media about climate and environmental issues and affect institutions for deliberative democracy (Dryzek et al. 2019). 
So far, the technological changes to our social systems have not come about with the purpose of promoting global sustainability (van der Leeuw 2019). This remains true of recent and emerging technologies, such as online social media and information technology, causing changes that are increasingly far-reaching, ambiguous, and largely unregulated (Del Vicario et al. 2016). For example, "online social networks are highly dynamic systems that change as a result of numerous feedbacks between people and machines". Algorithms suggest connections, to which users respond, and the algorithms, trained to optimize user experience, adapt to the responses. "Together, these interactions and processes alter what information people see and how they view the world" (Bergstrom and BakColeman 2019).

Hence, applications of novel technologies stemming from advancements in AI could at best be benevolent and lead to improved stewardship of landscapes, seascapes, water, or climate dynamics, through improved monitoring and interventions, as well as more effective resource use (Chaplin-Kramer et al. 2019). Negative impacts of novel technologies on vulnerable groups (Barocas et al. 2017) are also pertinent since they diffuse rapidly into society, or when used in sectors with clear impacts on the climate, or on land and ocean ecosystems. This issue needs to be taken seriously as technological changes influence decisions with very long-term climatic and biosphere consequences (Cave and Óhéigeartaigh 2019).

\section{Social media and social change}

The participatory nature of social media gives it a central role in shaping individual attitudes, feelings, and behaviours (Williams et al. 2015; Lazer et al. 2018), can underpin large social mobilization and protests (SteinertThrelkeld et al. 2015), and influence social norms and policy making (Barbier et al. 2018; Stewart et al. 2019). It is well known that dire warnings can lead to disconnect of the audience if it is not accompanied by a feasible perspective for action (Weber 2015). Social media changes our perception of the world, by promoting a sense of crisis and unfairness. This happens as activist groups seek to muster support (Gerbaudo and Treré 2015) and lifestyle movements seek to inspire alternative choices (Haenfler et al. 2012). For instance, social media catalysed the Arab spring among other things by depicting atrocities of the regime (Breuer et al. 2015), and veganism is promoted by social media campaigns highlighting appalling animal welfare issues (Haenfler et al. 2012).

On the worrying side, isolationism stimulated by socialmedia-boosted discontent may hamper global cooperation needed to curb global warming, biodiversity loss, wealth concentration, and other trends. On the other hand, social media has powered movements such as school strikes, extinction rebellion, voluntary simplicity, bartering, flight shame, the eat-local movement and veganism to promote a steadily rising global awareness of pressing issues that may ultimately shift social norms (Nyborg et al. 2016), trigger reforms towards sustainability (Otto et al. 2020) and perhaps also towards wealth equalization at all institutional levels (Scheffer et al. 2017).

The combination of discontent and self-organization not only promotes rebellion against the old way of doing things, as in street protests, populist votes, radicalization, and terrorism, but also catalyses the search for alternative ways, as in bartering and sharing platforms, or voluntary simplicity and other lifestyle movements (Haenfler et al. 2012; Carpenter et al. 2019).

The rise of social media and technologies such as bots and profiling has been explosive, and the mere rate of change has made it difficult for society to keep pace (Haenfler et al. 2012). Crowd-sourced fact checking may be combined with computer-assisted analyses and judgements from professionals (Hassan et al. 2019), and labelling quality of media sources ranging from internet fora to newspapers and television stations may alert users to the risk of disinformation and heavy political bias (Pennycook and Rand 2019). With time, such approaches together with legislation, best-practice agreements, and individual skills of judging the quality of sources may catch up to control some of the negative side-effects (Walter et al. 2019).

The emerging picture is that social media have become a global catalyst for social change by facilitating shifts on scales ranging from individual attitudes to broad social norms and institutions. It remains unclear, however, whether this new "invisible hand" will move the world on more sustainable and just pathways. Can the global, fast moving capacity for information sharing and knowledge generation through social media help lead us towards a just world where future generations thrive within the limits of our planet's capacity?

\section{Social innovation and transformation}

Transformations towards sustainability in the Anthropocene cannot be achieved by adaptation alone, and certainly not by incremental change only, but rather that more fundamental systemic transformations will be needed (Hackmann and St. Clair 2012; Kates et al. 2012; O’Brien 2012). Transformation implies fundamentally rewiring the system, its structure, functions, feedbacks, and properties (Reyers et al. 2018). But, despite such changes, there is hope for systemic transformations with dignity, respect and in democratic fashions (Olsson et al. 2017), in contrast to large-scale disruptive or revolutionary societal transformations like those of earlier civilizations (van der Leeuw 
2019). It will require trust building, cooperation, collective action, and flexible institutions (Ostrom 2010; Westley et al. 2011).

A characteristic feature of transformations is that change across different system states (trajectories or pathways) is not predetermined but rather emerges through diverse interactions across scales and among diverse actors (Westley et al. 2011). Therefore, the literature on transformations towards sustainability emphasize framing and navigating transformations rather than controlling those. Work on socio-technical sustainability transitions, socialecological transformations, and social innovation provide insights into these dynamics (Geels et al. 2017; Olsson et al. 2017; Westley et al. 2017).

These literatures have illustrated the importance of connectivity and cross-level interactions for understanding the role of technological and social innovation and transformative systemic change. The work emphasizes the importance of fostering diverse forms of novelty and innovations at the micro-level, supported by the creation of "transformative spaces", shielded from the forces of dominant system structures. These allow for experimentation with new mental models, ideas, and practices that could help shift societies onto more desirable pathways (Loorbach et al. 2017; Pereira et al. 2018a, b). The examples of the "Seeds of a Good Anthropocene" project reflect ongoing local experiments that, under the right conditions, could accelerate the adoption of pathways to transformative change (Bennett et al. 2016). As multiple demands and stressors degrade the ocean, transformative change in ocean governance seems required, shifting current economic and social systems towards ocean stewardship, e.g. through incorporation of niche innovations within and across economic sectors and stakeholder communities (Brodie Rudolph et al. 2020).

It has been shown that real-world transformations come about through the alignment of mutually reinforcing processes within and between multiple levels. For example, the alignment of "niche innovations" or "shadow networks' (which differ radically from the dominant existing system but have been able to gain a foothold in particular market niches or geographical areas) with change at broader levels and scales can create rapid change. Both slow moving trends (e.g., demographics, ideologies, accumulation of GHG) and sudden shocks (e.g. elections, economic crises, pandemics, extreme events) can start to weaken or disturb the existing social-ecological system and create windows-of-opportunity for niche innovations-new practices, governance systems, value orientations-to become rapidly dominant (Olsson et al. 2004, 2006; Chaffin and Gunderson 2016; Geels et al. 2017) (Fig. 9).

Hence, turbulent times may unlock gridlocks and traps and open up space for innovation and novelty (Gunderson and Holling 2002). Crises or anticipated risks can trigger people to experiment with new practices and alternative governance modes and key individuals, often referred to as policy, institutional or moral entrepreneurs, mobilize and combine social networks in new ways, preparing the system for change (Folke et al. 2005; Westley et al. 2013; O'Brien 2015). The preparation phase seems particularly important in building capacity to transform rather than simply returning to the status quo and reinforcing existing power structures following change. Bridging organizations tend to emerge, within or with new institutions, connecting governance levels and spatial and temporal scales (Cash et al. 2006; Hahn et al. 2006; Brondizio et al. 2009; Rathwell and Peterson 2012). In several cases, the broader social contexts provide an enabling environment for such emergence, for example, through various incentive structures or legal frameworks. When a window opens, there is skilful navigation of change past thresholds or tipping points and, thereafter, a focus on building resilience of the transformed system (Gelcich et al. 2010).

In general, the resulting transformation goes beyond the adoption of a new technology or a local social innovation alone. Instead it includes a portfolio of actions like investment in new infrastructures, establishment of new markets, changes in incentives, development of new social preferences, or adjustment of user practices. Furthermore, transformations gain momentum when multiple innovations are linked together, improving the functionality of each and acting in combination to reconfigure systems (Geels et al. 2017; Westley et al. 2017).

Successful social innovations are recognized by their capacity to radically shift broad social institutions (economies, political philosophies, laws, practices, and cultural beliefs) that provide structure to social life. In addition, social innovations seldom unfold in a deterministic manner, but with a kind of punctuated equilibrium, first languishing and then accelerating at times of opportunity or crisis. There is also the need for awareness of the shadow side of all innovation, the consequences of intervention in a complex system (Holling et al. 1998; Ostrom 2007). This is unavoidable but manageable if caught early, but needs attention, particularly in times of rapid change (Westley et al. 2017).

Social innovation is currently underway in many domains linked to climate change, like renewable energy (Geels et al. 2017) or agriculture (Pigford et al. 2018) and highlight the importance of innovations not only in science and technology, but also in institutions, politics, and social goals for sustainability. Substantial attention is also directed towards sustainability of the ocean, where policy makers, industries, and other stakeholders are increasingly engaged in collaboration (Österblom et al. 2017; Brodie Rudolf et al. 2020; UNGC 2020) and innovations 


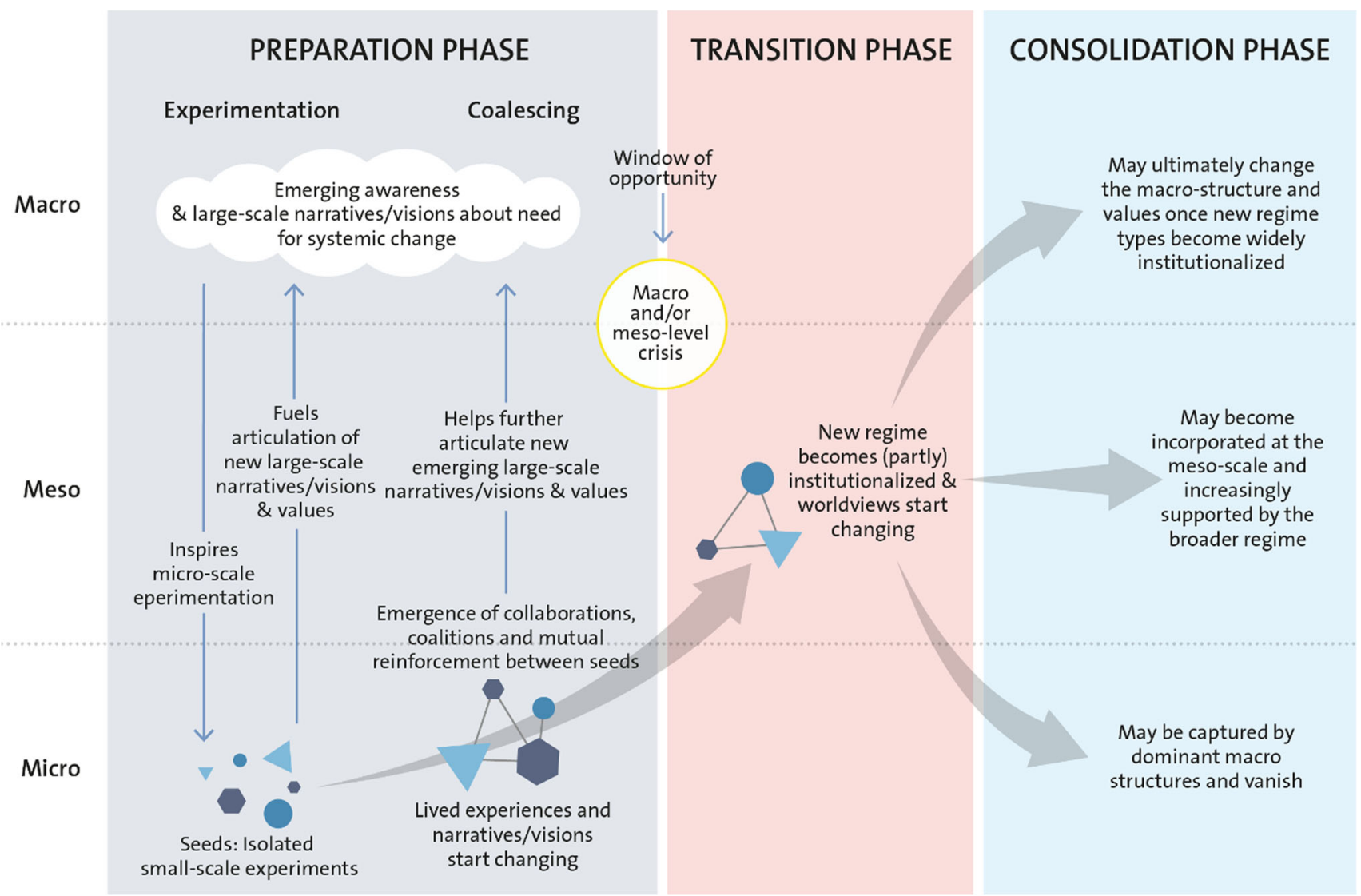

Fig. 9 The transformation process. A social innovation, a seed, matures to the extent that the initiative becomes prepared for change. And when change happens, when the window-of-opportunity unlocks at broader levels of governance, often in relation to a shock or disturbance, the new initiative can be skilfully navigated through the window and transitioned into a new development pathway, making it possible to transform the governance system and start building resilience of the new situation and taking it to scale (based on Olsson et al. 2004, Geels et al. 2002 and adapted from Pereira et al. 2018b). Reprinted with permission

(McCauley et al. 2016; Blasiak et al. 2018; Costello et al. 2020), aimed to create new incentives (Lubchenco et al. 2016; Jouffray et al. 2019; Sumaila et al. 2020) for action. However, for these to have transformative impact, shifts in cultural repertoires (schemas, frames, narratives, scripts, and boundaries that actors draw on in social situations) (Lamont et al. 2017) similar to those that accelerated the anti-smoking movement and the LGBTQ movement need to occur (Marshall et al. 2012; Moore et al. 2015; Nyborg et al. 2016).

There are suggestions for social tipping interventions to activate large-scale systemic shifts through, for example, rapidly spreading of technologies, shifts in social norms and behaviors, or structural reorganization of sectors, corporations, and societies (Folke et al. 2019; Otto et al. 2020). There are signs that such shifts are underway in western cultures, a desire for fundamental change towards a more sustainable way of life (Wibeck et al. 2019) aided by social movements such as the youth-led Extinction Rebellion, as well as a strong move to more healthy and sustainable diets (Willet et al. 2019). Again, all these changes unfold as part of cultural evolution, which needs attention as urgently as the decarbonization of our economy (Waring et al. 2015; Creanza et al. 2017; Jörgensen et al. 2019).

\section{Narratives of action for the future}

Social innovation and transformation require an individual and collective attention on the future. There are many documented obstacles to such future focus, from cognitive myopia to present-biased individual and institutional incentives and norms (Weber and Johnson 2016; Weber 2017, 2020). Choice architecture provides tools that reduce status-quo bias and encourage more foresightful decisions in specific circumstances (Yoeli et al. 2017), but rapid and systemic change will require more fundamental shifts in narratives at a collective level (Lubchenco and Gaines 2019).

Narratives are ways of presenting or understanding a situation or series of events that reflects and promotes a particular point of view or set of values. Narratives can 
serve as meaning-making devices, provide actors with confidence to act and coordinate action. They are of significance in shaping and anchoring worldviews, identities, and social interactions (van der Leeuw 2020).

Narratives of hope have proven essential for social resilience (Lamont 2019). Social resilience refers to the capacity of individuals, groups, communities, and nations "to secure favourable outcomes (material, symbolic, emotional) under new circumstances and when necessary by new means, even when this entails significant modifications to behaviour or to the social frameworks that structure and give meaning to behaviour" (Hall and Lamont 2012).

Transforming towards sustainable futures will require broadening cultural membership by promoting new narratives that resonate, inspire, and provide hope centred on a plurality of criteria of worth and social inclusion. Here, we are concerned with the challenge of motivating a collective recognition of our interdependence with the biosphere (Schill et al. 2019) and economic and political action based on that recognition.

Collective conceptions of the future have many aspects. They include (1) whether the future is conceived as near or far and is understood in terms of long, medium and shortterm rewards; (2) what is likely and possible and how contingent these outcomes are; (3) whether the future will be good or bad; (4) how much agency individuals have on various aspects of their individual and collective future (concerning for instance, politics, societal orientation, personal and professional life; (5) who can influence the collective future (e.g., the role of the state policies and various societal forces in shaping them); (6) whether the future is conceived as a cyclical or as a linear progression; (7) how stable peoples' conceptions of the future are and how they are influenced by events (terrorist attacks, recessions, pandemics); and (8) whether aspirations are concealed or made public.

Behind these various issues, one finds other basic conceptions about agency (to what extent are individuals master of their fate), the impact of networks (to what extent is fate influenced by peers, family, and others), the impact of social structure (what is the impact of class, race, gender, place of origin) on where we end up, and how much does our environment (segregation, resource availability, environmental conditions) influence our opportunities. Therefore, it is important to remember that, although individuals play essential roles in narratives of hope, such images of the future are seldom creations of individuals alone but shaped by many cultural intermediaries working in the media, in education, in politics, in social movements, and in other institutions.

Cultural scripts represent commonly held assumptions about social interaction, which serve as a kind of interpretive background against which individuals position their own acts and those of others (Lamont et al. 2017). Narratives of hope as cultural scripts are more likely to become widely shared if they offer possible course of action, something that reasonable people can aspire to. Such sharing bolsters people's sense of agency, the perception that they can have an impact on the world and on their own lives that they can actually achieve what is offered to them (Lamont et al. 2017). In contrast to doomsday or climate-denying narratives, these scripts feed a sense of active agency. Such "fictional expectations", anchored in narratives that are continually adapted, are at the core of market dynamics confronted with an uncertain future affecting money and credit, investment, innovation, and consumption (Beckert 2016).

Narratives of hope represent ideas about "imagined futures" or alternative ways of visualizing and conceptualizing what has yet to happen and motivate action towards new development pathways (Moore and Milkoreit 2020). As they circulate and become more widely shared, such imagined futures have the potential to foster predictable behaviours, and stimulate the emergence of institutions, investments, new laws, and regulations. Therefore, decisions under uncertainty are not only technical problems easily dealt with by rational calculation but are also a function of the creative elements of decision-making (Beckert 2016).

There is a rich literature on scenarios for sustainable futures, narratives articulating multiple alternative futures in relation to critical uncertainties, increasingly emphasizing new forms of governance, technology as a bridge between people and the deep reconnection of humanity to the biosphere, and engaging diverse stakeholder in participatory processes as part of the scenario work (Carpenter et al. 2006; Bennett et al. 2016). The implication of inherent unpredictability is that transformations towards sustainable and just futures can realistically be pursued only through strategies that not only attend to the dynamics of the system, but also nurture our collective capacity to guide development pathways in a dynamic, adaptive, and reflexive manner (Clark and Harley 2020; Freeman et al. 2020). Rather than striving to attain some particular future it calls for a system of guided self-organization. It involves anticipating and imagining futures and behaving and acting on those in a manner that does not lead to loss of opportunities to live with changing circumstances, or even better enhances those opportunities, i.e. builds resilience for complexity and change (Berkes et al. 2003).

In order to better understand the complex dynamics of the Anthropocene and uncertain futures, work is now emerging on human behaviour as part of complex adaptive systems (Levin et al. 2013), like anticipatory behaviour (using the future in actual decision processes), or capturing 
behaviour as both "enculturated" and "enearthed" and coevolving with socio-cultural and biophysical contexts (Boyd et al. 2015; Waring et al. 2015; Poli 2017; Merçon et al. 2019; Schill et al. 2019; Schlüter et al. 2019; Haider et al. 2021), illustrating that cultural transmission and evolution can be both continuous and abrupt (Creanza et al. 2017)

Narratives of hope for transformations towards sustainable futures are in demand. Clearly, technological change plays a central role in any societal transformation. Technological change has been instrumental in globalization and will be instrumental for global sustainability. No doubt, the new era of technological breakthroughs will radically change the structure and operation of societies and cultures. But, as has been made clear here, the recipe for sustainable futures also concerns cultural transformations that guide technological change in support of a resilient biosphere; that reconnect development to the biosphere foundation.

\section{BIOSPHERE STEWARDSHIP FOR PROSPERITY}

Transformation towards sustainability in the Anthropocene has at least three systemic dimensions. First, it involves a shift in human behaviour away from degrading the lifesupport foundation of societal development. Second, it requires management and governance of human actions as intertwined and embedded within the biosphere and the broader Earth system. Third, it involves enhancing the capacity to live and develop with change, in the face of complexity and true uncertainty, that is, resilience-building strategies to persist, adapt, or transform. For major pathways for such a transformation are presented in Box 2 .

BOX 2 Four major pathwys towards global sustainability

1. Recognize and act on the fact that societal development is embedded in and critically dependent on the biosphere and the broader Earth system for prosperity and wellbeing.

2. Create incentives and design policies that enable societies to collaborate towards just and sustainable futures within planetary boundaries.

3 . Transform the current pathways of social, economic, cultural development into stewardship of human actions that enhance the resilience of the biosphere.

4. Make active use of emerging and converging technologies for enabling the societal stewardship transformation.
Biosphere stewardship incorporates economic, social, and cultural dimensions with the purpose of safeguarding the resilience of the biosphere for human wellbeing and fostering the sustainability of a rapidly changing planet. Stewardship is an active shaping of social-ecological change that integrates reducing vulnerability to expected changes, fostering resilience to sustain desirable conditions in the face of the unknown and unexpected, and transforming from undesirable pathways of development when opportunities emerge (Chapin et al. 2010). It involves caring for, looking after, and cultivating a sense of belonging in the biosphere, ranging from people and environments locally to the planet as a whole (Enqvist et al. 2018; Chapin 2020; Plummer et al. 2020).

Such stewardship is not a top-down approach forced on people, nor solely a bottom-up approach. It is a learningbased process with a clear direction, a clear vision, engaging people to collaborate and innovate across levels and scales as integral parts of the systems they govern (Tengö et al. 2014; Clark et al. 2016; Norström et al. 2020).

Here, we focus on biosphere stewardship in relation to climate change, biodiversity, and transformations for sustainable futures.

\section{From emission reductions alone to biosphere stewardship}

Global sustainability involves shifting into a renewable energy-based economy of low waste and greater circularity within a broader value foundation. Market-driven progress combined with technological change certainly plays an important role in dematerialization (Schmidheiny 1992; McAfee 2019) but does not automatically redirect the economy towards sustainable futures. Public awareness, responsible governments, and international collaborations are needed for viable economic developments, acknowledging that people, nations, and the global economy are intertwined with the biosphere and a global force in shaping its dynamics.

Since climate change is not an isolated phenomenon but a consequence of the recent accelerating expansion of human activities on Earth, the needed changes concern social organization and dynamics influencing the emissions of greenhouse gases from burning fossil fuels, technologies, and policies for reducing such emissions, and various approaches for carbon capture and storage. However, to reduce the effects of climate change, it will not be sufficient to remove emissions only. The resilience of the biosphere and the Earth system needs to be regenerated and enhanced (Nyström et al. 2019). This includes governance of critical biosphere processes linked to climate change, such as in agriculture, forestry, and the ocean. In addition, guarding and enhancing biodiversity will help us live with 


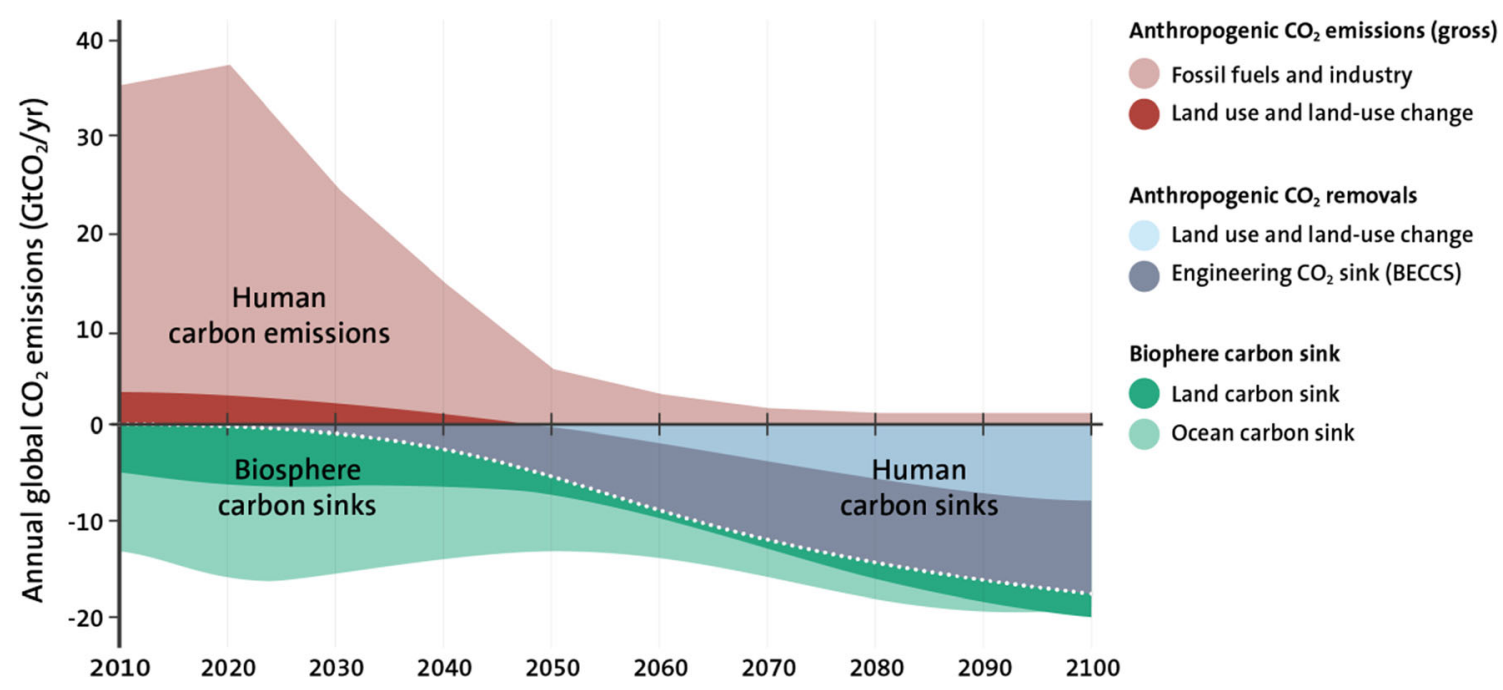

Fig. 10 A Roadmap for Rapid Decarbonization—without deep emissions cuts the world takes a high-risk strategy (currently the default strategy) of over-reliance on risky negative emissions technologies in the near future. Avoiding this trap means cutting emissions by half every decadethe Carbon Law trajectory. Meeting the Paris Agreement goals will require bending the global curve of $\mathrm{CO}_{2}$ emissions by 2020 and reaching netzero emissions by 2050. It furthermore depends on rising anthropogenic carbon sinks, by transitioning world agriculture from a major carbon source (red) to become a major carbon sink by the 2nd half of this century, carbon sinks from bioenergy and other forms of carbon capture and storage (BECCS), engineering (grey) and land use (light blue), as well as sustained biosphere carbon sinks, to stabilize global temperatures. Green represents natural carbon sinks, which will shrink as emissions decrease (adapted from Rockström et al. 2017). Reprinted with permission

climate change, mitigating climate change by storing and sequestering carbon in ecosystems, and building resilience and adaptive capacity to the inevitable effects of unavoidable climate change (Dasgupta 2021).

The global pandemic caused a sharp fall in $\mathrm{CO}_{2}$ emissions in 2020 (Le Quéré et al. 2020), while the cumulative emissions continue to rise (Friedlingstein et al. 2020). The fall was not caused by a long-term structural economic shift so it is unlikely to persist without strong government intervention. Political action is emerging from major nations and regions and on net-zero GHG emissions within decades. Shifts towards renewable energy are taking place in diverse sectors. Carbon pricing through taxes, tariffs, tradeable permits, as well as removal of fossil-fuel subsidies and incentives for renewable energy and carbon sequestration (e.g. CCS techniques) are on the table and increasingly implemented. There are substantial material and emission gains to be made from altered consumption patterns, infrastructure changes, and shifts towards a circular economy. Voluntary climate action among some large corporations is emerging (Vandenbergh and Gilligan 2017). There is general agreement that the pace of these promising changes must rapidly increase in order to meet the Paris climate target (Fig. 10).

In addition, active biosphere stewardship of critical tipping elements and carbon sinks, as in forests, agricultural land, savannas, wetlands, and marine ecosystems is crucial to avoid the risk of runaway climate change (Steffen et al. 2018). Such stewardship involves protecting, sustaining, restoring, and enhancing such sinks. The existence of connections between finance actors, capital markets, and the tipping elements of tropical and boreal forests has also gained attention and needs to be acted upon in policy and practice (Galaz et al. 2018).

Furthermore, ecosystem restoration has the potential to sequester large amounts of carbon dioxide from the atmosphere. The amount of carbon dioxide in the atmosphere derived from destroyed and degraded land is roughly equal to the carbon that remains in ecosystems on land (about 450 billion tonnes of carbon) (Erb et al. 2018). The amount of degraded lands in the world is vast, and restoring their productivity, biodiversity, and ecosystem services could help keep global temperature increases within acceptable levels (Lovejoy and Hannah 2018). It has been estimated that nature-based solutions on land (from agriculture to reforestation and afforestation) have the potential to provide over $30 \%$ of the emission reductions needed by 2050 to keep global temperature increases to not more than $2{ }^{\circ} \mathrm{C}$ (Griscom et al. 2017; Roe et al. 2019).

There is scope for new policies and practices for naturebased solutions (Kremen and Merenlender 2018; Diaz et al. 2018). These solutions will require shifts in governance towards active stewardship of water and ecosystem dynamics and processes across landscapes, precipitation sheds, and seascapes (Österblom et al. 2017; Plummer et al. 2020), reconfiguring nation state governance, empowering the commons through justice, equity and knowledge, and making ownership regenerative by integrating rights with responsibilities (Brodie Rudolph et al. 2020). Also, the socalled "social tipping interventions" towards biosphere 
stewardship have the potential to activate contagious processes of rapidly spreading technologies, behaviors, social norms, and structural reorganization, where current patterns can be disrupted and lead to fast reduction in anthropogenic greenhouse gas emissions (Otto et al. 2020). The window of opportunity for such shifts may emerge in times of turbulence and social discontent with the status quo (Carpenter et al. 2019). Creating conditions for processes of deliberate democracy may guide such transformative change (Dryzek et al. 2019).

\section{Resilience and biosphere stewardship}

Societal development needs to strengthen biosphere capacity for dealing with extreme events, both climate driven and as a consequence of a tightly coupled and complex globalized world in deep interplay with the rest of the biosphere (Helbing 2013; Reyers et al. 2018). For example, the challenge of policy and practice in satisfying demands for food, water and other critical ecosystem services will most likely be set by the potential consequences of the emergent risk panorama and its consequences, rather than hard upper limits to production per se (Cottrell et al. 2019; Nyström et al. 2019; Xu et al. 2020).

In this sense, a resilience approach to biosphere stewardship becomes significant. Such an approach is very different from those who understand resilience as return to the status quo, to recover to business-as-usual. Resilience in relation to stewardship of complex adaptive systems concerns capacities to live with changing circumstances, slow or abrupt, predictable or surprising. It becomes especially relevant for dealing with the uncertain and unknown and is in stark contrast to strategies that support efficiency and effectiveness for short term gain at the expense of redundancy and diversity. Such strategies may work under relatively stable and predictable conditions but, as stressed here, will create vulnerability in periods of rapid change, during turbulent times, and are ill-suited to confront the unknown (Carpenter et al. 2009; Walker et al. 2009). Financial crises and pandemics serve as real-world examples of such vulnerabilities and make explicit the tension between connectivity and modularity in complex adaptive systems (Levin 1999).

In contrast, intertwined systems of people and nature characterized by resilience will have the capacity, whether through strategies like portfolio management, polycentric institutions, or building trust and nurturing diversity (Costanza et al. 2000; Ostrom 2010; Biggs et al. 2012; Carpenter et al. 2012), to confront turbulent times and the unknown. Policy decisions will no longer be the result of optimization algorithms that presuppose quantifiable uncertainty, but employ decision-making procedures that iteratively identify policy options most robust to present and future shocks under conditions of deep uncertainty (Polasky et al. 2011). Resilience provides capacities for novelty and innovation in times of change, to turn crises into opportunities for not only adapting, but also transforming into sustainable futures (Folke et al. 2016).

The immediate future will require capacities to confront challenges that we know we know little about (Kates and Clark 1996). Given the global connectivity of environmental, social, and economic systems, there is no scale at which resource pooling or trade can be used to hedge against all fluctuations at smaller scales. This begs the question of what types of investments may lead to a generalized capacity to develop with a wide range of potential and unknown events (Polasky et al. 2011). One strategy is to invest in global public goods common to all systems, e.g., education, capacity to learn and collaborate across sectors, multi-scale governance structures that enable systems to better detect changes and nimbly address problems by reconfiguring themselves through transformative change. Such strategies, often referred to as building "general resilience", easily erode if not actively supported (Biggs et al. 2012; Carpenter et al. 2012; Quinlan et al. 2015). General resilience is critical for keeping options alive to face an uncertain turbulent world (Walker et al. 2009; Elmqvist et al. 2019).

\section{Collaborating with the biosphere}

Clearly, a shift in perspective and action is needed (Fig. 11) that includes extending management and governance from the focus on producing food, fibre, and timber in simplified ecosystems to rebuilding and strengthening resilience through investing in portfolios of ecosystem services for human wellbeing in diversity-rich social-ecological systems (Reyers et al. 2013; Bennett et al. 2015; Isbell et al. 2017).

Numerous activities protecting, restoring, and enhancing diversity are taking place in this direction ranging from traditional societies, local stewards of wildlife habitats, marine systems, and urban areas, to numerous NGOs, companies and enterprises, and various levels of government, to international collaborations, agreements, and conventions (Barthel et al. 2005; Forbes et al. 2009; Raymond et al. 2010; Andersson et al. 2014; Barrett 2016; Brondizio and Le Tourneau 2016; Österblom et al. 2017; Barbier et al. 2018; Bennett et al. 2018).

Examples include widespread use of marine protected areas from local places to marine spatial planning to proposals for protecting the open ocean, enhancing marine biodiversity, rebuilding fisheries, mitigating climate change, and shifting towards ocean stewardship (Worm et al. 2009; Sumaila et al. 2015; Lubchenco and GrorudColvert 2015; Lubchenco et al. 2016; Sala et al. 2016; 


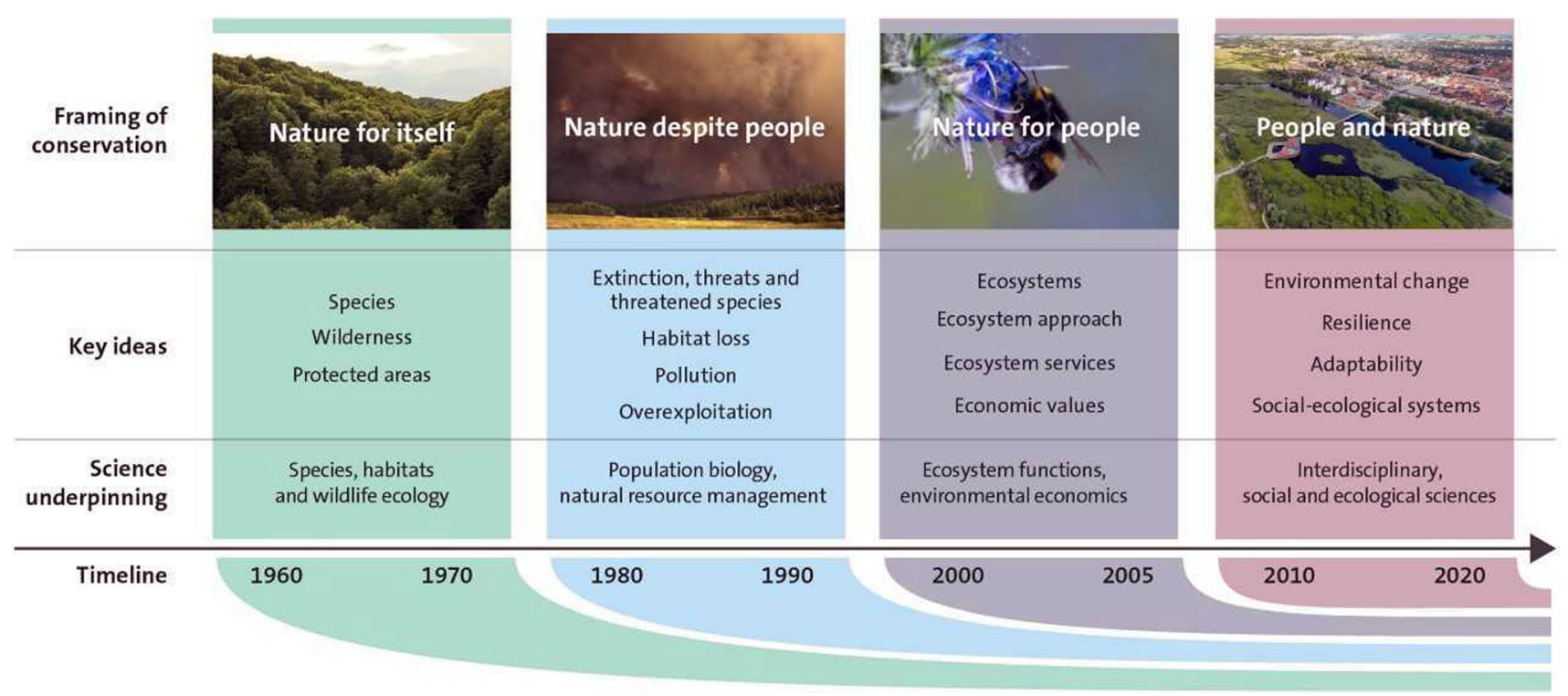

Fig. 11 Reconfiguring the human-nature relationship over time (adapted from Mace 2014). Reprinted with permission

Gaines et al. 2018; Tittensor et al. 2019; Cinner et al. 2020; Duarte et al. 2020; Brodie Rudolph et al. 2020). The latter is the focus of the High Level Panel for a Sustainable Ocean Economy, with 14 heads of state and more than 250 scientists engaged. They aim to stimulate transformative change for the ocean by committing to sustainably managing $100 \%$ of their own waters by 2030 (Stuchtey et al. 2020).

There are major restoration programmes of forests, wetlands, and abandoned and degraded lands and even revival of wildlife and rewilding of nature (Perino et al. 2019). Other efforts include "working-lands conservation" like agroforestry, silvopasture, diversified farming, and ecosystem-based forest management, enhancing livelihoods and food security (Kremen and Merenlender 2018).

The world's ecosystems can be seen as essential capital assets, if well managed, their lands, waters, and biodiversity yield a flow of vital life-support services (Daily et al. 2009). Investing in natural capital has become a core strategy of agencies and major nations, like China, for wellbeing and sustainability, providing greater resilience to climate change (Guerry et al. 2015; Ouyang et al. 2016). It involves combining science, technology, and partnerships to develop nature-based solutions and enable informed decisions for people and nature to thrive and invest in green growth (Mandle et al. 2019).

There are several examples of adaptive management and adaptive governance systems that have transformed socialecological dynamics of landscapes and seascapes into biosphere stewardship (Chaffin et al. 2014; Schultz et al. 2015; Walker 2019; Plummer et al. 2020). Stewardship of diversity as a critical feature in resilience building is about reducing vulnerability to change and multiplying the portfolio of options for sustainable development in times of change. Stewardship shifts focus from commodity to redundancy to response diversity for dealing with change (Elmqvist et al. 2003; Grêt-Regamey et al. 2019; Dasgupta 2021).

Clearly, the economic contributions of biodiversity are highly significant as reflected in the many efforts to expose and capture economic values of biodiversity and ecosystem services (Daily et al. 2000; Sukhdev et al. 2010; Kinzig et al. 2011; Costanza et al. 2014; Naeem et al. 2015; Barbier et al. 2018; Dasgupta 2021). Inclusive (or genuine) wealth aims at capturing the aggregate value of natural, human, and social capital assets to provide a comprehensive, long-term foundation for human wellbeing (Dasgupta and Mäler 2000; Polasky et al. 2015). Inclusive wealth provides a basis for designing incentives for more sustainable market transactions (Dasgupta 2014; Clark and Harley 2020).

Also, the role of the cultural context is fundamental (Diaz et al. 2018) and biocultural diversity, and coevolution of people and nature is gaining ground as a means to understand dynamically changing social-ecological relations (Barthel et al. 2013; Merçon et al. 2019; Haider et al. 2019). Broad coalitions among citizens, businesses, nonprofits, and government agencies have the power to transform how we view and act on biosphere stewardship and build Earth resilience. Science has an important new role to play here as honest broker, engaging in evidence-informed action, and coproduction of knowledge in collaboration with practice, policy, and business (Reyers et al. 2015; Wyborn et al. 2019; Norström et al. 2020).

In this context, work identifying leverage points for anticipated and deliberate transformational change towards 


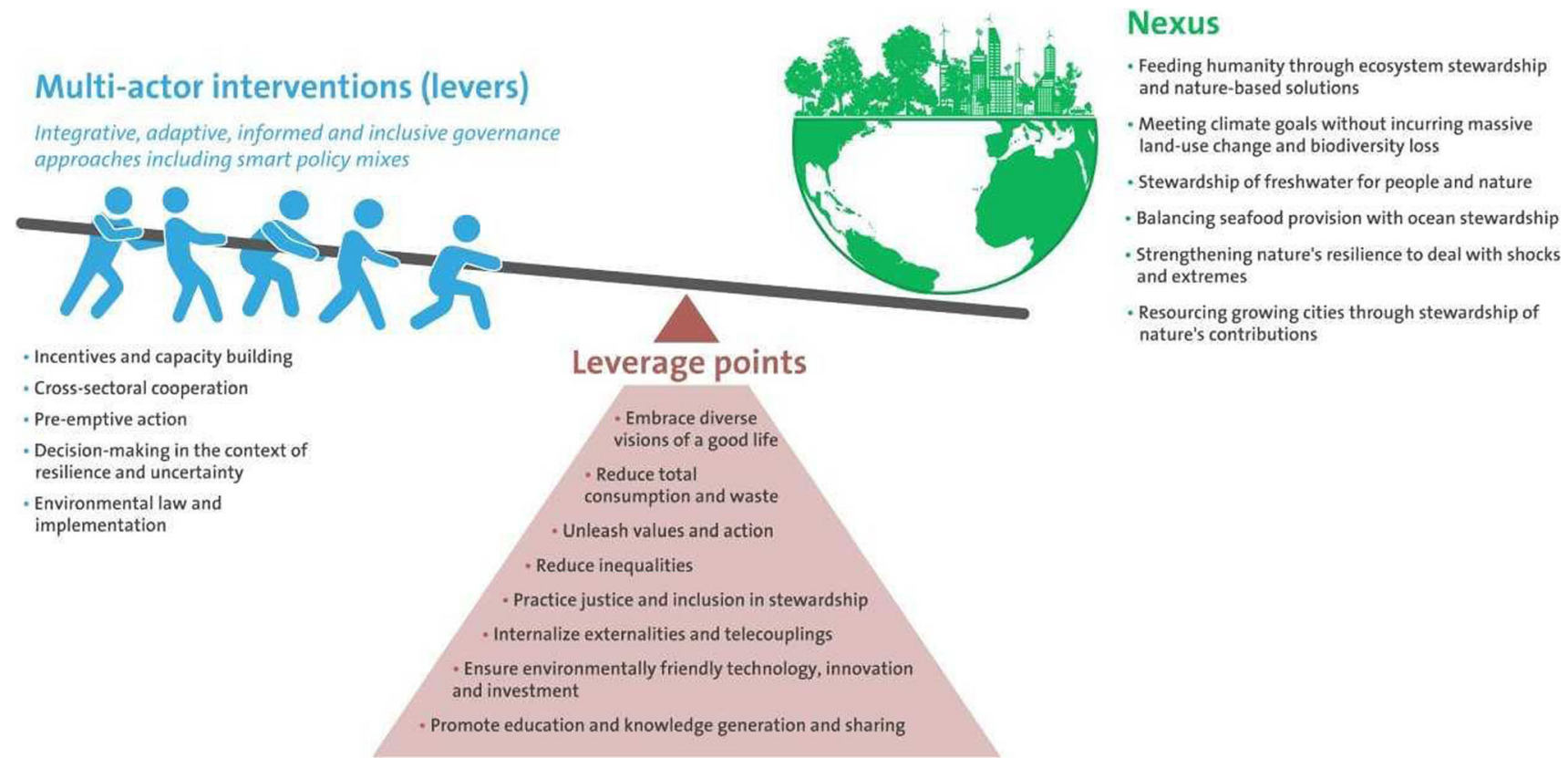

Fig. 12 Collaborative implementation of priority interventions (levers) targeting key points of intervention (leverage points representing major indirect drivers) could enable transformative change from current trends towards more sustainable ones. Effectively addressing these levers and leverage points requires innovative governance approaches and organizing the process around nexuses, representing closely interdependent and complementary goals (adapted from Diaz et al. 2018). Reprinted with permission

sustainability is gaining ground, centred on reconnecting people to nature, restructuring power and institutions, and rethinking how knowledge is created and used in pursuit of sustainability (Abson et al. 2017; Fischer and Riechers 2019). Such actions range from direct engagements between scientists and local communities (Tengö et al. 2014) or through the delivery of scientific knowledge and method into multi-stakeholder arenas, such as boundary or bridging organizations (Cash et al. 2003; Hahn et al. 2006; Crona and Parker 2012) where it can provide a basis for learning and be translated into international negotiations (Biermann and Pattberg 2008; Galaz et al. 2016; Tengö et al. 2017). It includes efforts to accelerate positive transformations by identifying powerful actors, like financial investors or transnational corporations, and articulating key domains with which these actors need to engage in order to enable biosphere stewardship (Österblom et al. 2017; Galaz et al. 2018; Folke et al. 2019; Jouffray et al. 2019). The International science-policy platform for biodiversity and ecosystem services (IPBES), an international body for biodiversity similar to the IPCC for the climate, has proposed key features for enabling transformational change (Fig. 12). These efforts serve an increasingly important space for scientists to engage in, helping hold corporations accountable, stimulating them to take on responsibility for the planet and develop leadership in sustainability. Such science-business engagement will become increasingly important to ensure that companies' sustainability agendas are framed by science rather than the private sector alone (Österblom et al. 2015; Barbier et al. 2018; Blasiak et al. 2018; Galaz et al. 2018; Folke et al. 2019; Jouffray et al. 2019).

The rapid acceleration of current Earth system changes provides new motivations for action. Climate change is no longer a vague threat to some distant future generation but an environmental, economic, and social disruption that today's youth, communities, corporations, and governments are increasingly experiencing. This provides both ethical and selfish motivations for individuals and institutions to launch transformative actions that shape their futures rather than simply reacting to crises as they emerge. Shaping the future requires active stewardship for regenerating and strengthening the resilience of the biosphere.

Given the urgency of the situation and the critical challenge of stabilizing the Earth system in Holocene-like conditions, the pace of current actions has to rapidly increase and expand to support a transformation towards active stewardship of human actions in concert with the biosphere foundation. It will require reform of critical social, economic, political, and cultural dimensions (Tallis et al. 2018; Diaz et al. 2018; Barrett et al. 2020).

\section{CONCLUDING REMARKS}

The success of social organization into civilizations and more recently into a globalized world has been impressive and highly efficient. It has been supported by a resilient 
biosphere and a hospitable climate. Now, in the Anthropocene, a continuous expansion mimicking the development pathways of the past century is not a viable option for shifting towards sustainable futures.

Humanity is embedded within, intertwined with, and dependent upon the living biosphere. Humanity has become a global force shaping the operation and future of the biosphere and the broader Earth system. Climate change and loss of biodiversity are symptoms of the situation. The accelerating expansion of human activities has eroded biosphere and Earth system resilience and is now challenging human wellbeing, prosperity, and possibly even the persistence of societies and civilizations.

The expansion has led to hyper-connectivity, homogenization, and vulnerability in times of change, in contrast to modularity, redundancy, and resilience to be able to live with changing circumstances. In the Anthropocene, humanity is confronted with turbulent times and with new intertwined dynamics of people and planet where fast and slow change interplay in unexperienced and unpredictable ways. This is becoming the new normal.

Our future on our planet will be determined by our ability to keep global warming well below $2{ }^{\circ} \mathrm{C}$ and foster the resilience of the living biosphere. A pervasive thread in science is that building resilient societies, ecosystems, and ultimately the health of the entire Earth system hinges on supporting, restoring and regenerating diversity in intertwined social and ecological dimensions. Diversity builds insurance and keeps systems resilient to changing circumstances. Clearly, nurturing resilience is of great significance in transformations towards sustainability and requires collective action on multiple fronts, action that is already being tested by increasing turbulence incurred by seemingly unrelated shocks.

Equality holds communities together, and enables nations, and regions to evolve along sustainable development trajectories. Inequality, in terms of both social and natural capitals, are on the rise in the world, and need to be addressed as an integral part of our future on Earth.

We are facing a rapid and significant repositioning of sustainability as the lens through which innovation, technology and development is driven and achieved. What only a few years ago was seen as a sacrifice is today creating new purposes and meanings, shaping values and culture, and is increasingly seen as a pathway to novelty, competitiveness and progress.

This is a time when science is needed more than ever. Science provides informed consensus on the facts and trade-offs in times of misinformation and polemics. The planetary challenges that confront humanity need governance that mobilizes the best that science has to offer with shared visions for sustainable futures and political will and competence to implement choices that will sustain humanity and the rest of the living world for the next millennium and beyond.

There is scope for changing the course of history into sustainable pathways. There is urgent need for people, economies, societies and cultures to actively start governing nature's contributions to wellbeing and building a resilient biosphere for future generations. It is high time to reconnect development to the Earth system foundation through active stewardship of human actions into prosperous futures within planetary boundaries.

Acknowledgements We dedicate this article to our late colleague and friend Paul Crutzen, a pioneer in clarifying the human global imprint on planet Earth and who coined the concept of the Anthropocene. Work with this White Paper was supported by the Kjell and Märta Beijer Foundation, the Marianne and Marcus Wallenberg Foundation, and the Erling-Persson Family Foundation. Figures by J. Lokrantz/Azote unless else stated.

Author contributions CF led the design, development and writing of the article with text contributions by SP, JR, VG, FW, ML, MS, and HÖ. All authors provided input, wrote, and commented on the manuscript.

Funding Open access funding provided by Stockholm University.

Conflicts of interest The authors declare no conflicts of interests.

Open Access This article is licensed under a Creative Commons Attribution 4.0 International License, which permits use, sharing, adaptation, distribution and reproduction in any medium or format, as long as you give appropriate credit to the original author(s) and the source, provide a link to the Creative Commons licence, and indicate if changes were made. The images or other third party material in this article are included in the article's Creative Commons licence, unless indicated otherwise in a credit line to the material. If material is not included in the article's Creative Commons licence and your intended use is not permitted by statutory regulation or exceeds the permitted use, you will need to obtain permission directly from the copyright holder. To view a copy of this licence, visit http://creativecommons. org/licenses/by/4.0/.

\section{REFERENCES}

Abson, D.J.J., J. Fischer, J. Leventon, J. Newig, T. Schomerus, U. Vilsmaier, H. von Wehrden, P. Abernethy, et al. 2017. Leverage points for sustainability transformation. Ambio 46: 30-39.

Adger, W.N., H. Eakin, and A. Winkels. 2009. Nested and teleconnected vulnerabilities to environmental change. Frontiers in Ecology and the Environment 7: 150-157.

Alberti, M., C. Correa, J.M. Marzluff, A.P. Hendry, E.P. Palkovacs, K.M. Gotanda, V.M. Hunt, T.M. Apgar, et al. 2017. Global urban signatures of phenotypic change in animal and plant populations. Proceedings of the National Academy of Sciences, USA 114: 8951-8956.

Althor, G., J.E.M. Watson, and R.A. Fuller. 2016. Global mismatch between greenhouse gas emissions and the burden of climate change. Science Reports 6: 20281.

Anderies, J.M., S.R. Carpenter, W. Steffen, and J. Rockström. 2013. The topology of non-linear global carbon dynamics: From 
tipping points to planetary boundaries. Environmental Research Letters 8: 044048.

Andersson, E., S. Barthel, S. Borgström, J. Colding, T. Elmqvist, C. Folke, and A. Gren. 2014. Reconnecting cities to the biosphere: Stewardship of green infrastructure and urban ecosystem services. Ambio 43: 445-453.

Arneth, A., F. Denton, F. Agus, A. Elbehri, K. Erb, B. Osman Elasha, M. Rahimi, M. Rounsevell, et al. 2019. Framing and Context. In Climate Change and Land. An IPCC Special Report on Climate Change, Desertification, Land Degradation, Sustainable Land Management, Food Security, and Greenhouse Gas Fluxes in Terrestrial Ecosystems (IPCC, 2019).

AWG. 2019. The Anthropocene Working Group http://quaternary. stratigraphy.org/working-groups/anthropocene/

Bain, W. 2019. Continuity and change in international relations 1919-2019. International Relations 33: 132-141.

Baland, J.M., P. Bardhan, and S. Bowles, eds. 2007. Inequality, cooperation, and environmental sustainability. Princeton, USA: Princeton University Press.

Barbier, E.B., J.C. Burgess, and T.J. Dean. 2018. How to pay for saving biodiversity. Science 360: 486-488.

Barnosky, A.D., E.A. Hadly, J. Bascompte, E.L. Berlow, J.H. Brown, M. Fortelius, W.M. Getz, J. Harte, et al. 2012. Approaching a state shift in Earth's biosphere. Nature 486: 52-58.

Barocas, S., K. Crawford, A. Shapiro, H. Wallach. 2017. The problem with bias: from allocative to representational harms in machine learning Information and Society (SIGCIS) Special Interest Group for Computing.

Bar-On, Y.M., R. Phillips, and R. Milo. 2018. The biomass distribution on Earth. Proceedings of the National Academy of Sciences, USA 115: 6506-6511.

Barrett, S. 2016. Coordination vs. voluntarism and enforcement in sustaining international environmental cooperation. Proceedings of the National Academy of Sciences, USA 113: 14515-14522.

Barrett, S., A. Dasgupta, P. Dasgupta, W.N. Adger, J. Anderies, J. van den Bergh, C. Bledsoe, et al. 2020. Fertility behavior and consumption patterns in the Anthropocene. Proceedings of the National Academy of Sciences, USA 117: 6300-6307.

Barthel, S., C. Crumley, and U. Svedin. 2013. Bio-cultural refugia: Safeguarding diversity of practices for food security and biodiversity. Global Environmental Change 23: 1142-1152.

Barthel, S., J. Colding, T. Elmqvist, and C. Folke. 2005. History and local management of a biodiversity rich, urban, cultural landscape. Ecology and Society 10: 10.

Beckert, J. 2016. Imagined Futures: Fictional Expectations and Capitalist Dynamics. Cambridge, MA: Harvard University Press.

Bennett, E.M., M. Solan, R. Biggs, T. McPhearson, A.V. Norström, P. Olsson, L. Pereira, G.D. Peterson, et al. 2016. Bright spots: Seeds of a good Anthropocene. Frontiers in Ecology and the Environment 14: 441-448.

Bennett, E.M., W. Cramer, A. Begossi, G. Cundill, S. Diaz, B.N. Egoh, I.R. Geijzendorffer, C.B. Krug, et al. 2015. Linking biodiversity, ecosystem services, and human well-being: Three challenges for designing research for sustainability. Current Opinion in Environmental Sustainability 14: 76-85.

Bennett, N.J., T.S. Whitty, E. Finkbeiner, J. Pittman, H. Bassett, S. Gelcich, and E.H. Allison. 2018. Environmental stewardship: A conceptual review and analytical framework. Environmental Management 61: 597-614.

Bergstrom, C.T., and J.B. Bak-Coleman. 2019. Gerrymandering in social networks. Nature 573: 40-41.

Berkes, F., J. Colding, and C. Folke, eds. 2003. Navigating Socialecological systems: Building resilience for complexity and change. Cambridg: Cambridge University Press.
Biermann, F., and P. Pattberg. 2008. Global environmental governance: Taking stock, moving forward. Annual Review of Environment and Resources 33: 277-294.

Biermann, F., K. Abbott, S. Andresen, K. Bäckstrand, S. Bernstein, M.M. Betsill, H. Bulkeley, B. Cashore, et al. 2012. Navigating the anthropocene: Improving earth system governance. Science 335: 1306-1307.

Biggs, R., M. Schlüter, D. Biggs, E.L. Bohensky, S. BurnSilver, G. Cundill, V. Dakos, T.M. Daw, et al. 2012. Toward principles for enhancing the resilience of ecosystem services. Annual Review of Environment and Resources 37: 421-448.

Blasiak, R., J. Spijkers, K. Tokunaga, J. Pittman, N. Yagi, and H. Österblom. 2017. Climate change and marine fisheries: Least developed countries top global index of vulnerability. PLOS ONE 12: $\mathrm{e} 0179632$.

Blasiak, R., J.-B. Jouffray, C.C.C. Wabnitz, E. Sundström, and H. Österblom. 2018. Corporate control and global governance of marine genetic resources. Sciences Advances 4: 5237.

Blasiak, R., R. Wynberg, K. Grorud-Colvert, S. Thambisetty, N.M. Bandarra, A.V.M. Canário, J. da Silva, C.M. Duarte, et al. 2020. The ocean genome and future prospects for conservation and equity. Nature Sustainability 3: 588-596.

Bowles, S., S.N. Durlauf, and K. Hoff. 2006. Poverty Traps. Princeton, NJ: Princeton University Press.

Boyd, E., B. Nykvist, S. Borgström, and I.A. Stacewicz. 2015. Anticipatory governance for social-ecological resilience. Ambio 44: S149-S161.

Breuer, A., T. Landman, and D. Farquhar. 2015. Social media and protest mobilization: Evidence from the Tunisian revolution. Democratization 22: 764-792.

Brienen, R., O.L. Phillips, T.R. Feldpausch, E. Gloor, T.R. Baker, J. Lloyd, G. Lopez-Gonzalez, A. Monteagudo-Mendoza, et al. 2015. Long-term decline of the Amazon carbon sink. Nature 519: 344-348.

Brodie Rudolph, T., M. Ruckelshaus, M. Swilling, E.H. Allison, H. Österblom, S. Gelcich, and P. Mbatha. 2020. A transition to sustainable ocean governance. Nature Communication 11: 3600.

Brondizio, E.S., and F.-M. Le Tourneau. 2016. Environmental governance for all. Science 352: 1272-1273.

Brondizio, E.S., E. Ostrom, and O.R. Young. 2009. Connectivity and the governance of multilevel social-ecological systems: The role of social capital. Annual Review of Environment and Resources 34: $253-278$.

Brown, K. 2016. Resilience, Development and Global Change. London, UK: Routledge.

Burke, K.D., J.W. Williams, M.A. Chandler, A.M. Haywood, D.J. Lunt, and B.L. Otto-Bliesner. 2018. Pliocene and Eocene provide best analogs for near-future climates. Proceedings of the National Academy of Sciences, USA 115: 13288-13293.

Carpenter, S.R., and E.M. Bennett. 2011. Reconsideration of the planetary boundary for phosphorus. Environmental Research Letters 6: 014009.

Carpenter, S.R., E.M. Bennett, and G.D. Peterson. 2006. Scenarios for ecosystem services: An overview. Ecology and Society 11: 29.

Carpenter, S.R., C. Folke, M. Scheffer, and F. Westley. 2009. Resilience: Accounting for the non-computable. Ecology and Society 14: 13.

Carpenter, S.R., K.J. Arrow, S. Barrett, R. Biggs, W.A. Brock, A.-S. Crépin, G. Engström, C. Folke, et al. 2012. General resilience to cope with extreme events. Sustainability 4: 3248-3259.

Carpenter, S.R., W. Brock, C. Folke, E. van der Nees, and M. Scheffer. 2015. Allowing variance may enlarge the safe operating space for exploited ecosystems. Proceedings of the National Academy of Sciences, USA 112: 14384-14389. 
Carpenter, S.R., C. Folke, M. Scheffer, and F.R. Westley. 2019. Dancing on the volcano: Social exploration in times of discontent. Ecology and Society 24: 23.

Cash, D.W., W. Adger, F. Berkes, P. Garden, L. Lebel, P. Olsson, L. Pritchard, and O. Young. 2006. Scale and cross-scale dynamics: Governance and information in a multilevel world. Ecology and Society 11: 8.

Cash, D.W., W.C. Clark, F. Alcock, N. Dickson, N. Eckley, D.H. Guston, J. Jäger, and R.B. Mitchell. 2003. Knowledge systems for sustainable development. Proceedings of the National Academy of Sciences, USA 100: 8086-8091.

Cave, S., and S.S. Óhéigeartaigh. 2019. Bridging near- and long-term concerns about AI. Nature Machine Intelligence 1: 5-6.

Centeno, M.A., M. Nag, T.S. Patterson, A. Shaver, and A.J. Windawi. 2015. The emergence of global systemic risk. Annual Review of Sociology 41: 65-85.

Chaffin, B.C., and L.H. Gunderson. 2016. Emergence, institutionalization, and renewal: rhythms of adaptive governance in complex social-ecological systems. Journal of Environmental Management 165: 81-87.

Chaffin, B.C., H. Gosnell, and B.A. Cosens. 2014. A decade of adaptive governance scholarship: Synthesis and future directions. Ecology and Society 19: 56.

Chapin, F.S., III., B.H. Walker, R.J. Hobbs, D.U. Hooper, J.H. Lawton, O.E. Sala, and D. Tilman. 1997. Biotic control over the functioning of ecosystems. Science 277: 500-504.

Chapin, F.S., III., S.R. Carpenter, G.P. Kofinas, C. Folke, N. Abel, W.C. Clark, P. Olsson, D.M.S. Smith, et al. 2010. Ecosystem stewardship: Sustainability strategies for a rapidly changing planet. Trends in Ecology and Evolution 25: 241-249.

Chapin, F.S., III. 2020. Grassroots stewardship: Sustainability within our reach. Oxford: Oxford University Press.

Chaplin-Kramer, R., R.P. Sharp, C. Weil, E.M. Bennett, U. Pascual, K.K. Arkema, K.A. Brauman, B.P. Bryant, et al. 2019. Global modelling of nature's contributions to people. Science 366: $255-258$

Ciais, P., C. Sabine, B. Govindasamy, L. Bopp, V. Brovkin, J. Canadell, A. Chhabra, R. DeFries, et al. 2013. Chapter 6: Carbon and Other Biogeochemical Cycles. In Climate Change 2013: The Physical Science Basis, eds. T. Stocker, D. Qin, G.-K. Platner, et al. Cambridge, UK: Cambridge University Press.

Cinner, J.E., J. Zamborain-Mason, G.G. Gurney, N.A.J. Graham, M.A. MacNeil, A.S. Hoey, C. Mora, S. Villéger, et al. 2020. Meeting fisheries, ecosystem function, and biodiversity goals in a human-dominated world. Science 368: 307-311.

Cinner, J.E., W.N. Adger, E.H. Allison, M.L. Barnes, K. Brown, P.J. Cohen, S. Gelcich, C.C. Hicks, et al. 2018. Building adaptive capacity to climate change in tropical coastal communities. Nature Climate Change 8: 117-123.

Clark, W.C., and A.G. Harley. 2020. Sustainability science: Towards a synthesis. Annual Review of Environment and Resources 45: 331-386.

Clark, W.C., L. van Kerkhoff, L. Lebel, and G. Gallopi. 2016. Crafting usable knowledge for sustainable development. Proceedings of the National Academy of Sciences, USA 113: $4570-4578$.

Conselice, C.J., A. Wilkinson, K. Duncan, and A. Mortlock. 2016. The evolution of galaxy number density at $\mathrm{Z}<8$ and its implications. The Astrophysical Journal 830: 83.

Coe, N.M., M. Hess, H.W.-C. Yeung, P. Dicken, and J. Henderson. 2004. 'Globalizing' regional development: a global production networks perspective. Transactions of the Institute of British Geographers 29: 468-484.

Conway, D., R.J. Nicholls, S. Brown, M.G.L. Tebboth, W.N. Adger, B. Ahmad, H. Biemans, F. Crick, et al. 2019. The need for bottom-up assessments of climate risks and adaptation in climate-sensitive regions. Nature Climate Change 9: 503-511.

Costanza, R., H. Daly, C. Folke, P. Hawken, C.S. Holling, T. McMichael, D. Pimentel, and D. Rapport. 2000. Managing our environmental portfolio. BioScience 50: 149-155.

Costanza, R., R. de Groot, P. Sutton, S. vad der Ploeg, S.J. Anderson, I. Kubiszewski, S. Farber, and R.K. Turner. 2014. Changes in the global value of ecosystem services. Global Environmental Change 26: 152-158.

Costello, C., L. Cao, S. Gelcich, M.A. Cisneros-Mata, C.M. Free, H.E. Froehlich, C.G. Golden, G. Ishimura, et al. 2020. The future of food from the sea. Nature 588: 95-100.

Cottrell, R.S., K.L. Nash, B.S. Halpern, T.A. Remeny, S.P. Corney, A. Fleming, E.A. Fulton, S. Hornborg, et al. 2019. Food production shocks across land and sea. Nature Sustainability 2: 130-137.

Creanza, N., O. Kolodny, and M.W. Feldman. 2017. Cultural evolutionary theory: how culture evolves and why it matters. Proceedings of the National Academy of Sciences, USA 114: 7782-7789.

Crona, B.I., and J.N. Parker. 2012. Learning in support of governance: Theories, methods, and a framework to assess how bridging organizations contribute to adaptive resource governance. Ecology and Society 17: 32.

Crona, B.I., T. Daw, W. Swartz, A. Norström, M. Nyström, M. Thyresson, C. Folke, J. Hentati-Sundberg, et al. 2016. Masked, diluted, and drowned out: Global seafood trade weakens signals from marine ecosystems. Fish and Fisheries 17: 1175-1182.

Crona, B.I., T. Van Holt, M. Petersson, T.M. Daw, and E. Buchary. 2015. Using social-ecological syndromes to understand impacts of international seafood trade on small-scale fisheries. Global Environmental Change 35: 162-175.

Cumming, G.S., and G.D. Peterson. 2017. Unifying research on social-ecological resilience and collapse. Trends in Ecology \& Evolution 32: 695-713.

Daily, G.C., ed. 1997. Nature's services: Societal dependence on natural ecosystems. Washington DC: Island Press.

Daily, G., T. Söderqvist, S. Aniyar, K. Arrow, P. Dasgupta, P.R. Ehrlich, C. Folke, A.-M. Jansson, et al. 2000. The value of nature and the nature of value? Science 289: 395-396.

Daily, G.C., S. Polasky, J. Goldstein, P. Kareiva, H.A. Mooney, L. Pejchar, T.H. Ricketts, J. Salzman, et al. 2009. Ecosystem services in decision making: time to deliver. Frontiers in Ecology and the Environment 7: 21-28.

Dasgupta, P. 2014. Measuring the wealth of nations. Annual Review of Resource Economics 6: 17-31.

Dasgupta, P. 2021. The economics of biodiversity: The dasgupta review. London: HMTreasury.

Dasgupta, P., and V. Ramanathan. 2014. Pursuit of the common good. Science 345: 1457-2145.

Dasgupta, P., and K.-G. Mäler. 2000. Net national product, wealth and social well-being. Environment and Development Economics 5: 69-93.

de Vries, W., J. Kros, C. Kroeze, and S.P. Seitzinger. 2013. Assessing planetary and regional nitrogen boundaries related to food security and adverse environmental impacts. Current Opinion in Environmental Sustainability 5: 392-402.

Dearing, J.A., R. Wang, K. Zhang, J.G. Dyke, H. Haberl, Md. Sarwar Hossain, P.G. Langdon, T.M. Lenton, et al. 2014. Safe and just operating spaces for regional social-ecological systems. Global Environmental Change 28: 227-238.

Del Vicario, M., A. Bessi, F. Zollo, F. Petroni, A. Scala, G. Caldarelli, H.E. Stanley, and W. Quattrociocchi. 2016. The spreading of misinformation online. Proceedings of the National Academy of Sciences, USA 113: 554-559. 
Díaz, S., J. Settle, E.S. Brondízio, H.T Ngo, J. Agard, A. Arneth, P. Balvanera, K.A. Brauman, et al. 2019. Pervasive human-driven decline of life on Earth points to the need for transformative change. Science 366: eaax3100eaax3100.

Diaz, S., U. Pascual, M. Stenseke, B. Martín-López, R.T. Watson, Z. Molnár, R. Hill, K.M.A. Chan, et al. 2018. Assessing nature's contributions to people: recognizing culture, and diverse sources of knowledge, can improve assessments. Science 359: 270-272.

Diffenbaugh, N.S. 2020. Verification of extreme event attribution: using out-of-sample observations to assess changes in probabilities of unprecedented events. Science Advances 6: 2368.

Downing, A.S., A. Bhowmik, D. Collste, S.E. Cornell, J. Donges, I. Fetzer, T. Häyhä, J. Hinton, et al. 2019. Matching scope, purpose and uses of planetary boundaries science. Environmental Research Letters 14: 073005.

Drefahl, S., M. Wallace, E. Mussino, S. Aradhya, M. Kolk, M. Brandén, and B.G. MalmbergAndersson. 2020. A populationbased cohort study of socio-demographic risk factors for COVID-19 deaths in Sweden. Nature Communications 11: 5097.

Dryzek, J.S., A. Bächtiger, S. Chambers, J. Cohen, J.N. Druckman, A. Felicetti, J.S. Fishkin, D.M. Farrell, et al. 2019. The crisis of democracy and the science of deliberation. Science 363: $1144-1146$.

Duarte, C.M., S. Agusti, E. Barbier, G.L. Britten, J.-C. Castilla, J.-P. Gattuso, R.W. Fulweiler, T.P. Hughes, et al. 2020. Rebuilding marine life. Nature 580: 39-51.

Durante, F., S.T. Fiske, M.J. Gelfand, F. Crippa, C. Suttora, A. Stillwell, F. Asbrock, Z. Aycan, et al. 2017. Ambivalent stereotypes link to peace, conflict, and inequality across 38 nations. Proceedings of the National Academy of Sciences, USA 114: 669-674.

Elhacham, E., L. Ben-Uri, J. Grozovski, Y.M. Bar-On, and R. Milo. 2020. Global human-made mass exceeds all living biomass. Nature 588: 442-444.

Ellen MacArthur Foundation. 2019. Completing the Picture: How the Circular Economy Tackles Climate Change. http://www. ellenmacarthurfoundation.org/publications

Ellis, E.C. 2015. Ecology in an anthropogenic biosphere. Ecological Monographs 85: 287-331.

Ellis, E.C., and N. Ramankutty. 2008. Putting people in the map: Anthropogenic biomes of the world. Frontiers in Ecology and the Environment 6: 439-447.

Elmqvist, T., C. Folke, M. Nyström, G. Peterson, J. Bengtsson, B. Walker, and J. Norberg. 2003. Response diversity, ecosystem change, and resilience. Frontiers in Ecology and the Environment 1: 488-494.

Elmqvist, T., E. Andersson, N. Frantzeskaki, T. McPhearson, P. Olsson, O. Gaffney, K. Takeuchi, and C. Folke. 2019. Sustainability and resilience for transformation in the urban century. Nature Sustainability 2: 267-273.

Engström, G., J. Gars, C. Krishnamurthy, D. Spiro, R. Calel, T. Lindahl, and B. Narayanan. 2020. Carbon pricing and planetary boundaries. Nature Communications 11: 4688.

Enqvist, J.P., S. West, V.A. Masterson, L.J. Haider, U. Svedin, and M. Tengö. 2018. Stewardship as a boundary object for sustainability research: Linking care, knowledge and agency. Landscape and Urban Planning 179: 17-37.

Erb, K.H., T. Kastner, C. Plutzar, A.L.S. Bais, N. Carvalhais, T. Fetzel, S. Gingrich, C. Lauk, et al. 2018. Unexpectedly large impact of forest management and grazing on global vegetation biomass. Nature 553: 73-76.

Estes, J.A., J. Terborgh, J.S. Brashares, M.E. Power, J. Berger, W.J. Bond, S.R. Carpenter, T.E. Essington, et al. 2011. Trophic downgrading of Planet Earth. Science 333: 301-306.
Falkenmark, M., L. Wang-Erlandsson, and J. Rockström. 2019. Understanding of water resilience in the Anthropocene. Journal of Hydrology X 2: 100009.

Ferrara, E., O. Varol, C. Davis, F. Menczer, and A. Flammini. 2016. The rise of social bots. Communications of the ACM 59: 96-104.

Fischer, J., and M. Riechers. 2019. A leverage points perspective on sustainability. People and Nature 1: 115-120.

Folke, C., S.R. Carpenter, B. Walker, M. Scheffer, T. Elmqvist, L. Gunderson, and C.S. Holling. 2004. Regime shifts, resilience, and biodiversity in ecosystem management. Annual Review of Ecology, Evolution and Systematics 35: 557-581.

Folke, C., T. Hahn, P. Olsson, and J. Norberg. 2005. Adaptive governance of social-ecological systems. Annual Review of Environment and Resources 30: 441-473.

Folke, C., S.R. Carpenter, B.H. Walker, M. Scheffer, F.S. Chapin III., and J. Rockström. 2010. Resilience thinking: integrating resilience, adaptability and transformability. Ecology and Society 15: 20.

Folke, C., A. Jansson, J. Rockström, P. Olsson, S.R. Carpenter, F.S. Chapin III., A.-S. Crépin, G. Daily, et al. 2011. Reconnecting to the Biosphere. Ambio 40: 719-738.

Folke, C., R. Biggs, A.V. Norström, B. Reyers, and J. Rockström. 2016. Social-ecological resilience and biosphere-based sustainability science. Ecology and Society 21: 41.

Folke, C., H. Österblom, J.-B. Jouffray, E. Lambin, M. Scheffer, B.I. Crona, M. Nyström, S.A. Levin, et al. 2019. Transnational corporations and the challenge of biosphere stewardship. Nature Ecology \& Evolution 3: 1396-1403.

Folke, C., S. Polasky, J. Rockström, V. Galaz, F. Westley, M. Lamont, M. Scheffer, H. Österblom, et al. 2020. Our future in the Anthropocene biosphere: Global sustainability and resilient societies. Paper for the Nobel Prize Summit - Our Planet, Our Future. Beijer Discussion Paper 272. Beijer Institute, Royal Swedish Academy of Sciences, Stockholm, Sweden.

Forbes, B.C., F. Stammler, T. Kumpula, N. Meschtyb, A. Pajunen, and E. Kaarlejarvi. 2009. High resilience in the Yamal-Nenets social-ecological system, West Siberian Arctic, Russia. Proceedings of the National Academy of Sciences, USA 106: 22041-22048.

Fortnam, M., K. Brown, T. Chaigneau, B. Crona, T.M. Daw, D. Goncalves, C. Hicks, M. Revmatas, et al. 2019. The gendered nature of ecosystem services. Ecological Economics 159: $312-325$.

Freeman, J., J.A. Baggio, and T.R. Coyle. 2020. Social and general intelligence improves collective action in a common pool resource systems. Proceedings of the National Academy of Sciences, USA 117: 7712-7718.

Frei, B., C. Queiroz, B. Chaplin-Kramer, E. Andersson, D. Renard, J.M. Rhemtulla, and E.M. Bennett. 2020. A brighter future: Complementary goals of diversity and multifunctionality to build resilient agricultural landscapes. Global Food Security 26: 100407.

Friedlingstein, P., M.W. Jones, M. O’Sullivan, R.M. Andrew, J. Hauck, A. Olsen, G.P. Peters, W. Peters, et al. 2020. Global carbon budget 2020. Earth Systems Science Data 12: 3269-3340.

Gaines, S.D., C. Costello, B. Owashi, T. Mangin, J. Bone, J.G. Molinos, M. Burden, H. Dennis, et al. 2018. Improved fisheries management could offset many negative effects of climate change. Science Advances 4: 1378.

Galaz, V. 2014. Global environmental governance, technology and politics: The anthropocene gap. Cheltenham: Edward Elgar Publishing.

Galaz, V., B. Crona, H. Österblom, P. Olsson, and C. Folke. 2012. Polycentric systems and interacting planetary boundaries: 
Emerging governance of climate change - ocean acidificationmarine biodiversity. Ecological Economics 81: 21-32.

Galaz, V., H. Österblom, Ö. Bodin, and B. Crona. 2016. Global networks and global change-induced tipping points. International Environmental Agreements 16: 189-221.

Galaz, V., J. Tallberg, A. Boin, C. Ituarte-Lima, E. Hey, P. Olsson, and F. Westley. 2017. Global governance dimensions of globally networked risks: the state of the art in social science research. Risk, Hazards, \& Crisis in Public Policy 8: 4-27.

Galaz, V., B. Crona, A. Dauriach, B. Scholtens, and W. Steffen. 2018. Finance and the Earth system: Exploring the links between financial actors and non-linear changes in the climate system. Global Environmental Change 53: 296-302.

Gaupp, F., J. Hall, S. Hochrainer-Stigler, and S. Dadson. 2020. Changing risks of simultaneous global breadbasket failure. Nature Climate Change 10: 54-57.

Geels, F.W. 2002. Technological transitions as evolutionary reconfiguration processes: A multi-level perspective and a case-study. Research Policy 31: 1257-1274.

Geels, F.W., B.K. Sovacool, T. Schwanen, and S. Sorrell. 2017. Sociotechnical transitions for deep decarbonisation. Science 357: $1242-1244$.

Gelcich, S., T.P. Hughes, P. Olsson, C. Folke, O. Defeo, M. Fernández, S. Foale, L.H. Gunderson, et al. 2010. Navigating transformations in governance of Chilean marine coastal resources. Proceedings of the National Academy of Sciences, USA 107: 16794-16799.

Gerbaudo, P., and E. Treré. 2015. In search of the 'we'of social media activism: introduction to the special issue on social media and protest identities. Information, Communication \& Society 18: 865-871.

Gleeson, T., L. Wang-Erlandsson, M. Porkka, S.C. Zipper, F. Jaramillo, D. Gerten, I. Fetzer, S.E. Cornell, et al. 2020a. Illuminating water cycle modifications and Earth System resilience in the Anthropocene. Water Resources Research 56: e2019WR024957.

Gleeson, T., L. Wang-Erlandsson, S.C. Zipper, M. Porkka, F. Jaramillo, D. Gerten, I. Fetzer, S.E. Cornell, et al. 2020. The water planetary boundary: interrogation and revision. One Earth 2: 223-234.

Gordon, L.J., V. Bignet, B. Crona, P. Henriksson, T. van Holt, M. Jonell, T. Lindahl, M. Troell, et al. 2017. Rewiring food systems to enhance human health and biosphere stewardship. Environmental Research Letters 12: 100201.

Green, J.F., and B. Rudyk. 2020. Closing the high seas to fishing: A club approach. Marine Policy 115: 103855.

Grêt-Regamey, A., S.H. Huber, and R. Huber. 2019. Actors' diversity and the resilience of social-ecological systems to global change. Nature Sustainability 2: 290-297.

Grinberg, N., K. Joseph, L. Friedland, B. Swire-Thompson, and D. Lazer. 2019. Fake news on Twitter during the 2016 U.S. presidential election. Science 363: 374-378.

Griscom, B.W., J. Adams, P.W. Ellis, R.A. Houghton, G. Lomax, D.A. Miteva, W.H. Schlesinger, D. Shoch, et al. 2017. Natural climate solutions. Proceedings of the National Academy of Sciences, USA 114: 11645-11650.

Gruber, N., D. Clement, B.R. Carter, R.A. Feely, S. van Heuven, M. Hoppema, M. Ishii, R.M. Key, et al. 2019. The oceanic sink for anthropogenic $\mathrm{CO}_{2}$ from 1994 to 2007. Science 363: 1193-1199.

Guerry, A.D., S. Polasky, J. Lubchenco, R. Chaplin-Kramer, G.C. Daily, R. Griffin, M. Ruckelshaus, I.J. Bateman, et al. 2015. Natural capital informing decisions: From promise to practice. Proceedings of the National Academy of Sciences, USA 112: 7348-7355.
Gunderson, L.H., and C.S. Holling, eds. 2002. Panarchy: Understanding transformations in human and natural systems. Washington DC: Island Press.

Hackmann, H., A.L. St. Clair. 2012. Transformative cornerstones of social science research for global change. Paris: Report of the international Social Science Council.

Haenfler, R., B. Johnson, and E. Jones. 2012. Lifestyle movements: Exploring the intersection of lifestyle and social movements. Social Movement Studies 11: 1-20.

Hahn, T., P. Olsson, C. Folke, and K. Johansson. 2006. Trust building, knowledge generation and organizational innovations: The role of a bridging organization for adaptive co-management of a wetland landscape around Kristianstad, Sweden. Human Ecology 34: 573-592.

Haider, L.J., W.J. Boonstra, A. Akobirshoeva, and M. Schlüter. 2019. Effects of development interventions on biocultural diversity: A case study from the Pamir Mountains. Agriculture and Human Values 37: 683-697.

Haider, L.J., M. Schlüter, C. Folke, and B. Reyers. 2021. Rethinking resilience and development: A coevolutionary perspective. Ambio. https://doi.org/10.1007/s13280-020-01485-8.

Hall, P.A., and M. Lamont, eds. 2013. Social resilience in the Neoliberal Era. Cambridge: Cambridge University Press.

Hallegatte, S., M. Bangalore, L. Bonzanigo, M. Fay, T. Kane, U. Narloch, J. Rozenberg, D. Treguer, et al. 2016. Shock waves: managing the impacts of climate change on poverty. Washington, DC: World Bank.

Halpern, B.S., S. Walbridge, K.A. Selkoe, C.V. Kappel, F. Micheli, C. D'Agrosa, J.F. Bruno, K.S. Casey, et al. 2008. A global map of human impact on marine ecosystems. Science 319: 948-952.

Hamann, M., R. Biggs, and B. Reyers. 2015. Mapping socialecological systems: identifying 'green-loop' and 'red-loop' dynamics based on characteristic bundles of ecosystem service use. Global Environmental Change 34: 218-226.

Hamann, M., K. Berry, T. Chaigneau, T. Curry, R. Heilmayr, P.J.G. Henriksson, J. Hentati-Sundberg, A. Jina, et al. 2018. Inequality and the biosphere. Annual Review of Environment and Resources 43: 61-83.

Harper, S., D. Zeller, M. Hauzer, D. Pauly, and U.R. Sumaila. 2013. Women and fisheries: Contribution to food security and local economies. Marine Policy 39: 56-63.

Hassan, N., M. Yousuf, M.A. Mahfuzul Haque, J. Suarez Rivas, and M. Khadimul Islam. 2019. Examining the roles of automation, crowds and professionals towards sustainable fact-checking. Companion Proceedings of The 2019 World Wide Web Conference, 1001-1006.

Häyhä, T., P.L. Lucas, D.P. van Vuuren, S.E. Corell, and H. Hoff. 2016. From Planetary Boundaries to national fair shares of the global safe operating space: How can the scales be bridged? Global Environmental Change 40: 60-72.

Heal, G., B.H. Walker, S.A. Levin, K. Arrow, P. Dasgupta, G. Daily, P. Ehrlich, K.-G. Maler, et al. 2004. Genetic diversity and interdependent crop choices in agriculture. Resource and Energy Economics 26: 175-184.

Helbing, D. 2013. Globally networked risks and how to respond. Nature 497: 51-59.

Hendershot, J.N., J.R. Smith, C.B. Anderson, A.D. Letten, L.O. Frishkoff, J.R. Zook, T. Fukami, and G.C Daily. 2020. Intensive farming drives long-term shifts in community composition. Nature 579: 393-396.

Hicks, C.C., P.J. Cohen, N.A.J. Graham, K.L. Nash, E.H. Allison, C. D’Lima, D.J. Mills, M. Roscher, et al. 2019. Harnessing global fisheries to tackle micronutrient deficiencies. Nature 574: 95-98.

Hino, M., E. Benami, and N. Brooks. 2018. Machine learning for environmental monitoring. Nature Sustainability 1: 583-588. 
Hirota, M., M. Holmgren, E.H. van Nes, and M. Scheffer. 2011. Global resilience of tropical forest and savanna to critical transitions. Science 334: 232-235.

Holling, C.S., F. Berkes, and C. Folke. 1998. Science, sustainability, and resource management. In Linking social and ecological systems: Management practices and social mechanisms for building resilience, ed. F. Berkes and C. Folke, 342-362. Cambridge: Cambridge University Press.

Hooper, D.U., F.S. Chapin III., J.J. Ewel, A. Hector, P. Inchausti, S. Lavorel, J.H. Lawton, D.M. Lodge, et al. 2005. Effects of biodiversity on ecosystem functioning: A consensus of current knowledge. Ecological Monographs 75: 3-35.

Houghton, R.A. 2007. Balancing the global carbon budget. Annual Review of Earth and Planetary Sciences 35: 313-347.

Huang, K., X. Li, X. Liu, and K.C. Seto. 2019. Projecting global urban land expansion and heat island intensification through 2050. Environmental Research Letters 14: 114037.

Hughes, T.P., M.J. Rodrigues, D.R. Bellwood, D. Ceccarelli, O. Hoegh-Guldberg, L. McCook, N. Moltschaniwsky, M.S. Pratchett, et al. 2007. Phase shifts, herbivory, and the resilience of coral reefs to climate change. Current Biology 17: 1-6.

Hughes, T.P., S.R. Carpenter, J. Rockström, M. Scheffer, and B.H. Walker. 2013. Multiscale regime shifts and planetary boundaries. Trends in Ecology \& Evolution 28: 389-395.

Ide, T., M. Brzoska, J.F. Donges, and C.-F. Schleussner. 2020. Multimethod evidence for when and how climate-related disasters contribute to armed conflict risk. Global Environmental Change 62: 102063.

Ilieva, R.T., and T. McPhearson. 2018. Social-media data for urban sustainability. Nature Sustainability 1: 553-565.

IPCC. 2014. Climate Change 2014: Synthesis Report. Contribution of Working Groups I, II and III to the Fifth Assessment Report of the Intergovernmental Panel on Climate Change. Core Writing Team, R.K. Pachauri and L.A. Meyer (eds.). IPCC, Geneva, Switzerland, $151 \mathrm{pp}$.

Isbell, F., A. Gonzalez, M. Loreau, J. Cowles, S. Diaz, A. Hector, G.M. Mace, D.A. Wardle, et al. 2017. Linking the influence and dependence of people on biodiversity across scales. Nature 546: $65-72$.

Islam, S.N., and J. Winkel. 2017. Climate Change and Social Inequality. DESA Working Paper 152. Department of Economic \& Social Affairs, United Nations.

Jachimowicz, J.M., S. Chafik, S. Munrat, J. Prabhu, and E.U. Weber. 2017. Community trust reduces myopic decisions in low-income individuals. Proceedings of the National Academy of Sciences, USA 114: 5401-5406.

Joppa, L.N. 2017. AI for Earth. Nature 552: 325-328.

Jørgensen, P.S., A. Aktipis, Z. Brown, Y. Carrière, S. Downes, R.R. Dunn, G. Epstein, G.B. Frisvold, et al. 2018. Antibiotic and pesticide susceptibility and the Anthropocene operating space. Nature Sustainability 1: 632-641.

Jørgensen, P.S., C. Folke, and S.P. Carroll. 2019. Evolution in the Anthropocene: Informing governance and policy. Annual Review of Ecology, Evolution, and Systematics 50: 527-546.

Jouffray, J.-B., B. Crona, E. Wassenius, J. Bebbington, and B. Scholtens. 2019. Leverage points in the financial sector for seafood sustainability. Science Advances 5: eaax3324.

Jouffray, J.-B., R. Blasiak, A.V. Norström, H. Österblom, and M. Nyström. 2020. The blue acceleration: The trajectory of human expansion into the ocean. One Earth 2: 43-54.

Kartha, S., E. Kemp-Benedict, E. Ghosh, A. Nazareth, and T. Gore. 2020. The Carbon Inequality Era: An assessment of the global distribution of consumption emissions among individuals from 1990 to 2015 and beyond. Joint Research Report. Stockholm Environment Institute and Oxfam International
Kates, R.W., and W.C. Clark. 1996. Environmental surprise: expecting the unexpected. Environment 38: 6-11.

Kates, R.W., and P. Dasgupta. 2007. African poverty: A great challenge for sustainability science. Proceedings of the National Academy of Sciences, USA 104: 16747-16750.

Kates, R.W., W.R. Travis, and T.J. Wilbanks. 2012. Transformational adaptation when incremental adaptations to climate change are insufficient. Proceedings of the National Academy of Sciences, USA 109: 7156-7161.

Keohane, R.O., S. Macedo, and A. Moravcsik. 2009. Democracyenhancing multilateralism. International Organization 63: 1-31.

Keys, P.W., L. Wang-Erlandsson, and L.J. Gordon. 2016. Revealing invisible water: Moisture recycling as an ecosystem service. PLOS ONE 11: e0151993.

Keys, P.W., L. Wang-Erlandsson, and L.J. Gordon. 2018. Megacity precipitationsheds reveal tele-connected water security challenges. PLoS ONE 13: e0194311.

Keys, P., V. Galaz, M. Dyer, N. Matthews, C. Folke, M. Nyström, and S. Cornell. 2019. Anthropocene risk. Nature Sustainability 2: 667-673.

Khoury, K.C., A.D. Bjorkman, H. Dempewolf, J. Ramirez-Villegas, L. Guarino, A. Jarvis, L.H. Rieseberg, and P.C. Struik. 2014. Increasing homogeneity in global food supplies and the implications for food security. Proceedings of the National Academy of Sciences, USA 111: 4001-4006.

King, A.D., and L.J. Harrington. 2018. The inequality of climate change from 1.5 to $2^{\circ} \mathrm{C}$ of global warming. Geophysical Research Letters 45: 5030-5033.

Kinzig, A.P., C. Perrings, F.S. Chapin III., S. Polasky, V.K. Smith, D. Tilman, and B.L. Turner. 2011. Paying for ecosystem services: promise and peril. Science 334: 603-604.

Kremen, C., and A.M. Merenlender. 2018. Landscapes that work for biodiversity and people. Science 362: eaau6020

Kummu, M., P. Kinnunen, E. Lehikoinen, M. Porkka, C. Queiroz, E. Röös, M. Troell, and C. Weil. 2020. Interplay of trade and food system resilience: Gains on supply diversity over time at the cost of trade independency. Global Food Security 24: 100360.

Lachat, C., J.E. Raneri, K. Walker Smith, P. Kolsteren, P. Van Damme, K. Verzelen, D. Penafiel, W. Vanhove, et al. 2018. Dietary species richness as a measure of food biodiversity and nutritional quality of diets. Proceedings of the National Academy of Sciences, USA 115: 127-132.

Lade, S.J., L.J. Haider, G. Engström, and M. Schlüter. 2017. Resilience offers escape from trapped thinking on poverty alleviation. Science Advances 3: e1603043.

Lade, S.J., W. Steffen, W. de Vries, S.R. Carpenter, J.F. Donges, D. Gerten, H. Hoff, T. Newbold, et al. 2020. Human impacts on planetary boundaries amplified by Earth system interactions. Nature Sustainability 3: 119-128.

Laliberte, E., J.A. Wells, F. DeClerck, D.J. Metcalfe, C.P. Catterall, C. Queiroz, I. Aubin, S.P. Bonser, et al. 2010. Land-use intensification reduces functional redundancy and response diversity in plant communities. Ecology Letters 13: 76-86.

Lambin, E.F., and P. Meyfroidt. 2011. Global land use change, economic globalization, and the looming land scarcity. Proceedings of the National Academy of Sciences, USA 108: $3465-3472$.

Lamont, M. 2018. Addressing recognition gaps: destigmatization and the reduction of inequality. American Sociological Review 83: 419-444.

Lamont, M. 2019. From 'having' to 'being': self-worth and the current crisis of American society. The British Journal of Sociology 70: 660-707.

Lamont, M., L. Adler, B.Y. Park, and X. Xiang. 2017. Bridging cultural sociology and cognitive psychology in three 
contemporary research programmes. Nature Human Behaviour 1: 886-872.

Lazer, D.M., M.A. Baum, Y. Benkler, A.J. Berinsky, K.M. Greenhill, F. Menczer, M.J. Metzger, B. Nyhan, et al. 2018. The science of fake news. Science 359: 1094-1096.

Le Quéré, C., R.B. Jackson, M.W. Jones, A.J.P. Smith, S. Abernethy, R.M. Andrew, A.J. De-Gol, D.R. Willis, et al. 2020. Temporary reduction in daily global $\mathrm{CO}_{2}$ emissions during the COVID-19 forced confinement. Nature Climate Change 10: 647-653.

Leach, M., B. Reyers, X. Bai, E.S. Brondizio, C. Cook, S. Díaz, G. Espindola, M. Scobie, et al. 2018. Equity and sustainability in the Anthropocene: A social-ecological systems perspective on their intertwined futures. Global Sustainability 1: e13.

Lenton, T.M. 2016. Earth system science. Oxford: Oxford University Press.

Lenton, T.M., J. Rockström, O. Gaffney, S. Rahmstorf, K. Richardson, W. Steffen, and H.J. Schellnhuber. 2019. Climate tipping points: too risky to bet against. Nature 575: 592-595.

Levin, S.A., T. Xepapadeas, A.-S. Crepin, J. Norberg, A. de Zeeuw, C. Folke, T. Hughes, K. Arrow, et al. 2013. Social-ecological systems as complex adaptive systems: Modeling and policy implications? Environment and Development Economics 18: 111-132.

Levin, S.A. 1999. Fragile dominion: Complexity and the commons. Cambridge MA: Helix Books. Perseus.

Limburg, K.E., D. Breitburg, D.P. Swaney, and G. Jacinto. 2020. Ocean deoxygenation: A primer. One Earth 2: 24-29.

Liu, J., H. Mooney, V. Hull, S.J. Davis, J. Gaskell, T. Hertel, J. Lubchenco, K.C. Seto, et al. 2015. Systems integration for global sustainability. Science 347: 1258832.

Liu, J., W. Yang, and S.X. Li. 2016. Framing ecosystem services in the telecoupled Anthropocene. Frontiers in Ecology and the Environment 14: 27-36.

Loorbach, D., N. Frantzeskaki, and F. Avelino. 2017. Sustainability transitions research: Transforming science and practice for societal change. Annual Review of Environment and Resources 42: 599-626.

Lovejoy, T.E., and L. Hannah. 2018. Avoiding the climate failsafe point. Science Advances 4: eaau9981.

Lovejoy, T.E., and C. Nobre. 2018. Amazon tipping point. Sciences Advances 4: eaat 2340

Lubchenco, J., and K. Grorud-Colvert. 2015. Making waves: The science and politics of ocean protection. Science 350: 382-383.

Lubchenco, J., and S.D. Gaines. 2019. A new narrative for the ocean. Science 364: 911.

Lubchenco, J., E.B. Cerny-Chipman, J.N. Reimer, and S.A. Levin. 2016. The right incentives enable ocean sustainability successes and provide hope for the future. Proceedings of the National Academy of Sciences, USA 113: 14507-14514.

Mace, G.M. 2014. Whose conservation? Science 345: 1558-1560.

Mace, G.M., B. Reyers, R. Alkemade, R. Biggs, F.S. Chapin III., S.E. Cornell, S. Díaz, S. Jennings, et al. 2014. Approaches to defining a planetary boundary for biodiversity. Global Environmental Change 28: 289-297.

Mach, K.J., C.M. Kraan, W.N. Adger, H. Buhaug, M. Burke, J.D. Fearon, C.B. Field, C.S. Hendrix, et al. 2019. Climate as a risk factor for armed conflict. Nature 571: 193-197.

Maharani, C.D., M. Moelionon, G.Y. Wong, M. Brockhaus, R. Carmenta, and M. Kallio. 2019. Development and equity: A gendered inquiry in a swidden landscape. Forest Policy and Economics 101: 120-128.

Mandle, L., J. Salzman, and G.C. Daily, eds. 2019. Green Growth that works: Natural capital policy and finance mechanisms from around the world. Washington DC: Island Press.

Marshall, N.A., S.E. Park, W.N. Adger, K. Brown, and S.M. Howden. 2012. Transformational capacity and the influence of place and identity. Environmental Research Letters 7: 034022.
Mbow, C., C. Rosenzweig, L.G. Barioni, T.G. Benton, M. Herrero, et al. 2019. Food Security. In Climate Change and Land: an IPCC special report on climate change, desertification, land degradation, sustainable land management, food security, and greenhouse gas fluxes in terrestrial ecosystems, eds. P.R. Shukla, et al.

McAfee, A. 2019. More from less: The surprising story of how we learned to prosper using fewer resources, and what happens next. New York: Scribner.

McCauley, D.J., P. Woods, B. Sullivan, B. Bergman, C. Jablonicky, A. Roan, M. Hirshfield, K. Boerder, and B. Worm. 2016. Ending hide and seek at sea: new technologies could revolutionize ocean observation. Science 351: 1148-1150.

McWethy, D.B., T. Schoennagel, P.E. Higuera, M. Krawchuk, B.J. Harvey, E.C. Metcalf, C. Schultz, C. Miller, et al. 2019. Rethinking resilience to wildfire. Nature Sustainability 2: 797-804.

Merçon, J., S. Vetter, M. Tengö, M. Cocks, P. Balvanera, J.A. Rosell, and B. Ayala-Orozco. 2019. From local landscapes to international policy: Contributions of the biocultural paradigm to global sustainability. Global Sustainability 2: 1-11.

Meyfroidt, P., R.R. Chowdhury, A. de Bremond, E.C. Ellis, K.H. Erb, T. Filatova, R.D. Garrett, J.M. Grove, et al. 2018. Middle-range theories of land system change. Global Environmental Change 53: 52-67.

Moore, M.L., and M. Milkoreit. 2020. Imagination and transformations to sustainable and just futures. Elementa 8: 1.

Moore, M.-L., D. Riddell, and D. Vosicano. 2015. Scaling out, up and deep. The Journal of Corporate Citizenship 58: 67-84.

Moran, D., K. Kanemoto, M. Jiborn, R. Wood, J. Többen, and K.C. Seto. 2018. Carbon footprints of 13,000 cities. Environmental Research Letters 13: 064041.

Mori, A.S., T. Furukawa, and T. Sasaki. 2013. Response diversity determines the resilience of ecosystems to environmental change. Biological Reviews 88: 349-364.

Morton, J.F. 2007. The impact of climate change on smallholder and subsistence agriculture. Proceedings of the National Academy of Sciences, USA 104: 19680-19685.

Mounier, A., and M.M. Lahr. 2019. Deciphering African late middle Pleistocene hominin diversity and the origin of our species. Nature Communications 10: 3406.

Myers, S.S., and J.J. Patz. 2009. Emerging threats to human health from global environmental change. Annual Review of Environment and Resources 34: 223-252.

Naeem, S., J.C. Ingram, A. Varga, T. Agardy, P. Barten, G. Bennett, E. Bloomgarden, L.L. Bremer, et al. 2015. Get the science right when paying for nature's services. Science 347: 1206-1207.

Nash, K.L., N.A. Graham, S. Jennings, S.K. Wilson, and D.R. Bellwood. 2016. Herbivore cross-scale redundancy supports response diversity and promotes coral reef resilience. Journal of Applied Ecology 53: 646-655.

Neukom, R., N. Steiger, J.J. Gómez-Navarro, J. Wang, and J.P. Werner. 2019. No evidence for globally coherent warm and cold periods over the preindustrial Common Era. Nature 571: $550-572$.

Newbold, T., L.N. Hudson, S. Contu, S.L.L. Hill, J. Beck, Y. Liu, C. Meyer, H.R.P. Philips, et al. 2018. Widespread winners and narrow-ranged losers: Land use homogenizes biodiversity in local assemblages worldwide. PLOS Biology 16: e2006841.

Newbold, T., L.N. Hudson, A.P. Arnell, S. Contu, A. De Palma, S. Ferrier, S.L.L. Hill, A.J. Hoskins, et al. 2016. Has land use pushed terrestrial biodiversity beyond the planetary boundary? A global assessment. Science 353: 288-291.

Norström, A.V., C. Cvitanovic, M.F. Löf, S. West, C. Wyborn, P. Balvanera, A.T. Bednarek, E.M. Bennett, et al. 2020. Principles for knowledge co-production in sustainability research. Nature Sustainability 3: 182-190. 
Nyborg, K., J.M. Anderies, A. Dannenberg, T. Lindahl, C. Schill, M. Schluter, W.N. Adger, K.J. Arrow, et al. 2016. Social norms as solutions: policies may influence large-scale behavioral tipping. Science 354: 42-43.

Nyström, M., J.-B. Jouffray, A. Norström, P.S. Jørgensen, V. Galaz, B.E. Crona, S.R. Carpenter, and C. Folke. 2019. Anatomy and resilience of the global production ecosystem. Nature 575: 98-108.

O'Brien, K. 2012. Global environmental change II: From adaptation to deliberate transformation. Progress in Human Geography 36: $667-676$

O'Brien, K. 2015. Political agency: The key to tackling climate change. Science 350: 1170-1171.

O'Neill, D.W., A.L. Fanning, W.F. Lamb, and J.K. Steinberger. 2018. A good life for all within planetary boundaries. Nature Sustainability 1: 88-95.

Odum, E.P. 1989. Ecology and our endangered life-support systems. Sunderland, MA: Sinauer.

Olsson, P., C. Folke, and T. Hahn. 2004. Social-ecological transformation for ecosystem management: The development of adaptive co-management of a wetland landscape in southern Sweden. Ecology and Society 9: 2.

Olsson, P., L.H. Gunderson, S.R. Carpenter, P. Ryan, L. Lebel, C. Folke, and C.S. Holling. 2006. Shooting the rapids: Navigating transitions to adaptive governance of social-ecological systems. Ecology and Society 11: 8.

Olsson, P., M.-L. Moore, F.R. Westley, and D.D.P. McCarthy. 2017. The concept of the Anthropocene as a game-changer: A new context for social innovation and transformations to sustainability. Ecology and Society 22: 31.

Oppenheimer, S. 2004. Out of Eden: The Peopling of the World. London, UK: Little, Brown Book Group.

Ortiz, A.M., C.L. Outhwaite, C. Dalin, and T. Newbold. 2021. A review of the interactions between biodiversity, agriculture, climate change, and international trade: Research and policy priorities. One Earth 4: 88-101.

Österblom, H., J.-B. Jouffray, C. Folke, and J. Rockström. 2017. Emergence of a global science-business initiative for ocean stewardship. Proceedings of the National Academy of Sciences, USA 114: 9038-9043.

Österblom, H., C.C.C. Wabnitz, D. Tladi, E.H. Allison, S. Arnaud Haond, et al. 2019. Towards ocean equity. Washington, DC: World Resources Institute.

Österblom, H., J.-B. Jouffray, C. Folke, B. Crona, M. Troell, A. Merrie, and J. Rockström. 2015. Transnational corporations as keystone actors in marine ecosystem. PLoS ONE 10: e0127 533.

Ostrom, E. 2007. A diagnostic approach for going beyond panaceas. Proceeding of the Natural Academy of Sciences, USA 104: 15181-15187.

Ostrom, E. 2010. Polycentric systems for coping with collective action and global environmental change. Global Environmental Change 20: 550-557.

Otto, I.M., J.F. Donges, R. Cremades, A. Bhowmik, R.J. Hewitt, W. Lucht, J. Rockström, F. Allerberger, et al. 2020. Social tipping dynamics for stabilizing Earth's climate by 2050. Proceedings of the National Academy of Sciences USA 117: 2354-2365.

Ouyang, Z., H. Zheng, Y. Xiao, S. Polasky, J. Liu, W. Xu, Q. Wang, L. Zhang, et al. 2016. Improvements in ecosystem services from investments in natural capital. Science 352: 1455-1459.

Page, S.E., F. Siegert, J.O. Rieley, H.-D.V. Boehm, A. Jayak, and S. Limink. 2002. The amount of carbon released from peat and forest fires in Indonesia during 1997. Nature 420: 61-65.

Pennycook, G., and D.G. Rand. 2019. Fighting misinformation on social media using crowdsourced judgments of news source quality. Proceedings of the National Academy of Sciences USA 116: $2521-2526$
Pereira, L.M., T. Karpouzoglou, N. Frantzeskaki, and P. Olsson. 2018. Designing transformative spaces for sustainability in social-ecological systems. Ecology and Society 23: 32.

Pereira, L., E. Bennett, R. Biggs, G. Peterson, T. McPhearson, et al. 2018. Seeds of the future in the present: Exploring pathways for navigating towards "Good" anthropocenes. In Urban planet: Knowledge towards sustainable cities, ed. T. Elmqvist, X. Bai, N. Frantzeskaki, et al., 327-350. Cambridge: Cambridge University Press.

Perino, A., H.M. Pereira, L.M. Navarro, N. Fernández, J.M. Bullock, S. Ceausu, A. Cortés-Avizanda, R. van Klink, et al. 2019. Rewilding complex ecosystems. Science 364: eaav5570.

Peterson, G., C.R. Allen, and C.S. Holling. 1998. Ecological resilience, biodiversity, and scale. Ecosystems 1: 6-18.

Petit, J., J. Jouzel, D. Raynaud, N.I. Barkow, I. Basile, M. Bender, J. Chappelaz, M. Davis, et al. 1999. Climate and atmospheric history of the past 420,000 years from the Vostok ice core, Antarctica. Nature 399: 429-436.

Phillips, C.A., A. Caldas, R. Cleetus, K.A. Dahl, J. Declet-Barreto, R. Licker, L. Delta Merner, et al. 2020. Compound climate risk in the COVID-19 pandemics. Nature Climate Change 10: 586-588.

Pickering, J., and A. Persson. 2020. Democratising planetary boundaries: Experts, social values and deliberative risk evaluation in Earth system governance. Journal of Environmental Policy \& Planning 22: 59-71.

Pigford, A.A., G. Hickey, and L. Klerkx. 2018. Beyond agricultural innovation systems? exploring an agricultural innovation ecosystems approach for niche design and development in sustainability transitions. Agricultural Systems 164: 116-121.

Pihl, E., M.A. Martin, T. Blome, S. Hebden, M.P. Jarzebski, R.A. Lambino, C. Köhler, and J.G. Canadell. 2019. 10 New insights in climate science 2019. Stockholm: Future Earth \& The Earth League.

Piketty, T. 2014. Capital in the twenty-first century. Cambridge, MA: Belknap Press of Harvard University Press.

Plummer, R., J. Baird, S. Farhad, and S. Witkowski. 2020. How do biosphere stewards actively shape trajectories of social-ecological change? Journal of Environmental Management 261: 110139.

Polasky, S., B. Bryant, P. Hawthorne, J. Johnson, B. Keeler, and D. Pennington. 2015. Inclusive wealth as a metric of sustainable development. Annual Review of Environment and Resources 40: 445-446.

Polasky, S., S.R. Carpenter, C. Folke, and B. Keeler. 2011. Decisionmaking under great uncertainty: Environmental management in an era of global change. Trends in Ecology \& Evolution 26: 398-404.

Poli, R. 2017. Introduction to Anticipation Studies. Berlin, Germany: Springer.

Pörtner, H.-O., D.C. Roberts, V. Masson-Delmotte, P. Zhai, M. Tignor, E. Poloczanska, K. Mintenbeck, A. Alegría, et al. (eds.). 2019. IPCC Special Report on the Ocean and Cryosphere in a Changing Climate.

Quinlan, A.E., M. Berbés-Blázquez, L.J. Haider, and G.D. Peterson. 2015. Measuring and assessing resilience: Broadening understanding through multiple disciplinary perspectives. Journal of Applied Ecology 23: 677-687.

Rao, N., C. Singh, D. Solomon, L. Camfield, R. Sidiki, M. Angula, P. Poonacha, A. Sidibé, and E.T. Lawson. 2020. Managing risk, changing aspirations and household dynamics: Implications for wellbeing and adaptation in semi-arid Africa and India. World Development 125: 104667.

Rathwell, K.J., and G.D. Peterson. 2012. Connecting social networks with ecosystem services for watershed governance: A socialecological network perspective highlights the critical role of bridging organizations. Ecology and Society 17: 24. 
Raworth, K. 2012. A safe and just space for humanity: can we live within the doughnut? Oxfam Discussion Papers, February 2012.

Raymond, C.M., I. Fazey, M.S. Reed, L.C. Stringer, G.M. Robinson, and A.C. Evely. 2010. Integrating local and scientific knowledge for environmental management. Journal of Environmental Management 91: 1766-1777.

Reichstein, M., G. Camps-Valls, B. Stevens, M. Jung, J. Denzler, and N.P. Carvalhais. 2019. Deep learning and process understanding for data-driven Earth system science. Nature 566: 195-204.

Reyers, B., and E.R. Selig. 2020. Global targets that reveal the socialecological interdependencies of sustainable development. Nature Ecology \& Evolution 4: 1011-1019.

Reyers, B., R. Biggs, G.S. Cumming, T. Elmqvist, A.P. Hejnowicz, and S. Polasky. 2013. Getting the measure of ecosystem services: A social-ecological approach. Frontiers in Ecology and Evolution 11: 268-273.

Reyers, B., J.L. Nel, P.J. O'Farrell, N. Sitas, and D.C. Nel. 2015. Navigating complexity through knowledge coproduction: Mainstreaming ecosystem services into disaster risk reduction. Proceedings of the National Academy of Sciences, USA 112: 7362-7368.

Reyers, B., C. Folke, M.-L. Moore, R. Biggs, and V. Galaz. 2018. Social-ecological systems insights for navigating the dynamics of the Anthropocene. Annual Review of Environment and Resources 43: 267-289.

Rocha, J.C., G. Peterson, Ö. Bodin, and S. Levin. 2018. Cascading regime shifts within and across scales. Science 362: 1379-1383.

Rockström, J., W. Steffen, K. Noone, A. Persson, F.S. Chapin III., E.F. Lambin, T.M. Lenton, M. Scheffer, et al. 2009. A safe operating space for humanity. Nature 461: 472-475.

Rockström, J., O. Gaffney, J. Rogelj, M. Meinshausen, N. Nakicenovic, and H.J. Schellnhuber. 2017. A roadmap for rapid decarbonization: Emissions inevitably approach zero with a "carbon law." Science 355: 1269-1271.

Roe, S., C. Streck, M. Obersteiner, S. Frank, B. Griscom, L. Drouet, O. Fricko, M. Gusti, et al. 2019. Contribution of the land sector to a $1.5^{\circ} \mathrm{C}$ world. Nature Climate Change 9: $817-828$.

Rogelj, J., M. den Elzen, N. Hohne, T. Fransen, H. Fekete, H. Winkler, R. Schaeffer, F. Sha, et al. 2016. Paris Agreement climate proposals need a boost to keep warming well below 2 degrees C. Nature 534: 631-639.

Sachs, J.D., G. Schmidt-Traub, M. Mazzucato, D. Messner, N. Nakicenovic, and J. Rockström. 2019. Six transformations to achieve the sustainable development goals. Nature Sustainability 2: 805-814.

Saez, E., and G. Zucman. 2016. Wealth inequality in the United States since 1913: Evidence from capitalized income tax data. Quarterly Journal of Economics 131: 519-578.

Sakschewski, B., W. von Bloh, A. Boit, L. Poorter, Ma.. Peña-Claros, J. Heinke, J. Joshi, and K. Thonicke. 2016. Resilience of Amazon forests emerges from plant trait diversity. Nature Climate Change 6: 1032-1036.

Sala, E., C. Costello, J.D. Parme, M. Fiorese, G. Heal, K. Kelleher, R. Moffitt, L. Morgan, et al. 2016. Fish banks: An economic model to scale marine conservation. Marine Policy 73: 154-161.

Scheffer, M., S.R. Carpenter, T.M. Lenton, J. Bascompte, W. Brock, V. Dakos, J. van de Koppel, I.A. van de Leemput, et al. 2012. Anticipating critical transitions. Science 338: 344-348.

Scheffer, M., S. Barrett, S. Carpenter, C. Folke, A.J. Greene, M. Holmgren, T.P. Hughes, S. Kosten, et al. 2015. Creating a safe operating space for the world's iconic ecosystems. Science 347: 1317-1319.

Scheffer, M., B. Bavel, I.A. van de Leemput, and E.H. van Nes. 2017. Inequality in nature and society. Proceedings of the National Academy of Sciences, USA 114: 13154-13157.
Schill, C., J.M. Anderies, T. Lindahl, C. Folke, S. Polasky, J.C. Cárdenas, A.-S. Crépin, M.A. Janssen, et al. 2019. A more dynamic understanding of human behaviour for the Anthropocene. Nature Sustainability 2: 1075-1082.

Schlüter, M., L.J. Haider, S. Lade, E. Lindkvist, R. Martin, K. Orach, N. Wijermans, and C. Folke. 2019. Capturing emergent phenomena in social-ecological systems: An analytical framework. Ecology and Society 24: 11.

Schmidheiny, S., with the Business Council for Sustainable Development. 1992. Changing Course: A Global Business Perspective on Development and the Environment. Cambridge, MA: MIT Press

Schultz, L., C. Folke, H. Österblom, and P. Olsson. 2015. Adaptive governance, ecosystem management and natural capital. Proceedings of the National Academy of Sciences, USA 112: 7369-7374.

Seto, K.C., A. Reenberg, C.G. Boone, M. Fragkias, D. Haase, T. Langanke, P. Marcotullio, D.K. Munroe, et al. 2012. Urban land teleconnections and sustainability. Proceedings of the National Academy of Sciences, USA 109: 7687-7692.

Seto, K., B. Guneralp, and L. Hutyra. 2012. Global forecasts of urban expansion to 2030 and direct impacts on biodiversity and carbon pools. Proceedings of the National Academy of Sciences, USA 109: 16083-16088.

Seto, K.C., S. Dhakal, A. Bigio, H. Blanco, G.C. Delgado, et al. 2014. Human Settlements, Infrastructure and Spatial Planning. In Climate Change 2014: Mitigation of Climate Change. Contribution of Working Group III to the IPCC Fifth Assessment Report of the Intergovernmental Panel on Climate Change.

Singh, C., L. Wang-Erlandsson, I. Fetzer, J. Rockström, and R. van der Ent. 2020. Rootzone storage capacity reveals drought coping strategies along rainforest-savanna transitions. Environmental Research Letters 15: 124021.

Soliveres, S., F. van der Plas, P. Manning, D. Prati, M.M. Gossner, S.C. Renner, F. Alt, H. Arndt, et al. 2016. Biodiversity at multiple trophic levels is needed for ecosystem multifunctionality. Nature 536: 456-459.

Staver, C.A., S. Archibald, and S.A. Levin. 2011. The global extent and determinants of savanna and forest as alternative biome states. Science 334: 230-232.

Steffen, W., K. Richardson, J. Rockström, S.E. Cornell, I. Fetzer, E.M. Bennett, R. Biggs, S.R. Carpenter, et al. 2015. Planetary boundaries: Guiding human development on a changing planet. Science 347: 6223.

Steffen, W., J. Rockström, K. Richardson, T.M. Lenton, C. Folke, D. Liverman, C.P. Summerhayes, A.D. Barnosky, et al. 2018. Trajectories of the Earth system in the Anthropocene. Proceedings of the National Academy of Sciences, USA 115: 8252-8259.

Steffen, W., K. Richardson, J. Rockström, H.J. Schellnhuber, O.P. Dube, T.M. Lenton, and J. Lubchenco. 2020. The emergence and evolution of Earth System Science. Nature Reviews 1: 54-63.

Steinert-Threlkeld, Z.C., D. Mocanu, A. Vespignani, and J. Fowler. 2015. Online social networks and offline protest. EPJ Data Science 4: 19.

Sterner, T., E.B. Barbier, I. Bateman, I. van den Bijgaart, A.-S. Crépin, O. Edenhofer, C. Fischer, W. Habla, et al. 2019. Policy design for the Anthropocene. Nature Sustainability 2: 14-21.

Stewart, A.J., M. Mosleh, M. Diakonova, A.A. Arechar, and D.G. Rand. 2019. Information gerrymandering and undemocratic decisions. Nature 573: 117-121.

Stiglitz, J.E. 2012. The price of inequality. New York: W.W. Norton.

Stiglitz, J.E. 2020. Conquering the great divide. Finance \& Development, September 2020: 17-19.

Stuchtey, M., A. Vincent, A. Merkl, M. Bucher, P. Haugen, et al. 2020. Ocean solutions that benefit people, nature and the 
economy. Washington, DC: World Resources Institute. www. oceanpanel.org/ocean-solutions.

Sukhdev, P., H. Wittmer, C. Schröter-Schlaack, C. Nesshöver, J. Bishop, et al. 2010. Mainstreaming the Economics of Nature: A Synthesis of the Approach, Conclusions and Recommendations of TEEB. The Economics of Ecosystems and Biodiversity (TEEB). www.teebweb.org/our-publications/teeb-study-reports/ synthesis-report/

Sumaila, U.R., V.W.Y. Lam, J.D. Miller, L. Teh, R.A. Watson, D. Zeller, W.W.L. Cheung, et al. 2015. Winners and losers in a world where the high seas is closed to fishing. Scientific Reports 5: 8481.

Sumaila, U.R., M. Walsh, K. Hoareau, A. Cox, et al. 2020. Ocean finance: Financing the transition to a sustainable ocean economy. Washington, DC: World Resources Institute. www.oceanpanel.org/bluepapers/ocean-finance-financing-transition-sustainable-ocean-economy.

Tallis, H.M., P.L. Hawthorne, S. Polasky, J. Reid, M.W. Beck, K. Brauman, J.M. Bielicki, S. Binder, et al. 2018. An attainable global vision for conservation and human well-being. Frontiers in Ecology and the Environment 16: 563-570.

Tamea, S., F. Laio, and L. Ridolfi. 2016. Global effects of local food production crises: A virtual water perspective. Scientific Reports 6: 18803.

Tengö, M., E.S. Brondizio, T. Elmqvist, P. Malmer, and M. Spierenburg. 2014. Connecting diverse knowledge systems for enhanced ecosystem governance: The multiple evidence base approach. Ambio 43: 579-591.

Tengö, M., R. Hill, P. Malmer, C.M. Raymond, M. Spierenburg, F. Danielsen, T. Elmqvist, and C. Folke. 2017. Weaving knowledge systems in IPBES, CBD and beyond: Lessons learned for sustainability. Current Opinion in Environmental Sustainability 26-27: 17-25.

Tilman, D., F. Isbell, and J.M. Cowles. 2014. Biodiversity and ecosystem functioning. Annual Review of Ecology, Evolution, and Systematics 45: 471-493.

Tittensor, D.P., M. Berger, K. Boerder, D.G. Boyce, R.D. Cavanagh, A. Cosandey-Godin, G.O. Crespo, D.C Dunn, et al. 2019. Integrating climate adaptation and biodiversity conservation in the global ocean. Science Advances 5: eaay9969

Tu, C., S. Suweis, and P. D'Odorico. 2019. Impact of globalization on the resilience and sustainability of natural resources. Nature Sustainability 2: 283-289.

Turco, M., J.J. Rosa-Cánovas, J. Bedia, S. Jerez, J.P. Montávez, M.C. Llasat, and A. Provenzale. 2018. Exacerbated fires in Mediterranean Europe due to anthropogenic warming projected with nonstationary climate-fire models. Nature Communications 9: 3821.

UN DESA. 2018. The 2018 Revision of World Urbanization Prospects produced by the Population Division of the UN Department of Economic and Social Affairs (UN DESA) United Nations, New York.

UN. 2019. The 2019 Revision of World Population Prospects. The Population Division of the Department of Economic and Social Affairs of the United Nations Secretariat, United Nations, New York.

UNDP. 2019. United Nations Development Program. 2019. World Development Report 2019. Beyond Income, Beyond Averages, Beyond Today: Inequalities in Human Development in the 21st Century. New York: United Nations.

UNGC. 2020. Pretlove, B. Ocean Stewardship 2030-Ten ambitions and recommendations for growing sustainble ocean busines. United Nations Global Compact, New York

UN-Habitat. 2016. The widening urban divide. Chapter four in Urbanisation and Development: Emerging Futures. World Cities Report. 2016. United Nations Human Settlements Programme (UN-Habitat). Kenya: Nairobi. van der Leeuw, S.E. 2019. Social sustainability past and present: undoing unintended consequences for the Earth's survival. Cambridge: Cambridge University Press.

van der Leeuw, S.E. 2020. The role of narratives in humanenvironmental relations: an essay on elaborating win-win solutions to climate change and sustainability. Climatic Change 160: 509-519.

van Oldenborgh, G.J., F. Krikken, S. Lewis, N.J. Leach, F. Lehner, K.R. Saynders, M. van Weele, K. Haustein, et al. 2020. Attribution of the Australian bushfire risk to anthropogenic climate change. Natural Hazards and Earth System Sciences. https://doi.org/10.5194/nhess-2020-69.

Vandenbergh, M.P., and J.M. Gilligan. 2017. Beyond politics: The private governance response to climate change. Cambridge: Cambridge University Press.

Vang Rasmussen, L., B. Coolsaet, A. Martin, O. Mertz, U. Pascual, E. Corbera, N. Dawson, J.A. Fischer, et al. 2018. Social-ecological outcomes of agricultural Intensification. Nature Sustainability 1: 275-282.

Walker, B.H. 2019. Finding resilience. Canberra: CSIRO Press.

Walker, B.H., N. Abel, J.M. Anderies, and P. Ryan. 2009. Resilience, adaptability, and transformability in the Goulburn-Broken Catchment Australia. Ecology and Society 14: 12.

Walter, N., J. Cohen, R.L. Holbert, and Y. Morag. 2019. Factchecking: a meta-analysis of what works and for whom. Political Communication 37: 350-375.

Wang-Erlandsson, L., I. Fetzer, P.W. Keys, R.J. van der Ent, H.H.G. Savenije, and L.J. Gordon. 2018. Remote land use impacts on river flows through atmospheric teleconnections. Hydrology and Earth System Sciences 22: 4311-4328.

Waring, T.M., M.A. Kline, J.S. Brooks, S.H. Goff, J. Gowdy, M.A. Janssen, P.E. Smaldino, and J. Jacquet. 2015. A multilevel evolutionary framework for sustainability analysis. Ecology and Society 20: 34 .

Wearn, O.R., R. Freeman, and D.M.P. Jacoby. 2019. Responsible AI for conservation. Nature Machine Intelligence 1: 72-73.

Weber, E.U. 2015. Climate change demands behavioral change: What are the challenges? Social Research 82: 561-581.

Weber, E.U. 2017. Breaking cognitive barriers to a sustainable future. Nature Human Behavior 1: 0013.

Weber, E.U. 2020. Heads in the sand: why we fail to foresee and contain catastrophe. Foreign Affairs, Nov/Dec

Weber, E.U., and E.J. Johnson. 2016. Can we think of the future? Cognitive barriers to future-oriented thinking. In Global cooperation and the human factor, ed. D. Messner and S. Weinlich, 139-154. New York, NY: Routledge.

Westley, F., P. Olsson, C. Folke, T. Homer-Dixon, H. Vredenburg, D. Loorbach, J. Thompson, M. Nilsson, et al. 2011. Tipping toward sustainability: Emerging pathways of transformation. Ambio 40: 762-780.

Westley, F., O. Tjörnbo, L. Schultz, P. Olsson, C. Folke, B. Crona, and Ö. Bodin. 2013. A theory of transformative agency in linked social-ecological systems. Ecology and Society 18: 27.

Westley, F., K. McGowan, and O. Tjornbo, eds. 2017. The Evolution of social innovation. London: Edward Elgar Press.

Wibeck, V., B.-O. Linnér, M. Alves, T. Asplund, A. Bohman, M.T. Boykoff, P.M. Feetham, Y. Huang, et al. 2019. Stories of transformation: a cross-country focus group study on sustainable development and societal change. Sustainability 11: 2427.

Willeit, M., A. Ganopolski, R. Calov, and V. Brovkin. 2019. MidPleistocene transition in glacial cycles explained by declining $\mathrm{CO} 2$ and regolith removal. Science Advances 5: eaav7337.

Willett, W., J. Rockström, B. Loken, M. Springmann, T. Lang, S. Vermeulen, T. Garnett, D. Tilman, et al. 2019. Food in the Anthropocene: The EAT-Lancet Commission on healthy diets 
from sustainable food systems. The Lancet Commission 393: 447-492.

Williams, H.T.P., J.R. McMurray, T. Kurz, and F.H. Lambert. 2015. Network analysis reveals open forums and echo chambers in social media discussions of climate change. Global Environmental Change 32: 126-138.

WMO. 2020. World meteorological organization state of the global climate 2020, provisional report. Geneva: WMO.

Wood, S.A., M.R. Smith, J. Fanzo, R. Remans, and R. DeFries. 2018. Trade and the equitability of global food nutrient distribution. Nature Sustainability 1: 34-37.

World Bank. 2019. Poverty. https://www.worldbank.org/en/topic/ poverty/overview

World Inequality Report. 2018. https://wir2018.wid.world, UNESCO Publ. Paris.

Worm, B., E.B. Barbier, N. Beaumont, J.E. Duffy, C. Folke, B.S. Halpern, J.B.C. Jackson, H.K. Lotze, et al. 2006. Impacts of biodiversity loss on ocean ecosystem services. Science 314: 787-790.

Worm, B., R. Hilborn, J.K. Baum, T.A. Branch, J.S. Collie, C. Costello, M.J. Fogarty, E.A. Fulton, et al. 2009. Rebuilding global fisheries. Science 325: 578-585.

WRI. 2020. 4 Charts explain greenhouse gas emissions by countries and sectors. Washington DC: World Resources Institute.

Wyborn, C., A. Datta, J. Montana, M. Ryan, P. Leith, B. Chaffin, C. Miller, and L. van Kerkhoff. 2019. Co-producing sustainability: reordering the governance of science, policy, and practice. Annual Review of Environment and Resources 44: 319-346.

Xu, C., T.A. Kohler, T.M. Lenton, J.-C. Svenning, and M. Scheffer. 2020. Future of the human climate niche. Proceedings of the National Academy of Sciences, USA 117: 11350-11355.

Yin, J., P. Gentine, S. Zhou, S.C. Sullivan, R. Wang, Y. Zhang, and S. Guo. 2018. Large increase in global storm runoff extremes driven by climate and anthropogenic changes. Nature Communications 9: 4389.

Yoeli, E., D.V. Budescu, A.R. Carrico, M.A. Delmas, J.R. DeShazo, P.J. Ferraro, H.A. Forster, H. Kunreuther, et al. 2017. Behavioral science tools to strengthen energy and environmental policy. Behavioural Science and Policy 3: 69-79.

Zalasiewicz, J., M. Williams, C.N. Waters, A.D. Barnosky, J. Palmesino, A.-S. Rönnskog, M. Edgeworth, C. Neal, et al. 2017. Scale and diversity of the physical technosphere: A geological perspective. The Anthropocene Review 4: 9-22.

Zemp, D.C., C.F. Schleussner, H.M.J. Barbosa, M. Hirota, V. Montade, G. Sampaio, A. Staal, L. Wang-Erlandsson, et al. 2017. Self-amplified Amazon forest loss due to vegetationatmosphere feedbacks. Nature Communications 8: 1468.

Publisher's Note Springer Nature remains neutral with regard to jurisdictional claims in published maps and institutional affiliations.

\section{AUTHOR BIOGRAPHIES}

Carl Folke $(\varangle)$ is Professor and Director of the Beijer Institute of Ecological Economics of the Royal Swedish Academy of Sciences. $\mathrm{He}$ is also Chair of the Board and Science Director of the Stockholm Resilience Centre at Stockholm University.

Address: Beijer Institute of Ecological Economics, Royal Swedish Academy of Sciences, Stockholm, Sweden.

Address: Global Economic Dynamics and the Biosphere Programme (GEDB), Royal Swedish Academy of Sciences, Stockholm, Sweden. Address: Stockholm Resilience Centre, Stockholm University, Stockholm, Sweden.

e-mail: carl.folke@beijer.kva.se
Stephen Polasky is Professor at the Department of Applied Economics, and the Department of Ecology, Evolution \& Behavior, University of Minnesota.

Address: University of Minnesota, St. Paul, MN, USA.

Johan Rockström is Professor and Director of the Potsdam Institute for Climate Impact Research.

Address: Potsdam Institute for Climate Impact Research, Potsdam, Germany.

Victor Galaz is Associate Professor and Deputy Director of the Stockholm Resilience Centre, Stockholm University and programme director at the Beijer Institute, Royal Swedish Academy of Sciences. Address: Stockholm Resilience Centre, Stockholm University, Stockholm, Sweden.

Frances Westley is Professor at the the Waterloo Institute for Social Innovation and Resilience, and School for Environment, Enterprise and Development, the University of Waterloo.

Address: University of Waterloo, Waterloo, ON, Canada.

Michèle Lamont is Professor at the Department of Sociology and Director of the Weatherhead Center for International Affairs, Harvard University.

Address: Harvard University, Cambridge, MA, USA.

Marten Scheffer is Professor at the Department of Environmental Sciences, Wageningen University and Research.

Address: Wageningen University \& Research, Wageningen, The Netherlands.

Henrik Österblom is Professor and Science Director of the Stockholm Resilience Centre, Stockholm University.

Address: Stockholm Resilience Centre, Stockholm University, Stockholm, Sweden.

Stephen R. Carpenter is Professor Emeritus at the Center for Limnology, University of Wisconsin, Madison.

Address: University of Wisconsin, Madison, WI, USA.

F. Stuart Chapin III is Professor Emeritus at the Institute of Arctic Biology, University of Alaska Fairbanks.

Address: University of Alaska, Fairbanks, AK, USA.

Karen C. Seto is Professor at the School of the Environment, Yale University.

Address: Yale University, New Haven, USA.

Elke U. Weber is Professor at the Andlinger Center for Energy and Environment, and Department of Psychology, Princeton University. Address: Princeton University, Princeton, NJ, USA.

Beatrice I. Crona is Executive Director of the Global Economic Dynamics and the Biosphere Programme, Royal Swedish Academy of Sciences and Associate Professor at the Stockholm Resilience Centre, Stockholm University.

Address: Global Economic Dynamics and the Biosphere Programme (GEDB), Royal Swedish Academy of Sciences, Stockholm, Sweden. Address: Stockholm Resilience Centre, Stockholm University, Stockholm, Sweden.

Gretchen C. Daily is Professor at Department of Biology, Director of the Center for Conservation Biology, and Faculty Director of the Stanford Natural Capital Project, Stanford University. Address: Stanford University, Stanford, CA, USA. 
Partha Dasgupta is Professor Emeritus at the Faculty of Economics, University of Cambridge.

Address: University of Cambridge, Cambridge, UK.

Owen Gaffney is a global sustainability analyst and writer at Potsdam Institute for Climate Impact Research and Stockholm Resilience Centre, Stockholm University.

Address: Potsdam Institute for Climate Impact Research, Potsdam, Germany.

Address: Stockholm Resilience Centre, Stockholm University, Stockholm, Sweden.

Line J. Gordon is Professor and Director of the Stockholm Resilience Centre, Stockholm University.

Address: Stockholm Resilience Centre, Stockholm University, Stockholm, Sweden.

Holger Hoff is Senior Scientist at the Potsdam Institute for Climate Impact Research.

Address: Potsdam Institute for Climate Impact Research, Potsdam, Germany.
Simon A. Levin is Professor at the Department of Ecology and Evolutionary Biology and Director of the Center for BioComplexity, Princeton University.

Address: Princeton University, Princeton, NJ, USA.

Jane Lubchenco is Distinguished University Professor, Oregon State University.

Address: Oregon State University, Corvallis, OR, USA.

Will Steffen is Emeritus Professor, Fenner School of Environment and Society, Australian National University.

Address: Australian National University, Canberra, Australia.

Address: Stockholm Resilience Centre, Stockholm University, Stockholm, Sweden.

Brian H. Walker is Professor and Fellow at Australia's CSIRO Land and Water.

Address: CSIRO, Canberra, Australia. 